\title{
多孔氢键有机框架(HOFs)：现状与挑战
}

\author{
林祖金*,a,b曹荣*,b \\ ( ${ }^{a}$ 福建农林大学 生命科学学院应用化学系 福州 350002) \\ $\left({ }^{b}\right.$ 中国科学院福建物质结构研究所 结构化学国家重点实验室 福州 350002)
}

\begin{abstract}
摘要 氢键有机框架(HOFs) 已经发展成为一类独特的晶态多孔材料, 它一般是由有机或金属-有机构建单元通过分子 间的氢键相互连接而形成的框架材料. 由于氢键强度弱和柔性强, 因此大部分 HOFs 的框架都比较容易坍塌. 然而, 通 过合理地选择刚性且具有特定几何构型的构建单元、引入穿插或 $\pi-\pi$ 作用和静电作用等其它分子间的作用力, 稳定且 多孔的 HOFs 也逐渐地被制备出来. 与其它含有机组分的晶态多孔材料如金属-有机框架(MOFs)和共价有机框架 (COFs)相比, HOFs 具有自己的特点, 例如: 温和的合成条件、高度的结晶性、溶剂加工性、容易修复和再生等. HOFs 的这些特点能够使其成为一类独特的功能多孔材料. 本综述主要概述了稳定且多孔 HOFs 设计的一些基本原则, 系统 总结了构筑 HOFs 常用的超分子合成子以及脚手架, 重点综述了近十年 HOFs 在气体吸附与分离、质子传导、异相催 化、荧光和传感、生物应用、对映体拆分和芳香化合物的分离、环境污染物去除和有机结构测定等领域的重要进展. 关键词 氢键有机框架; 超分子合成子; 氢键; 结构设计; 永久多孔性
\end{abstract}

\section{Porous Hydrogen-bonded Organic Frameworks (HOFs): Status and Challenges}

\author{
Lin, Zu-Jin*,a,b Cao, Rong*,b \\ ( ${ }^{a}$ Department of Applied Chemistry, College of Life Science, Fujian Agriculture and Forestry University, \\ Fuzhou 350002, China) \\ ( ${ }^{b}$ State Key Laboratory of Structural Chemistry, Fujian Institute of Research on the Structure of Matter, \\ Chinese Academy of Sciences, Fuzhou 350002, China)
}

\begin{abstract}
Hydrogen-bonded organic frameworks (HOFs), usually self-assembled by organic or metal-organic building blocks via intermolecular H-bonding interactions, have become a unique type of crystalline porous material. Although the weak and flexible nature of hydrogen bonds makes most HOFs fragile, the high stability and permanent porosity could be realized by the judicious selection of rigid building blocks with special spatial configuration as well as the introduction of framework interpenetration and/or other intermolecular interactions like $\pi-\pi$ stacking and electrostatic interactions, etc. Compared with other crystalline porous materials like metal-organic frameworks (MOFs) and covalent-organic frameworks (COFs), HOFs feature mild preparation condition, high crystallinity, permissible solution processability, easy healing and regeneration, etc. These distinguishing merits make HOFs capable to be used as unique multifunctional porous materials. Herein, we first review the basic rules to design and synthesize stable and porous HOFs, and then systematically summarize the representative supramolecular synthons and backbones that have been used to build stable and porous HOFs. Emphasis is put on the potential applications of HOFs in gas adsorption and separation, proton conduction, heterogeneous catalysis, luminescence and sensing, biological applications, enantiomeric resolution and aromatic compounds separation, pollutants removal, and structure determination, etc.
\end{abstract}

Keywords hydrogen-bonded organic framework (HOF); supramolecular synthon; hydrogen bond; structural design; permanent porosity

\section{1 引言}

晶态多孔材料可以分为纯无机的晶态多孔材料和 含有机组分的晶态多孔材料, 前者主要包括沸石和分子 篮等, 而后者主要包括金属-有机框架 (metal-organic frameworks, MOFs) ${ }^{[1-2]}$ 或多孔配位聚合物(porous coor- dination polymers, PCPs) ${ }^{[3]}$, 共价有机框架(covalent organic frameworks, COFs $)^{[4-5]}$ 和氢键有机框架材料 (hydrogen-bonded organic frameworks, HOFs) ${ }^{[6]}$. 与纯无 机的晶态多孔材料相比, 含有机组分的晶态多孔材料具 有结构更丰富、孔道形状和尺寸大小更易调节、孔道表

* E-mail: linzujin@fafu.edu.cn; rcao@fjirsm.ac.cn

Received August 12, 2020; published September 3, 2020.

Project supported by the National Natural Science Foundation of China (No. 21520102001), Natural Science Foundation of Fujian Province of China (No. 2020J01549), and Fujian Agriculture and Forestry University (Nos. 118360020, XJQ201616).

项目受国家自然科学基金(No. 21520102001)、福建省自然科学基金(No. 2020J01549)和福建农林大学(Nos. 118360020, XJQ201616)资助. 
面更易修饰等特点. 在过去的几十年, 利用各种各样的 有机物, 科学家已成功开发出一系列具有气体吸附与分 离、催化、传感、苂光和质子传导等特殊功能的多孔 $\mathrm{MOFs} / \mathrm{COFs} / \mathrm{HOFs}$ 材料.

MOFs 是发展最快的一类含有机组分的晶态多孔材 料, 它是由金属离子 (簇)与有机配体通过配位键连接而 成的 ${ }^{[7]}$. 化学家从 1989 年就开始尝试利用配位键来构筑 多孔的框架材料 ${ }^{[8-9]}$, 但直到 1997 年才首次报道了具有 永久性孔道 MOFs 材料 ${ }^{[10-11]}$. 随着次级结构基元 (Secondary building units, SBUs)的提出 ${ }^{[12-13]}$ 和网络化学 (Reticular chemistry)的发展 ${ }^{[14-16]}$, 科学家已成功设计合 成了成千上万的微孔 MOFs 材料并将其应用于气体吸附 与分离、苂光和传感等领域 ${ }^{[17-19]}$. COFs 是由有机构建单 元通过各种各样的缩合反应形成的，它是基于共价键相 互连接而形成的一类晶态多孔材料 ${ }^{[14]}$. 由于配位键和 共价键都具有较大的强度和方向性, 因此 MOFs 与 COFs 在结构设计甚至是功能应用都具有高度的相似性. 事实上, COFs 从诞生之日就大量吸收了 MOFs 设计合成 (如网状化学) 和功能应用的经验. 因此, 在过去短短的 15 年间 COFs 就已经取得了巨大的发展 ${ }^{[20-22]}$.

HOFs 是由有机或金属-有机构建单元通过氢键连 接而成的一类晶态的多孔框架材料 ${ }^{[23-27]}$. 除了氢键外, $\pi-\pi$ 作用、静电作用和范德华力等其它分子间的作用力 对 HOFs 的构筑和稳定性也起了非常重要的作用 ${ }^{[28]}$. HOFs 的研究最早可以追溯到 1969 年, Marsh 和 Duchamp ${ }^{[29]}$ 利用均苯三甲酸作为构建单元报道了一例 晶态的化合物, 其结构为六边形蜂窝状的氢键网络. 然 而, 随后的几十年, HOFs 的发展基本上处于停滞状态. 直到 20 世纪 90 年代初, Wuest 等 ${ }^{[30-31]}$ 报道了一系列氢键 构筑的 HOFs 后, HOFs 材料才开始慢慢发展起来. 虽然 利用氢键来构筑 HOFs 材料和利用配位键来构筑 MOFs 材料的理念几乎在同一时代平行提出, 然而 HOFs 的发 展比 MOFs 的发展要慢得多, 并且早期制备的 HOFs 也 基本上没有受到太多的关注和重视. 这主要是因为氢键 的作用力弱、柔性强和方向性差, 因此目标 HOFs 结构 不但难以准确合成, 而且框架的稳定性一般也比相应的 MOFs 差得多. 事实上, 早期合成的 HOFs 在移除孔道 内填充的溶剂后框架往往会发生坍塌, 加之早期科学家 也没有过多关注 HOFs 的多孔性, 因而 HOFs 作为一类 多孔材料发展得极为缓慢. 直到 2010 年左右, HOFs 的 多孔性才开始逐渐地被建立起来 ${ }^{[6,32]}$. 2011 年, 陈邦林 等 ${ }^{[6]}$ 首次提出了 HOFs 的定义并将 HOFs 作为一类多孔 材料(HOF-1)首次应用于乙烯/乙烷的分离. HOFs 多孔性 的建立及其应用的开展, 掀开了多孔 HOFs 材料发展的 新纪元, 从此 HOFs 正式以一类新型且独特多孔框架材 料的身份展现在科学家的面前. 近年来, HOFs 吸引了各 个领域的科研工作者的关注, 一些具有超高稳定性的 HOFs 也相继被开发出来, HOFs 已驶入发展的超车道.
由于 $\mathrm{MOFs} / \mathrm{COFs} / \mathrm{HOFs}$ 都是含有有机组分的晶态 多孔材料，因此它们具有一些共同的特点，例如：它们 理论上都具有比表面积大、结构多样、孔道形状和尺寸 可调和孔表面可修饰等共同的特点. 但由于 HOFs 是氢 键构筑而成的，而氢键作用力一般比配位键或共价键的 强度弱和可逆性强, 因而 HOFs 材料具有一些自己独特 的优势: (1) HOFs 的制备条件更为温和 ${ }^{[33]}$; HOFs 的制备 通常只需要通过溶剂自然挥发、不良溶剂扩散到良溶剂, 或者饱和溶液降温析出晶体等重结晶过程来合成. (2) HOFs 具有较好的溶液加工性能, 因此相对于 $\mathrm{COFs} / \mathrm{MOFs}$ 更容易做成器件; HOFs 材料是由氢键等分 子间的作用力构筑的，因此 HOFs 材料在特定溶剂可以 具有很好的溶解性, 而当溶剂挥发后, HOFs 又可能会被 结晶出来, 赋予了 HOFs 材料的溶剂加工性能. 孙道峰 等 ${ }^{[93]}$ 报道了利用溶液加工技术来制备 UPC-HOF-6 薄膜 并将该薄膜应用于压力响应的 $\mathrm{H}_{2} / \mathrm{N}_{2}$ 分离. (3) HOFs 材 料具备更好的自愈能力和再生能力; HOFs 材料是基于 氢键构建的, 而氢键的柔性和可逆性则赋予 HOFs 良好 的自愈能力和再生能力. MOFs、COFs 和 HOFs 在实际 多次循环使用后框架都有可能受到不同程度的损伤从 而导致性能的下降，而结构自我修复和再生对于材料的 大规模的实际利用是非常重要的. HOFs 可以通过简单 重结晶的过程再生, 甚至这类材料具备良好的溶剂修 复/自愈能力, 这对于降低 HOFs 的实际使用成本是非常 有意义的. 例如, 袁大强和吴明燕等 ${ }^{[34]}$ 制备了一例高稳 定性和大比表面积的 HOFs 材料(HOF-TCBP), 将气体 吸附后的 HOF-TCBP 溶解在少量 DMF 中，通过旋蒸的 方法即可以实现 HOF-TCBP 的再生. 值得注意的是, 再 生的 HOF-TCBP 材料与原样品具有几乎一样的比表面 积. 再比如, UPC-HOF-6 薄膜在少量溶剂处理下甚至可 以实现结构的自我修复 ${ }^{[93]}$. (4) 由于大部分 HOFs 材料 不含金属离子, 这种无金属特性赋予了 HOFs 材料更好 的生物相容性和更低的细胞毒性，使得 HOFs 在生物应 用方面显示出巨大的应用潜力.

虽然 HOFs 具有上述的种种优点, 然而氢键作用力 弱和方向性差的本质也使得 HOFs 材料的发展受到不少 的限制. 首先, 合成目标结构的 HOFs 比 MOFs 和 COFs 要难很多, 这是因为氢键作用力弱和柔性强, HOFs 的结 构非常容易受到外界因素如其它分子间作用力的影响, 其最终结构高度依赖于制备所使用的溶剂和合成条件. 例如，利用 TPE-4pn 构建单元在不同溶剂当中可以制备 出 9 种不同结构的 HOFs 材料, 它们的孔隙率可以从 $4 \%$ 变到 $33.2 \%{ }^{[35]}$; 利用 $\mathrm{C} 3$ 构建单元在不同条件中居然可 以制备出互锁度分别为 18,24 和 36 的复杂结构 ${ }^{[36]}$, 这 些结构在制备之前根本无法准确预测. 其次, 大部分 HOFs 材料的稳定性相对较差, 在移除孔道中内溶剂后 框架容易坍塌，如何在去除孔道溶剂的同时保持 HOFs 框架的稳定性仍然是一个巨大挑战. 幸运的是, 一些由 
多重氢键组成的超分子合成子已经被证明具有较强作 用力与方向性, 并且已经被有效用于具有目标结构的 HOFs 材料的构筑, 甚至理论计算也已经成功地用于预 测和设计 HOFs 的结构及其性能 ${ }^{[37-39]}$. 通过增强分子间 的作用力如引入多重氢键、 $\pi-\pi$ 堆积、静电作用、范德 华力和引入穿插互锁，一些具有超高稳定性(强酸、强碱 和沸水中仍能保持晶态)以及超大比表面积(最大比表面 积高达 $3400 \mathrm{~m}^{2} \cdot \mathrm{g}^{-1}$ ) 的 HOFs 材料也已经被制备出来 ${ }^{[37]}$. 随着功能多孔 HOFs 材料的不断开发, HOFs 的独特性在 不同的应用领域中逐渐地体现出来. 本综述主要聚焦过 去十年 HOFs 材料的一些重要进展, 概述 HOFs 设计的 基本原理, 系统地总结构筑 HOFs 常见的超分子合成子 和脚手架, 重点介绍 HOFs 在气体吸附与分离、质子传 导、异相催化、苂光和传感、生物应用、对映体拆分和 芳香化合物的分离、环境污染物去除和结构测试等领域 中的应用.

\section{HOFs 的结构设计}

\subsection{HOFs 设计的基本原理}

由于氢键等分子间的作用力弱和方向性差, 因此 HOFs 框架在移除孔道内的溶剂分子后非常容易坍塌, 稳定且多孔 HOFs 材料的精准合成仍然是一个巨大的挑 战. 提高构建单元之间的作用力或尽量减小活化时框架 与溶剂之间的相互作用可以有效增强 HOFs 框架的稳定 性和提高合成目标结构的精准性. 前者可以通过引入多 重氢键(如使用超分子合成子)、静电作用和 $\pi-\pi$ 作用等 分子间作用力来实现，而后者则可以采取选择不具有额 外的质子给体或受体的构建单元和选择非极性的溶剂 来实现. 此外, 结构的穿插与互锁通常也有利于提高 HOFs 的稳定性, 但这种方法不但会减小 HOFs 的孔隙 率, 而且会使 HOFs 的结构变得更难以预测和控制.

与 HOFs 相反, 配位键和共价键的强度较强并且具 有方向性, 因此利用结构基元、拓扑学和网络化学的概 念就可以比较准确地设计和精准合成目标 MOFs 或 COFs 结构. HOFs 是基于较弱分子间作用力构筑而成的, 简单照搬 MOFs/COFs 的设计方法到 HOFs 体系往往很 难获得成功. 幸运的是, 超分子合成子(Supramolecular synthon) 的概念被引入了超分子化学 (包括多孔 HOFs $)^{[40]}$. 目前科学家已经总结出了一些基于多重氢键 的超分子合成子, 并成功将这些超分子合成子用于 HOFs 的设计合成(图 3). 这些超分子合成子一般包含着 多重氢键, 这些多重氢键不但增强了分子之间的作用力 (增强作用力), 而且在很大程度上决定了氢键网络的伸 展方向(提高方向性). 由于形状、尺寸大小、对称性以 及功能不同, 构建单元的脚手架(backbone 或 scaffold)不 但决定了氢键网络在三维空间的伸展方向, 并且影响 HOFs 的多孔性和功能. 若将超分子合成子与构建单元 的脚手架作为 HOFs 的基本构建单元, 再把超分子合成
子看成是 MOFs 中的构建基元(Spacers 或 Secondary building units, SBUs), 而把构建单元的脚手架看成是连 接器(linkers), 进一步结合拓扑和网络化学, 那么在一 定程度上就可以将 $\mathrm{MOF} / \mathrm{COFs}$ 的设计策略借鉴到 HOFs 体系(图 1). HOFs 的设计一般是基于超分子合成 子与构建单元的脚手架而言的, 合理的选择超分子合成 子与构造单元的脚手架则可以设计合成出具有特定结 构与功能的 HOFs 材料. 通常情况下, 选择具有多重氢 键的超分子合成子以及刚性的脚手架作为构建基元往 往更有利于多孔 HOFs 的结构设计和功能预测.
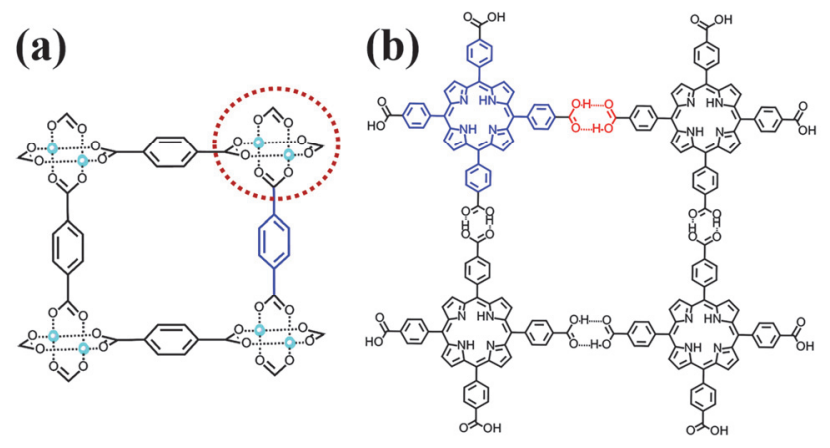

图 1 sql 网络的理论设计: (a) 采用平面 4-连接的 SBUs 如 $\mathrm{Cu}_{2}\left(\mathrm{CO}_{2}\right)_{4}$ 与线性的配体如对苯二甲酸构筑具有 sql 拓扑结构的 MOF 材料; (b) 采用线性的超分子合成子如羒酸二聚体(红色)和平面四连接的脚手架 (蓝色)构筑具有 sql 拓扑结构的 HOF 材料.

Figure 1 The construction of sql networks by (a) 4-connected planner SBUs like $\mathrm{Cu}_{2}\left(\mathrm{CO}_{2}\right)_{4}$ and linear ligands like terephthalic acid in MOFs, and (b) 4-connected planner scaffold (or backbone, blue) and supramolecular synthon (like carboxy dimer, red) in HOFs.

\section{2 超分子合成子}

\subsection{1 羧酸二聚体}

羧酸二聚体(carboxy dimer, 图 3a)是最常见的超分 子合成子，它不但有较强的作用力，而且具有很强的方 向性，因此非常适合构筑多孔 HOFs 材料. 1969 年, Marsh 和 Duchamp 等 ${ }^{[29]}$ 首次发现了羧酸二聚体. 在均苯 三甲酸 $(\mathrm{C} 1)$ 自组装体的过程中, 他们发现均苯三甲酸分 子之间可以通过羧酸二聚体相互连接, 形成具有二维褶 皱的蜂窝状氢键网络(即 $(6,3)$ 网格), 但由于 $(6,3)$ 网格相 互穿插互锁，该材料并没有表现出多孔性. 1987 年, Herbstein 等 $^{[41]}$ 同样利用均苯三甲酸构建了相似的二维 氢键网格，区别在于二维网格与网格之间通过 AA 堆积 从而得到一维孔道, 但孔道却被长链的模板剂所占据. 2019 年, Cooper 等 ${ }^{[38]}$ 利用计算的方法预测均苯三羧酸应 该还具有一个低密度堆积的稳定结构 $(\delta$-TMA) 并采用高 通量结晶实验的方法成功篎选出 $\delta$-TMA. $\delta$-TMA 具有永 久性的孔道, 它的比表面积达到 $920 \mathrm{~m}^{2} \cdot \mathrm{g}^{-1}$. 目前, 以 均苯三甲酸为构建单元已经陆续制备了 20 多个 HOFs, 但大部分框架都不具有多孔性. 事实上, $\delta$-TMA 稳定性 也不是特别好, 它非常容易转化成无孔的 $\alpha$-TMA. 为了 增强层与层之间的 $\pi-\pi$ 作用以及扩大孔道的大小, 含有 
更大共轭体系的三羧酸构建单元如 $\mathrm{H}_{3} \mathrm{BTB}(\mathrm{C} 2)^{[42]}$ 、 $\mathrm{H}_{3}$ TATB $(\mathrm{C} 3)^{[36]}$ 和 $\mathrm{H}_{3} \mathrm{NTC}(\mathrm{C} 4)^{[43-44]}$ 也逐渐被用于多孔 HOFs 材料的制备. 由于这些构建单元的脚手架与 $\mathrm{H}_{3} \mathrm{BTC}(\mathrm{C} 1)$ 类似, 因此它们都能通过羧酸二聚体相连 接形成蜂窝状的二维层. 有趣的是, 层与层之间的 $\pi-\pi$ 作用以及多重的穿插和互锁使 HOFs 的稳定性得到巨大 的提高, 例如: HOF-BTB 的 BET 比表面积高达 1095 $\mathrm{m}^{2} \cdot \mathrm{g}^{-1}[42]$; IISERP-HOF $1^{[43]}$ 或 HOF-11 ${ }^{[44]}$ 不但具有很高 的比表面积 $\left(1025 \mathrm{~m}^{2} \cdot \mathrm{g}^{-1}\right)$, 而且在 $3 \mathrm{~mol} / \mathrm{L}$ 的盐酸溶液 或者在 $300{ }^{\circ} \mathrm{C}$ 加热的情况下结构仍没有发生变化. Lai 等 ${ }^{[45]}$ 系统地研究了空间位阻对 $C_{3}$ 对称性的三羧酸构建 单元构筑的 HOFs 材料最终结构的影响. 他们研究发现, 甲基、甲氧基、甲基和甲氧基、以及氨基功能化的 $\mathrm{H}_{3} \mathrm{BTB}$ 同样都可以形成蜂窝状二维层, 且层与层之间同样存在 $\pi-\pi$ 作用以及多重穿插互锁. 然而基团的引入，导致构 建单元的中心苯环与外围苯环之间的空间位阻和扭转 角增大, 最终使得层与层之间的间距增大, 结构穿插程 度大大降低. 进一步采用位阻更大的 C5 自组装可以得 到 HOF-12 $2^{[46]}$, HOF-12 仅有六重穿插, 其比表面积达到 $320 \mathrm{~m}^{2} \cdot \mathrm{g}^{-1}$.

尽管多重穿插与互锁的结构有利于 HOFs 稳定性的 提高, 但是利用三足脚手架与羧酸二聚体形成的 $(6,3)$ 网 格或 hcb 二维层之间的穿插与互锁程度特别严重, 因此 这类 HOFs 的孔道一般较小, 孔隙率也不是很高. 在保 持羧酸二聚体作为构建基元的前提下, 适当增加羧酸二 聚体的密度, 有利于减小结构的穿插与互锁程度; 此外, 若能再使多足脚手架尽量处于共平面或尽量扩大脚手 架的共轭程度, 那么脚手架之间的 $\pi-\pi$ 作用则可以有效 地提高 HOF 的稳定性. 利用以上策略, 我们课题组 ${ }^{[47]}$ 选择平面的萠环作为脚手架中心, 利用 $\mathrm{H}_{4}$ TBAPy (C10) 制备了一例非穿插的 $\mathrm{HOF}$ 材料(PFC-1, 图 2b). 在 PFC-1 的结构中, 四足的脚手架与羧酸二聚体形成二维 的 sql 网格, 网格与网格之间通过 AA 堆积的方式堆叠 从而形成三维开放的框架. 由于 PCF-1 为非穿插的结 构, 其孔道的大小达到 $1.8 \mathrm{~nm} \times 2.3 \mathrm{~nm}$, 比表面积达到 $2122 \mathrm{~m}^{2} \cdot \mathrm{g}^{-1}$; 由于 AA 堆积, PFC-1 结构中萠与萠之间, 苯环与苯环之间存在非常强的 $\pi-\pi$ 作用, 所以 PFC- 1 具 有非常优秀的稳定性, 它在沸水中浸泡 $10 \mathrm{~d}$ 或者在浓盐 酸中浸泡 $117 \mathrm{~d}$ 或 $120{ }^{\circ} \mathrm{C}$ 加热的情况下框架结构仍没有 改变. 利用网络化学的策略, 陈邦林等 ${ }^{[48]}$ 进一步使用共 轭体系更大的 $\mathrm{H}_{4}$ PTTNA (C11)配体替代 $\mathrm{H}_{4}$ TBAPy (C10) 成功制备了与 PFC-1 同构的 HOF 材料(HOF-14, 图 2c). 由于配体的增大, HOF-14 的比表面积增大到 $2122 \mathrm{~m}^{2}$ $\mathrm{g}^{-1}$, 孔道大小增大到 $1.8 \mathrm{~nm} \times 2.3 \mathrm{~nm}$, 孔容达到创记录 的 $1.36 \mathrm{~cm}^{3} \cdot \mathrm{g}^{-1}$; 而由于 PFC-1 中苯环与苯环的 $\pi-\pi$ 作用 被更强的䒺环-䒺环的 $\pi-\pi$ 作用取代, sql 层与层之间的 $\pi-\pi$ 作用力进一步得到增强, 所以 HOF-14 的稳定性进一 步提高, 它不但在浓盐酸、沸水或 $300{ }^{\circ} \mathrm{C}$ 中加热 $2 \mathrm{~h}$ 下
结构不被破坏, 而且在 $\mathrm{pH}=14$ 的碱性溶剂中浸泡 $24 \mathrm{~h}$ 结构仍没有发生改变. Farha 等 ${ }^{[49]}$ 也分别利用 $\mathrm{H}_{4} \mathrm{TCPy}(\mathrm{C} 9), \mathrm{H}_{4} \mathrm{TBAPy}(\mathrm{C} 10)$ 和 $\mathrm{H}_{4} \mathrm{PTTNA}(\mathrm{C} 11)$ 分别合 成了 HOF-100 (图 2a), HOF-101 (图 2b)和 HOF-102 (图 2c). 与他们预测的结果相同, 这三个 HOFs 的比表面 积、孔容、稳定性顺序都为 HOF-100 $<$ HOF-101< HOF-102. 利用相似的设计策略 (拓扑学十网络化学), 即在保持超分子合成子(羧酸二聚体)和具有相似空间构 型的脚手架为构建基元的前提下, Hisaki 等 ${ }^{[50-63]}$ 利用各 种各样的六羧酸构建单元构筑了一系列多孔的 HOFs 材 料. 此外, 基于羧酸二聚体, 其它多羧酸构建单元也被 用于构筑各种结构和功能的 HOFs 材料 ${ }^{[39,64-74]}$. (a)

(b)
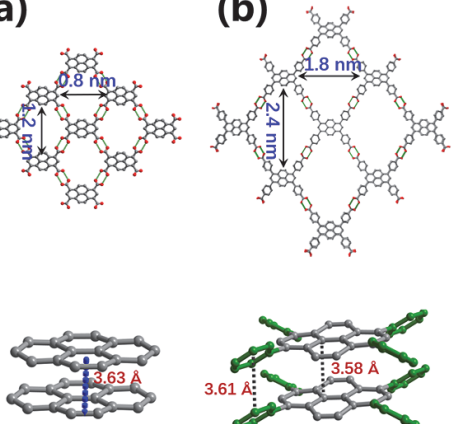
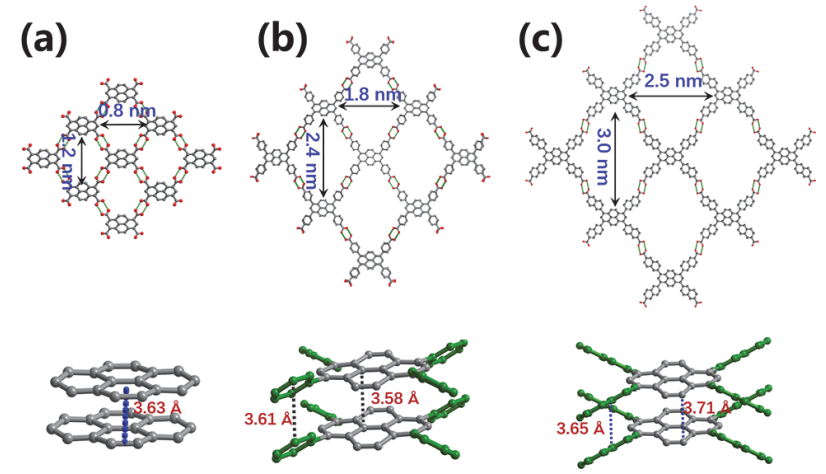

图 2 利用 C9-C11 构建单元分别制备 (a) HOF-100、(b) PFC-1/HOF-101 和 (c) HOF-14/HOF-102.

Figure 2 Construction of (a) HOF-100, (b) PFC-1/HOF-101, and (c) HOF-14/HOF-102 by C9-C11 building blocks respectively.

\section{2 .2 二氨基三嗪(DAT)二聚体}

二氨基三嗪(DAT)是非常容易形成超分子合成子的 官能团，两个 DAT 之间通过氢键可以形成三种不同结 构的超分子合成子(图 3b), 每个 DAT二聚体剩余两个氨 基再通过氢键和邻近的 DAT 之间相互连接从而延伸成 二维或者三维的氢键网络. 1997 年, Wuest 等 ${ }^{[75]}$ 制备了 第一例基于 DAT 的 HOFs. 近 20 年来, 他们又基于 DAT 功能化的构建单元构筑各种各样的 $\mathrm{HOFs}^{[76-83]}$. 2011 年, 陈邦林等 ${ }^{[6]}$ 利用气体吸附的方法首次确认了 HOF-1 具 有永久性的孔道并将其成功用于 $\mathrm{C}_{2} \mathrm{H}_{2} / \mathrm{C}_{2} \mathrm{H}_{4}$ 的分离. 随 后, 利用其它 DAT 功能化的构建单元, 陈邦林等相继构 筑了 HOF-2 $2^{[84]}, \mathrm{HOF}-3^{[85]}, \mathrm{HOF}-4^{[86]}, \mathrm{HOF}-5^{[87]}$, HOF-6 $6^{[88]}$, HOF-7 $7^{[89]}$, HOF-9 ${ }^{[90]}$ 和 HOF-10 $0^{[91]}$ 等一系列具 有开放孔道的 HOFs 并将这些材料应用于气体吸附/分 离和传感等领域, 这些研究工作极大地促进了多孔 HOFs 的发展 ${ }^{[92-93]}$.

\subsection{3 基于杂环的超分子合成子}

如图 3c 所示, 三个吡唑单元之间可以通过 $\mathrm{N}$ $\mathrm{H} \cdots \mathrm{N}$ 形成平面三角形的三聚体. 这种三聚体比较稳定, 并且具有较为固定的空间几何构型, 因此吡唑三聚体也 是构筑多孔 HOFs 的一种理想的超分子合成子. Miljanić 等 ${ }^{[94]}$ 利用 Pz1 构筑了一例三维开放的多孔 HOF 材料 
(a)<smiles>O=C1CCC(O)ON1</smiles>

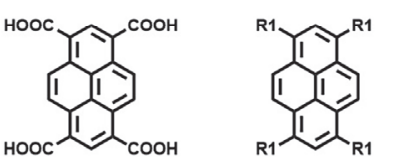

C9 (HOF-100)<smiles>O=C(O)c1cc(C(=O)O)cc(C(=O)O)c1</smiles><smiles>[R1]c1cc([R1])cc([R])c1</smiles><smiles>[R1]N([R1])[Tl]</smiles>

C2 (HOF-BTB) C3 (PFC-11, PFC-12, PCF-13) C4 (HOF-11)<smiles>[R1]c1c(C)c([R])c(C)c(C)c1C</smiles>

C5 (HOF-12)

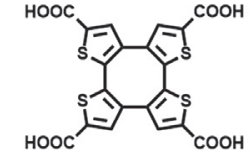

C8 (HOF-C8) $\mathrm{X}=\mathrm{C}, \mathrm{C} 6$ (TCF-1)

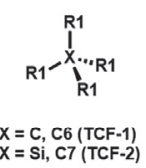

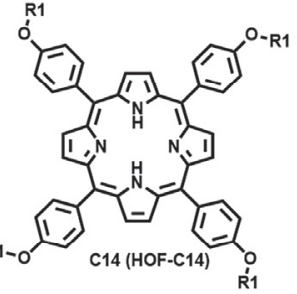<smiles>C#CC12C(=C)C(=C)C(C=C)(C(=C)C1=C)C(=C)C2=C</smiles>
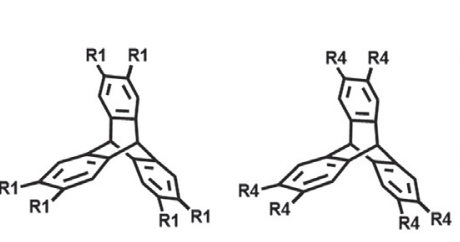

C15 (HOF-20)

C16 (HOF-76)

C17 (PETHOF-1, PETHOF-2)

C18 (PETHOF-3)

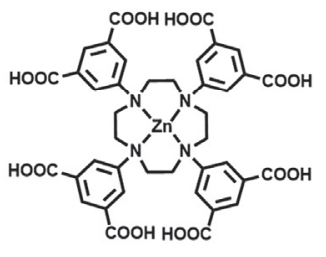

C19 (HMMCF-1)

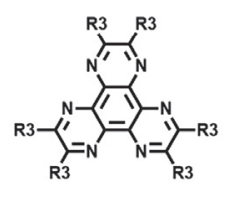

C20 (CBPHAT)

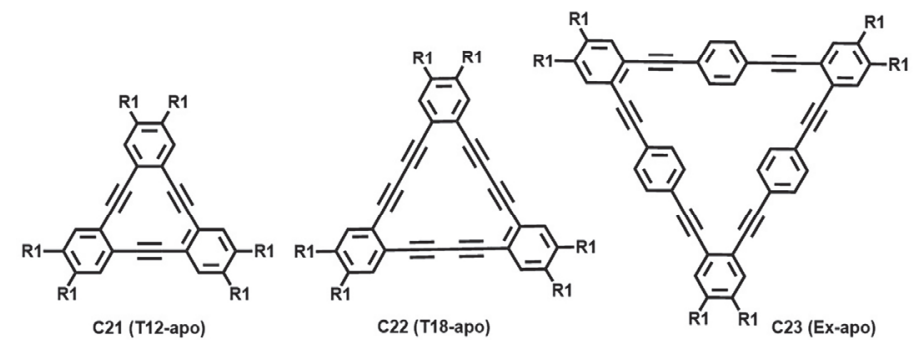

C22 (T18-apo)

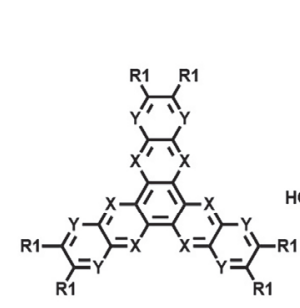

$\mathrm{C} 24, X=N, Y=C H \quad(C P H A T N-1)$
$C 25, X=C H, Y=N(C P B T Q-1)$

$\mathrm{R} 1=$<smiles>[R]=C=Cc1ccc2cc(C(=O)O)ccc2c1</smiles>

R3 = অ

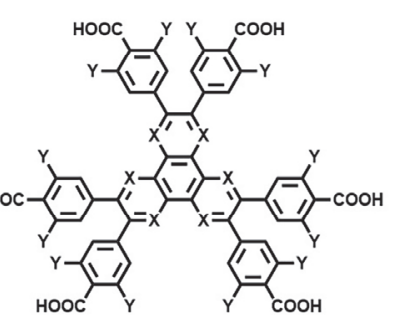

C26, $X=\mathrm{CH}, Y=\mathrm{H}$ (Tp-apo) $=\mathrm{CH}_{3}$ (TpMe-apo)
$=\mathrm{F}(\mathrm{TpF}-\mathrm{apo})$ C28, $X=C H, Y=F($ PF-apo) (b)

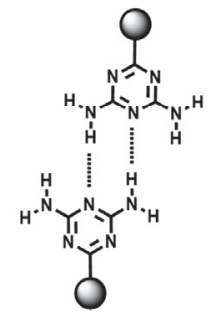

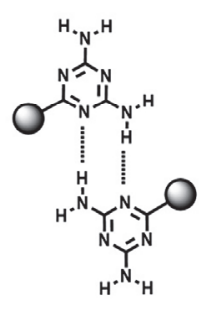<smiles>CCCCC(c1ccccc1)(c1ccccc1)c1ccccc1</smiles>

D1 (HOF-1)

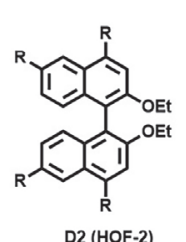

D2 (HOF-2)

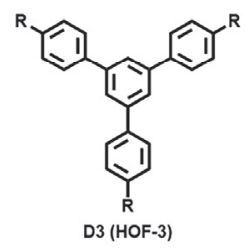

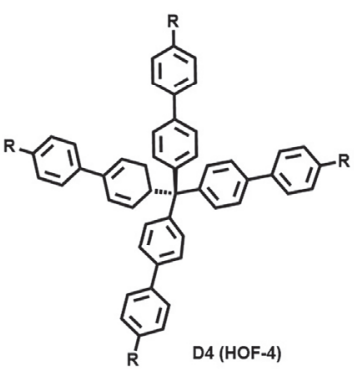

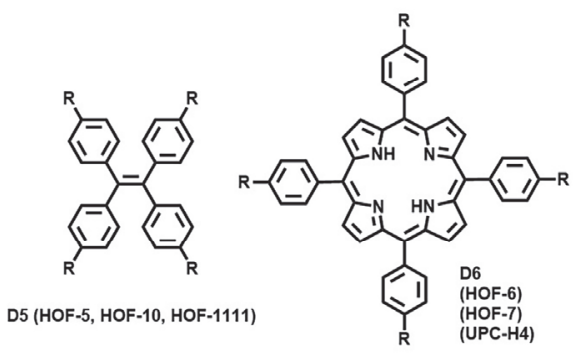<smiles>Cc1ccc(-c2ccc(N(C=CC(C)C)c3ccc(-c4ccc(C)cc4)cc3)cc2)cc1</smiles><smiles></smiles>

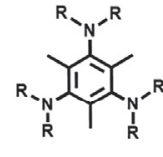

D8 (HOF-D8) 

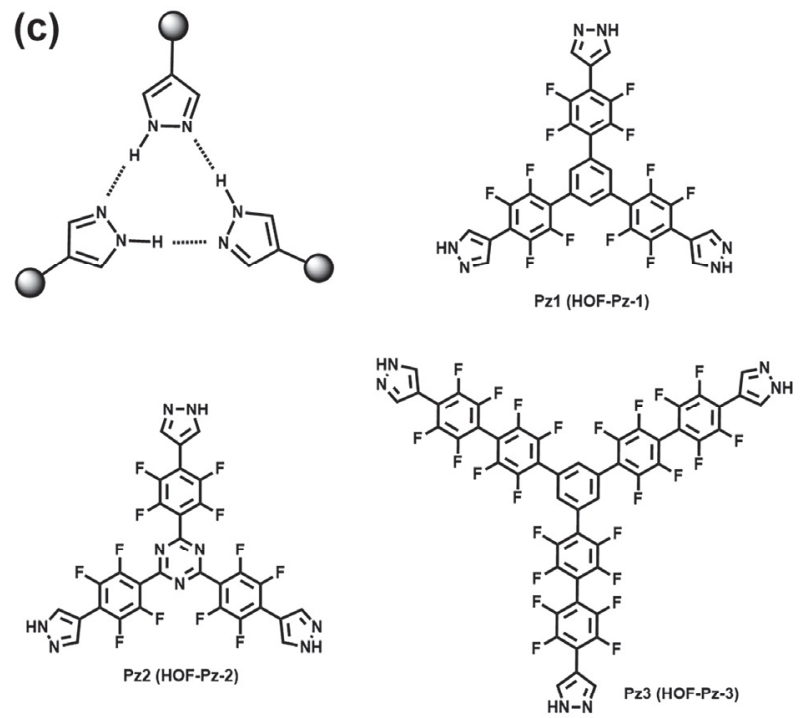

(d)
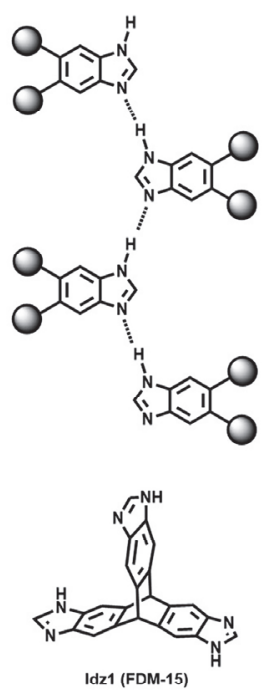

(e)<smiles>O=Cc1ccc(-n2ccc(O)c2)cc1</smiles>

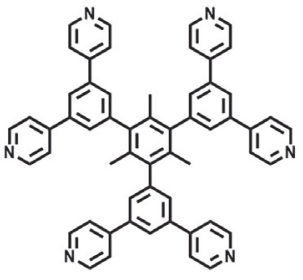

Py1 (Pyopen)

(f)
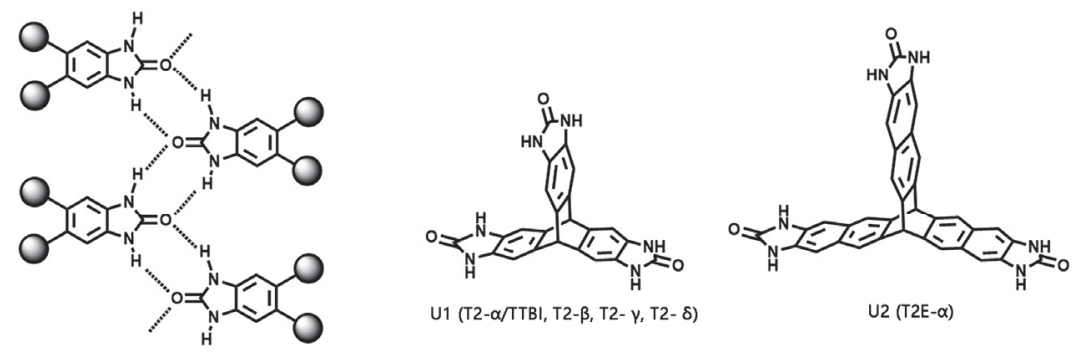

(g)

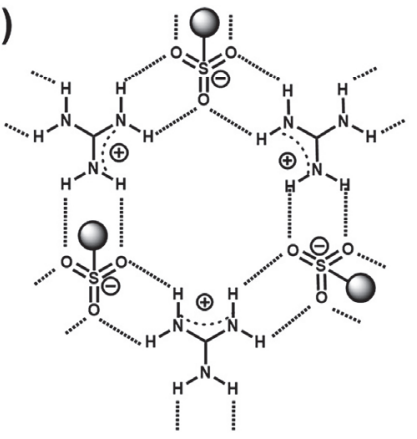

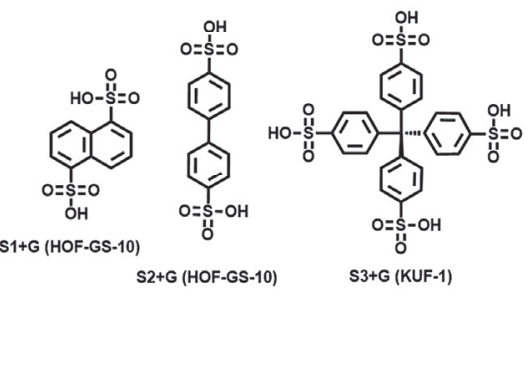

(h)

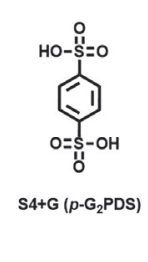

(i)

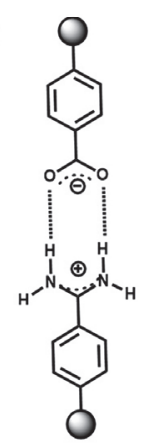

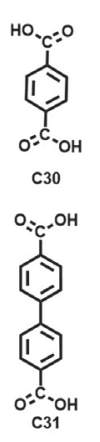

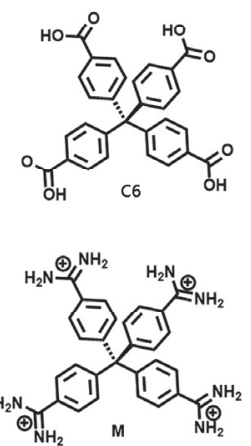

(j)

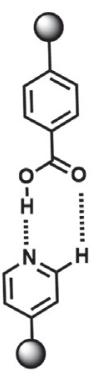

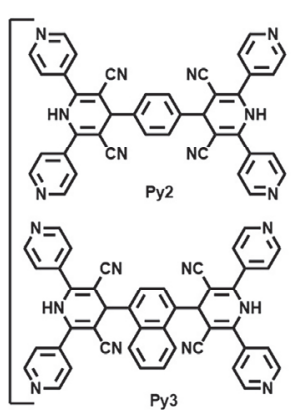

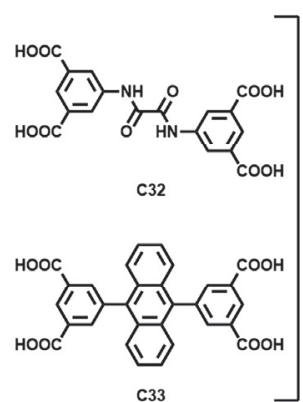

图 3 常见的用于构筑 HOFs 的超分子合成子和构建单元(括号表示相应 HOFs 名称缩写): (a) 羧酸二聚体, (b) DAT二聚体, (c) 吡唑三聚体, (d)咪 唑链, (e) 吡啶二聚体, (f) 腿链, (g) 磺酸-胍, (h) 磺酸-铵簇, (i) 羧酸-脒二聚体和(j) 羧酸-吡啶二聚体.

Figure 3 Some representative supramolecular synthons and building blocks reported for the construction of porous HOFs: (a) carboxy dimer, (b) DAT dimer, (c) pyrazolyl trimer, (d) imidazolyl chain, (e) pyridyl dimer, (f) urea chain, (g) sulfonate-guanidium sheet, (h) sulfonate-ammonium cluster, (i) carboxylate-amidinium dimer, and (j) carboxyl-pyridine dimer. 
(HOF-Pz-1, 图 4a). HOF-Pz-1 非常稳定, 孔道大小约为 $1.65 \mathrm{~nm}$, 比表面积达到 $1159 \mathrm{~m}^{2} \cdot \mathrm{g}^{-1}$, 吡唑三聚体之间 较强的氢键作用和富电子的吡唑与缺电子的四氟苯环 之间较强的 $\pi-\pi$ 作用是 HOF-Pz-1 具有较高稳定性的原 因. 通过改变脚手架的组成(Pz2)以及延长脚手架(Pz3), 结合网络化学, 另外两例同构的 HOFs 材料也被成功制 备出来(图 $4 b \sim 4 c)$. 采用配体的延长 $(\mathrm{Pz} 1$ 变成 $\mathrm{Pz} 3)$, 化 合物的孔道大小可以由 $1.65 \mathrm{~nm}$ 增大到 $2.64 \mathrm{~nm}$, 比表面 积从 $1159 \mathrm{~m}^{2} \cdot \mathrm{g}^{-1}$ 增加到 $1598 \mathrm{~m}^{2} \cdot \mathrm{g}^{-1}$ [95]. 一维的咪唑链 也可以作为超分子合成子(图 3d). 例如: 李桥伟等 ${ }^{\left[{ }^{[6]}\right.}$ 以 三蝶烯为脚手架 (Idz1), 以咪唑链作为超分子合成子成 功构筑了 FDM-15. FDM-15 具有一维开放的孔道, 它可 以被用于 $\mathrm{C}_{60}$ 的封装与富集. 此外, 吡啶或差基吡啶也 可以形成超分子合成子并用于微孔的 HOFs 材料的构筑 (图 3e $)^{[32,97-98]}$.

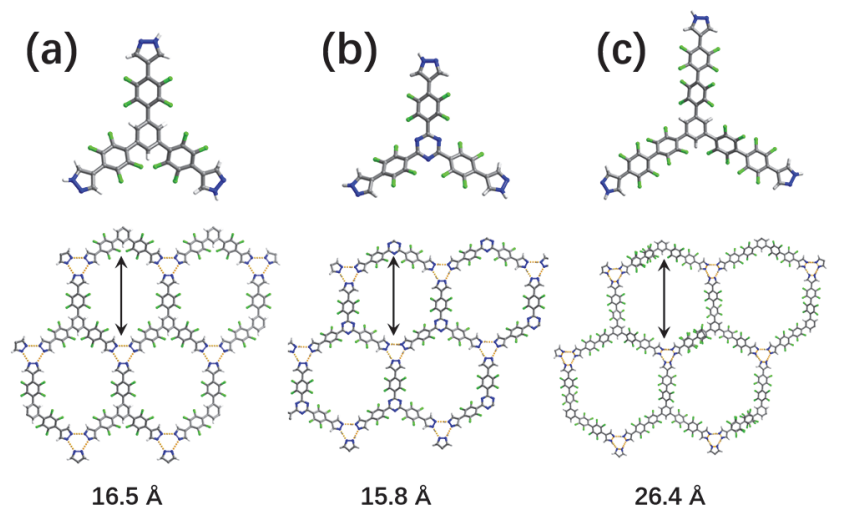

图 4 利用(a) Pz1, (b) Pz2 和(c) Pz3 构建单元分别构筑 HOF-Pz-1, HOF-Pz-2 和 HOF-Pz-3 材料.

Figure 4 The use of (a) Pz1, (b) Pz2, and (c) Pz3 building blocks to construct HOF-Pz-1, HOF-Pz-2, and HOF-Pz-3, respectively.

\subsection{4 基于腿的超分子合成子}

由双重氢键连接而成的一维的脲链是发现最早的 一种超分子合成子(图 3f) ${ }^{[99]}$, 这种超分子合成子已经被 广泛用于超分子自组装 ${ }^{[100]}$, 但是目前利用有机嫝作为 构建单元来构筑多孔 HOFs 的报道仍然非常少. 2012 年, Mastalerz 等 ${ }^{[101]}$ 基于三蝶烯脚手架 U1 和嫝链超分子合 成子构筑了多孔 TTBI(图 5a). TTBI 是非穿插的结构, 它 的孔道大小达到 $1.45 \mathrm{~nm}$, 孔容达到 $1.02 \mathrm{~cm}^{3} \cdot \mathrm{g}^{-1}, \mathrm{BET}$ 比表面积达到 $2796 \mathrm{~m}^{2} \cdot \mathrm{g}^{-1}$. Cooper 和 Day 等 ${ }^{[37]}$ 利用 $\mathrm{U} 1 / \mathrm{T} 2$ 制备了另外三种结构不同的 HOFs(图 $5 \mathrm{~b} \sim 5 \mathrm{~d}$ ). 气 体吸附实验结果表明, T2- $\gamma$ 具有最大的 BET 比表面积 $\left(3425 \mathrm{~m}^{2} \cdot \mathrm{g}^{-1}\right)$. 此外, 他们还利用 U2 制备了 T2E- $\alpha$, 其 孔道达到了 $2.8 \mathrm{~nm}$, 理论计算得到的 BET 比表面积达到 $3599 \mathrm{~m}^{2} \cdot \mathrm{g}^{-1}$.

\subsection{5 具有二元组分的超分子合成子}

在超分子自组装的过程中, 具有三重轴对称的胍阳 离子 $\left(\mathrm{G}=\mathrm{C}\left(\mathrm{NH}_{3}\right)_{3}{ }^{+}\right)$与有机磺酸根离子 $\left(\mathrm{S}=\mathrm{R}-\mathrm{SO}_{3}{ }^{-}\right)$可以 通过氢键连接形成蜂窝状的磺酸-胍 $(\mathrm{GS})$ 氢键网络. 磺

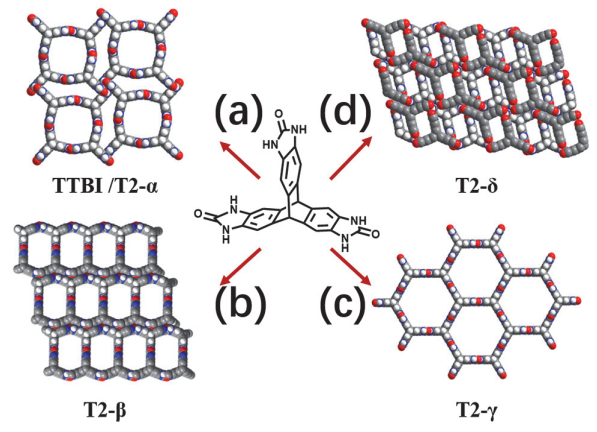

图 5 利用 $\mathrm{U} 1 / \mathrm{T} 2$ 构筑四种结构不同的 HOFs.

Figure 5 Construction of four different HOFs by U1/T2 building blocks.

酸-胍(图 3g)作为一种最常见的二元组分的超分子合成 子, 其 $\mathrm{G}$ 与 $\mathrm{S}$ 之间不但通过多重 $\mathrm{N}-\mathrm{H} \cdots \mathrm{O}-\mathrm{S}$ 氢键的相 互连接, 而且还存在静电作用, 加之 GS 网格具有很好 的折叠能力, 因而利用不同的有机磺酸根离子与胍阳离 子自组装能够得到十分丰富的结构 ${ }^{[102]}$. 自 1994 年首例 晶态的磺酸-胍超分子自组装体系报道以来, 化学家已 经制备了超过 500 例磺酸-胍的 HOFs 材料. 例如, Ghosth 等 ${ }^{[103]}$ 以 GS 网格为层而以线性的脚手架为柱子 构筑了两例具有层柱结构的 HOF 材料(HOF-GS-10 和 HOF-GS-11)并将这两例 HOFs 应用于质子传导; Hong 等 ${ }^{[104]}$ 制备了柔性的 KUF-1 可用于氨气吸附; Holman 等 ${ }^{[105]}$ 设计合成的 $p-\mathrm{G}_{2} \mathrm{BDS}$ 可用于 $\mathrm{CO}_{2}$ 和 $\mathrm{Xe}$ 的吸附.

有机磺酸-有机胺也常被用于构筑多孔 HOFs. 尤其 是当胺体积较大时(如三苯基甲胺), 胺和磺酸也可以形 成比较稳定的磺酸-铵氢键簇(图 $3 \mathrm{~h}$ ), 这种磺酸-铵氢键 簇可以作为二元的超分子合成子用于多孔 HOFs 材料的 设计合成 ${ }^{[106-108]}$. 羧酸-脒二聚体是另一种常见的二元组 分的超分子合成子(图 3i). 在该超分子合成子中, 羧酸 与脒之间不但具有双重的氢键作用, 而且还具有静电作 用, 多重氢键与静电联合作用有效地增强了羧酸与脒分 子间的结合力. White 等 ${ }^{[109-115]}$ 利用各种各样的直线型或 者四面体构型的羧酸和直线或者四面体构型的榺构筑 了一系列含羧酸-脒二聚体的 HOFs 材料, 例如: 使用四 面体的榺(M)分别与对苯二酸 $(\mathrm{C} 30)$ 或联苯二羧酸 $(\mathrm{C} 31)$ 自组装就可以制备两例具有 dia 拓扑结构的 HOFs(图 6). 尽管这两例 HOFs 的结构分别有 11 和 15 重穿插, 但它 们的孔道大小还分别达到 $1.3 \mathrm{~nm}$ 和 $0.85 \mathrm{~nm}$, 理论计算 的 BET 比表面积分别达到 1590 和 $520 \mathrm{~m}^{2} \cdot \mathrm{g}^{-1}[110,114]$.

羧酸-吡啶二聚体(图 3j) 也是常见的二组分的超分 子合成子，该二聚体存在着 $\mathrm{O}-\mathrm{H} \cdots \mathrm{N}$ 和 $\mathrm{O} \cdots \mathrm{H}-\mathrm{C}$ 双重 的氢键作用 ${ }^{[116-120]}$. 基于羧酸 - 吡啶二聚体, 吕健 等 ${ }^{[119-120]}$ 利用四羧酸与四吡啶的构建单元制备了一系列 具有永久性孔道的 HOF 材料(SOF-7-10). 孙柏旺 等 ${ }^{[117,121]}$ 利用羧酸-吡啶二聚体构筑了 TCPP-1,3-DPP 材 料并将其应用于肿瘤的化学-光动力联合治疗. 

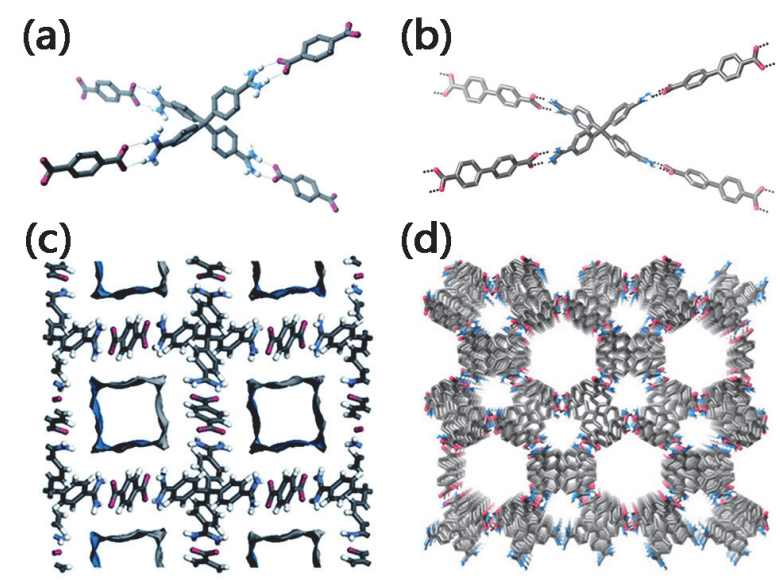

(d)

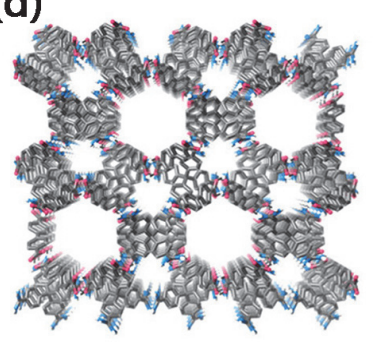

图 6 (a) M 与对苯二甲酸 $(\mathrm{C} 30$ )的连接方式; (b) M 与 4,4'-联苯二甲酸 (C31)的连接方式; (c) M-C30 和(d) M-C31 构筑的具有 dia 拓扑结构的 HOFs. 经参考文献[110, 114]许可转载, 版权 2017 英国皇家化学会和 2019 Wiley-VCH

Figure 6 (a) The connection motifs between $\mathrm{M}$ and $\mathrm{C} 30$ building block, and (b) M and C31 building block. HOFs with dia topology built by (c) M-C30 and (d) M-C31 building blocks, respectively. Reprinted with permission from ref. [110, 114], Copy right 2017 Royal Society of Chemistry and 2019 Wiley-VCH

\section{HOFs 的应用}

\section{1 气体吸附与分离}

HOFs 是一类晶态的多孔材料, 其孔道形状和尺寸 可调, 孔表面可修饰, 因此十分适合作为吸附剂用于气 体的吸附与分离. 由于大多数 HOFs 材料是由纯有机的 构建单元构筑而成的，即 HOFs 通常仅含有 C、H、N、 $\mathrm{O}$ 和 $\mathrm{S}$ 等原子量较小的元素, 因此 HOFs 作为气体吸附 剂通常能获得较大的质量吸附量. 通过合理设计具有特 定的孔道形状和孔道大小的 HOFs 或者在 HOFs 框架内 引入独特的吸附位点, 就有可能实现良好气体吸附与分 离性能.

\section{1 .1 气体吸附}

氢气是一种清洁的能源, 是未来最有希望替代化石 燃料的能源载体. 氢气的安全、高效存储是氢能实现大 规模利用的一个前提条件. 为了大规模地将氢气应用于 新能源汽车 (如燃料电池驱动的汽车), 美国能源部 (DOE) 提出氢气存储的目标是在 -40 到 $60{ }^{\circ} \mathrm{C}$ 之间、压 力为 $1 \times 10^{7} \mathrm{~Pa}$ 内, 氢气的质量存储能力达到 $5.5 \%$ 、体 积存储能力达到 $40 \mathrm{~g}\left(\mathrm{H}_{2}\right) / \mathrm{L}$ (吸附剂) ${ }^{[122]}$. 甲烷储量大、 污染小, 是另一种比较有前途的汽油替代品. DOE 提出 了甲烷的质量存储目标是 $0.5 \mathrm{~g}$ (甲烷) $/ \mathrm{g}$ (吸附剂), 体积存 储目标是 $0.188 \mathrm{~g}$ (甲烷) $/ \mathrm{mL}$ (吸附剂)或者 $263 \mathrm{~mL}$ (甲 烷 $) / \mathrm{mL}$ (吸附剂 $)^{[123]}$. 乙炔是一种非常重要的化工原料, 它的安全存储和运输是非常重要的. 目前, 开发具有高 效、高容量氢气、甲烷或乙炔存储性能的多孔吸附剂仍 然是一项巨大的挑战.

早在 HOFs 的多孔性刚被建立时, HOFs 就被用于气 体的吸附. 2010 年, Schröder 等 ${ }^{[32]}$ 报道了一例基于羧酸-
吡啶的多孔 HOF 材料(SOF-1). SOF- 1 的孔道大小为 0.74 $\mathrm{nm}$ ，比表面积达到 $474 \mathrm{~m}^{2} \cdot \mathrm{g}^{-1}$. SOF-1 具有优异的 $\mathrm{C}_{2} \mathrm{H}_{2}$ 吸附能力, 在 $195 \mathrm{~K}$ 和 $1 \times 10^{5} \mathrm{~Pa}$ 的条件下, SOF-1 对乙 炔的吸附达到 $124 \mathrm{mg} \cdot \mathrm{g}^{-1}\left(5.52 \mathrm{mmol} \cdot \mathrm{g}^{-1}\right)$. 此外, SOF-1 也能够吸附甲烷, 在 $270 \mathrm{~K}$ 和 $1 \times 10^{5} \mathrm{~Pa}$ 的条件下, 其甲 烷的吸附量达到 $61 \mathrm{~cm}^{3} \cdot \mathrm{g}^{-1}$.

提高吸附剂的比表面积是一个有效提升气体吸附 存储性能的方法. 2012 年, Mastalerz 等 ${ }^{[101]}$ 基于 U1 构建 单元制备一例具有超高比表面积的 HOF 材料(TTBI, 图 5a). TTBI 具有两种孔道，一种为圆形孔道，直径约为 $1.45 \mathrm{~nm}$, 另一种为狭缝形孔道, 尺寸大小为 $0.38 \mathrm{~nm} \times$ $0.58 \mathrm{~nm}$. TTBI 具有永久性孔道, 在脱除孔道内的溶剂 后其框架仍不发生坍塌. TTBI 的孔隙率达到 $60 \%$, 孔容 达到 $1.02 \mathrm{~cm}^{3} \cdot \mathrm{g}^{-1}$, BET比表面积高达 $2796 \mathrm{~m}^{2} \cdot \mathrm{g}^{-1}$. 由于 TTBI 具有非常大的比表面积, 因此它被用于 $\mathrm{H}_{2}$ 和 $\mathrm{CH}_{4}$ 的吸附存储. 在 $77 \mathrm{~K}$ 和 $1 \times 10^{5} \mathrm{~Pa}$ 的条件下, TTBI 的氢 气吸附量高达 $10.8 \mathrm{~mL} \cdot \mathrm{g}^{-1}$ (质量吸附量为 $2.2 \%$ ), 该氢 气吸附量为目前已报道的 HOFs 领域最大的氢气吸附 量. TTBI 对氢气的吸附可謧美于任何不含不饱和金属 配位点的 MOFs, 甚至可比肩于具有高密度不饱和金属 配位点的 Mg-MOF-74(质量吸附量为 $2.2 \%$ ) $^{[124]}$. 此外, 在 $273 \mathrm{~K}$ 和 $1 \times 10^{5} \mathrm{~Pa}$ 的条件下, TBBI 的甲烷吸附量达 到 $21 \mathrm{~mL} \cdot \mathrm{g}^{-1}$ (质量吸附量为 $1.5 \%$ ). Cooper 和 Day 等 [37]利用晶体结构预测方法(Crystal structure prediction method, CSP)计算对于给定的构建单元可能构筑的多孔 HOF 结构, 再为每个预测的结构计算其物理性能, 就可 以得到相应的能量-结构-功能关系图 (energy-structurefunction map, ESF). 根据 ESF, 他们认为, 以 U1 为构建 单元构筑的稳定多孔 HOFs 理论上应该会有四种(图 $5 b \sim 5 \mathrm{~d}$ ), 它们分别为 T2- $\alpha$ (即 TTBI), T2- $\beta, \mathrm{T} 2-\gamma$ 和 T2- $\delta$, 并且认为 T2- $\gamma$ 应该比 T2- $\alpha$ 具有更大的比表面积、更小 的密度以及更大的甲烷存储量. 高通量结晶实验结果表 明，这四种结构都能很好地被制备出来; 单晶测试结果 表明, 四种结构与理论预测的结构基本相同，其中 $\mathrm{T} 2-\gamma$ 的密度低至 $0.417 \mathrm{~g} \cdot \mathrm{cm}^{-3}$; 气体吸附测试的结果表明, $\mathrm{T} 2-\gamma$ 的比表面积达到 $3230 \mathrm{~m}^{2} \cdot \mathrm{g}^{-1}$ (目前报道的具有最大 比表面积的 HOFs 材料), $115 \mathrm{~K}$ 时饱和的甲烷吸附达到 $47.4 \mathrm{~mol} \cdot \mathrm{kg}^{-1}(437.4 \mathrm{~mL} / \mathrm{mL})$.

二氧化碳是最主要的一种温室气体, 大规模的 $\mathrm{CO}_{2}$ 排放导致全球气候变暖, 因此 $\mathrm{CO}_{2}$ 的减排已引起了全球 科研工作者的广泛关注. $\mathrm{CO}_{2}$ 的捕集与存储是减少 $\mathrm{CO}_{2}$ 排放的一种办法, 但这种方法十分依赖于 $\mathrm{CO}_{2}$ 吸附剂. 开发具有吸附容量高和选择性好的 $\mathrm{CO}_{2}$ 吸附剂对于缓 解温室效应具有重要的意义. 一般情况下, HOFs 框架与 $\mathrm{CO}_{2}$ 之间都具有较强的相互作用力, 而与 $\mathrm{N}_{2}$ 之间的作用 力则非常小, 所以大部分 $\mathrm{HOFs}$ 都具有优异的 $\mathrm{CO}_{2} / \mathrm{N}_{2}$ 选择性吸附的性能. 例如, SOF- $1 \mathrm{a}^{[32]}$ 在室温下基本不吸 附 $\mathrm{N}_{2}$, 但却能吸附 $\mathrm{CO}_{2}$; 在 $1.6 \times 10^{6} \mathrm{~Pa}$ 和 $298 \mathrm{~K}$ 的条件 
下, 其 $\mathrm{CO}_{2}$ 的吸附量达到 $69 \mathrm{~cm}^{3} \cdot \mathrm{g}^{-1}$. $\mathrm{TTBI}^{[101]}$ 同样具有 十分优异的 $\mathrm{CO}_{2}$ 吸附能力, 在 $273 \mathrm{~K}$ 和 $1 \times 10^{5} \mathrm{~Pa}$ 的条 件下, TTBI 能够吸附 $80.7 \mathrm{~mL} \cdot \mathrm{g}^{-1}$ (质量吸附量为 $15.9 \%$ ) 的 $\mathrm{CO}_{2}$, 该吸附量是当时报道的 HOFs 最大的 $\mathrm{CO}_{2}$ 吸附 量. TTBI 对 $\mathrm{CO}_{2}$ 的吸附可媲美于具有优异 $\mathrm{CO}_{2}$ 吸附能力 的 MOFs 材料如 $\mathrm{Co}_{4}(\mathrm{OH})_{2}(p-\mathrm{CDC})(16.4 \%)^{[125]}$.

2013 年, Zaworotko 等 ${ }^{[126]}$ 基于 $\left[\mathrm{Cu}_{2}(\mathrm{ade})_{4}\right]^{4+}(\mathrm{ade}=$ adenine, 腺嘌呤) 与 $\mathrm{TiF}_{6}{ }^{2-}$ 构筑了一例具有十分优异的 选择性吸附 $\mathrm{CO}_{2}$ 气体的 HOF 材料(MPM-1-TIFSIX, 图 7). 在 MPM-1-TIFSIX 的结构中, 每个 $\left[\mathrm{Cu}_{2}(\mathrm{ade})_{4}\right]^{4+}$ 通过 $\mathrm{N}-\mathrm{H} \cdots \mathrm{N}$ 和 $\mathrm{N}-\mathrm{H} \cdots \mathrm{F}-\mathrm{Ti}$ 与邻近的 $\mathrm{TiF}_{6}{ }^{2-}$ 或 $\left[\mathrm{Cu}_{2}(\mathrm{ade})_{4}\right]^{4+}$ 相连, 形成三维开放的框架(图 $7 \mathrm{a}$ ). MPM-1-TIFSIX 的孔隙率达到 49.4\%, 比表面积达到 $840 \mathrm{~m}^{2} \cdot \mathrm{g}^{-1}$. 在 $298 \mathrm{~K}$ 和 $1.01 \times 10^{5} \mathrm{~Pa}$ 的条件下, MPM-1-TIFSIX 能够吸附 $89.6 \mathrm{~cm}^{3} \cdot \mathrm{g}^{-1}$ 的 $\mathrm{CO}_{2}$ 但却只能 吸附 $8.0 \mathrm{c} \mathrm{m}^{3} \cdot \mathrm{g}^{-1}$ 的氮气(图 $7 \mathrm{~b}$ ). 在低压下, MPM-1-TIFSIX 的 $\mathrm{CO}_{2}$ 吸附焓达到 $44.4 \mathrm{~kJ} \cdot \mathrm{mol}^{-1}$ (图 7c), 这个吸附焓远远大于当时报道的其它 $\mathrm{HOFs}$ 的 $\mathrm{CO}_{2}$ 吸附 焓, 且该吸附焓也可媲美于具有优异 $\mathrm{CO}_{2}$ 吸附性能的 MOFs 材料如 SIFSIX-3-Zn (56 kJ・mol $\left.{ }^{-1}\right)$, UTSA-16 (45 $\left.\mathrm{kJ} \cdot \mathrm{mol}^{-1}\right), \mathrm{Mg}$-dobdc $\left(47 \mathrm{~kJ} \bullet \mathrm{mol}^{-1}\right)$ 等的吸附焓. 巨正则 蒙特卡罗模拟(Grand Canonical Monte Carlo, GCMC)结 果表明, MPM-1-TIFSIX上 $\mathrm{TiF}_{6}{ }^{2-}$ 的氟原子是重要的 $\mathrm{CO}_{2}$ 吸附位点. 理想吸附溶液理论(Ideal Adsorbed Solution Theory, IAST)计算的结果表明, 在 $298 \mathrm{~K}$ 和 $1.01 \times 10^{5} \mathrm{~Pa}$ 下, MPM-1-TIFSIX 的 $\mathrm{CO}_{2} / \mathrm{N}_{2}(10: 90)$ 分离系数高达 74.1 , 该分离系数甚至要高于大多数 $\mathrm{MOFs}$ 的 $\mathrm{CO}_{2} / \mathrm{N}_{2}$ (体积比为 $10: 90$, 全文涉及混气的比例均指体积比)分

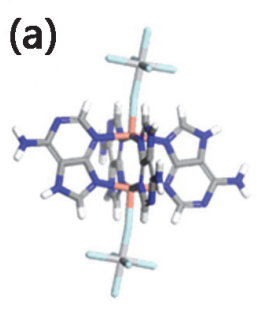

(b)

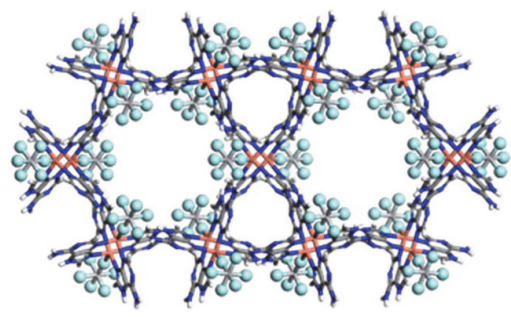

(c)
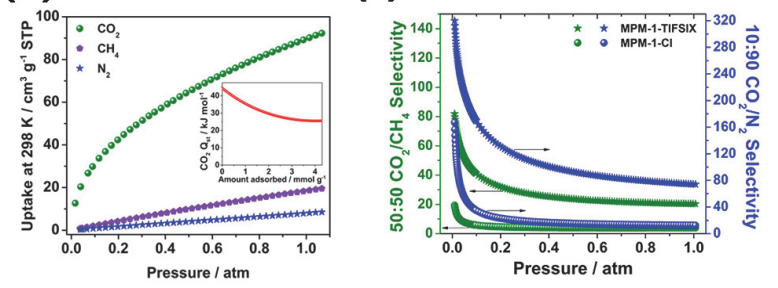

图 7 (a) MPM-1-TIFSIX 的结构; (b) MPM-1-TIFSIX 对 $\mathrm{CO}_{2}, \mathrm{CH}_{4}$ 和 $\mathrm{N}_{2}$ 的吸附 $(298 \mathrm{~K})$; (c) $\mathrm{CO}_{2} / \mathrm{N}_{2}$ 和 $\mathrm{CO}_{2} / \mathrm{CH}_{4}(50: 50)$ 的 IAST 分离系数 $(298 \mathrm{~K})$. 经参考文献[126]许可转载, 版权 2013 美国化学会

Figure 7 (a) The structure of MPM-1-TIFSIX and its building block; (b) $\mathrm{CO}_{2}, \mathrm{CH}_{4}$, and $\mathrm{N}_{2}$ adsorption over MPM-1-TIFSIX at $298 \mathrm{~K}$; (c) The IAST selectivities of $\mathrm{CO}_{2} / \mathrm{N}_{2}(50: 50)$ and $\mathrm{CO}_{2} / \mathrm{CH}_{4}(50: 50)$ at $298 \mathrm{~K}$. Reprinted with permission from ref. [126], Copy right 2013 American Chemical Society
离系数. 此外, MPM-1-TIFSIX 具有非常好的稳定性, 在 $568 \mathrm{~K}$ 的温度下或者在水溶液中浸泡 $24 \mathrm{~h}$ 仍能保持良好 的结晶性和吸附性能.

2014 年, Schröder 等 ${ }^{[119]}$ 基于羧酸-吡啶超分子合成 子 $(\mathrm{Py} 2+\mathrm{C} 32)$ 构筑了一例刚性的 SOF-7(图 8). SOF-7 的 孔道大小约为 $1.35 \mathrm{~nm} \times 1.4 \mathrm{~nm}$, 比表面积高达 900.0 $\mathrm{m}^{2} \cdot \mathrm{g}^{-1}$ (图 8a). SOF-7 基本不吸附 $\mathrm{N}_{2}$ 但却能良好地吸附 $\mathrm{CO}_{2}$. 在 $1 \times 10^{5} \mathrm{~Pa}$ 和 $273 \mathrm{~K}$ 或 $298 \mathrm{~K}$ 的条件下, SOF-7 吸附 $\mathrm{CO}_{2}$ 的质量吸附量分别为 $12.54 \%\left(2.85 \mathrm{mmol} \cdot \mathrm{g}^{-1}\right)$ 或 $6.53 \%\left(1.49 \mathrm{mmol}^{\circ} \mathrm{g}^{-1}\right)$; 而当压力升到 $2.02 \times 10^{6} \mathrm{~Pa}$ 时, $\mathrm{CO}_{2}$ 的质量吸附量分别增加到 31.09\% (7.07 mmol$\mathrm{g}^{-1}$ ) 和 $24.12 \%\left(5.48 \mathrm{mmol} \cdot \mathrm{g}^{-1}\right.$ ) (图 $8 \mathrm{~b}$ ). GCMC 和密度泛 函计算(Density functional calculations, DFT)计算的结果 表明, C32 上的酰胺基团与 Py2 上的氰基是 SOF-7 吸附 $\mathrm{CO}_{2}$ 的主要位点. 随后, 他们通过改变羧酸以及吡啶构 建单元又制备了三个羧酸-吡啶的 HOFs 材料 (SOF-8-10). 其中, SOF-9-10 具有较好的稳定性和永久 性的孔道. 在 $1 \times 10^{5} \mathrm{~Pa}$ 和 $273 \mathrm{~K} / 298 \mathrm{~K}$ 的条件下, SOF-9 和 SOF-10 的 $\mathrm{CO}_{2}$ 质量吸附量分别达到 $4.09 \%(0.93$ $\left.\mathrm{mmol} \cdot \mathrm{g}^{-1}\right) / 6.96 \%\left(1.58 \mathrm{mmol} \cdot \mathrm{g}^{-1}\right)$ 和 $9.28 \%$ (2.11 $\mathrm{mmol} \bullet$ $\left.\mathrm{g}^{-1}\right) / 5.67 \%\left(1.29 \mathrm{mmol} \bullet \mathrm{g}^{-1}\right)$.
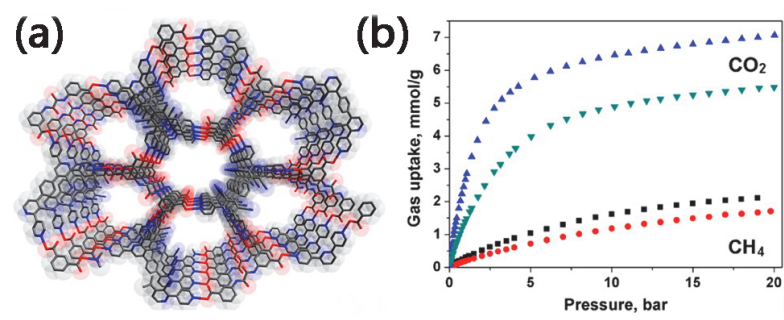

图 8 (a) SOF-7 的结构; (b) $\mathrm{CO}_{2}$ 和 $\mathrm{CH}_{4}$ 的吸附等温线 $(273$ 和 $298 \mathrm{~K}$ ). 经参考文献[119]许可转载, 版权 2014 美国化学会

Figure 8 (a) The structure of SOF-7. (b) $\mathrm{CO}_{2}$ and $\mathrm{CH}_{4}$ adsorption over SOF-7 at 273 and $298 \mathrm{~K}$. Reprinted with permission from ref. [119], Copy right 2014 American Chemical Society

2016 年, Vaidhyanathan 等合成了一例具有选择性吸 附 $\mathrm{CO}_{2}$ 的 $\mathrm{HOF}$ 料 (IISERP-HOF $1^{[43]}$ 或 $\mathrm{HOF}-11^{[44]}$ ). IISERP-HOF1 在晶体学 $a$ 方向具有一维的孔道 $(0.94 \mathrm{~nm}$ $\times 0.91 \mathrm{~nm}$ ) (图 9a), 比表面积高达 $1025 \mathrm{~m}^{2} \cdot \mathrm{g}^{-1}$. IISERP-HOF1 可以吸附 $4.8 \mathrm{mmol}^{\circ} \mathrm{g}^{-1}\left(1.01 \times 10^{5} \mathrm{~Pa}, 273\right.$ $\mathrm{K})$ 或 $2.9 \mathrm{mmol} \cdot \mathrm{g}^{-1}\left(1.01 \times 10^{5} \mathrm{~Pa}, 303 \mathrm{~K}\right)$ 的 $\mathrm{CO}_{2}$, 但却基 本不吸附 $\mathrm{N}_{2}$ (图 9b). 在 $0 \sim 1.01 \times 10^{5} \mathrm{~Pa}$ 之间, IISERP-HOF 1 的 $\mathrm{CO}_{2} / \mathrm{N}_{2}(15: 85)$ IAST 分离系数高达 $240 \sim 350$ (图 9c). 此外, 其它微孔的 HOFs 材料如 $\mathrm{HOF}-5^{[87]}$, HOF- $7^{[89]}$ 、HOF- $8^{[98]}$ 和 HOF-9 $9^{[90]}$ 等也具有十 分优异的 $\mathrm{CO}_{2}$ 捕集与存储性能.

氨气是化肥和医药工业不可或缺的原料, 也可以作 为氢源, 氨气同样也是一种有毒的气体, 开发具有选择 性吸附氨气的多孔材料具有非常重要的意义. Hong 等 ${ }^{[104]}$ 首次报道了一例具有氨气吸附的 HOF 材料 (KUF-1, 图 10). KUF-1 是由 $\mathrm{S} 3+\mathrm{G}$ 构筑而成的, 在它的 
表 1 一些代表性多孔 HOFs 的比表面积和应用

Table 1 The surface areas and applications of some representative porous HOFs.

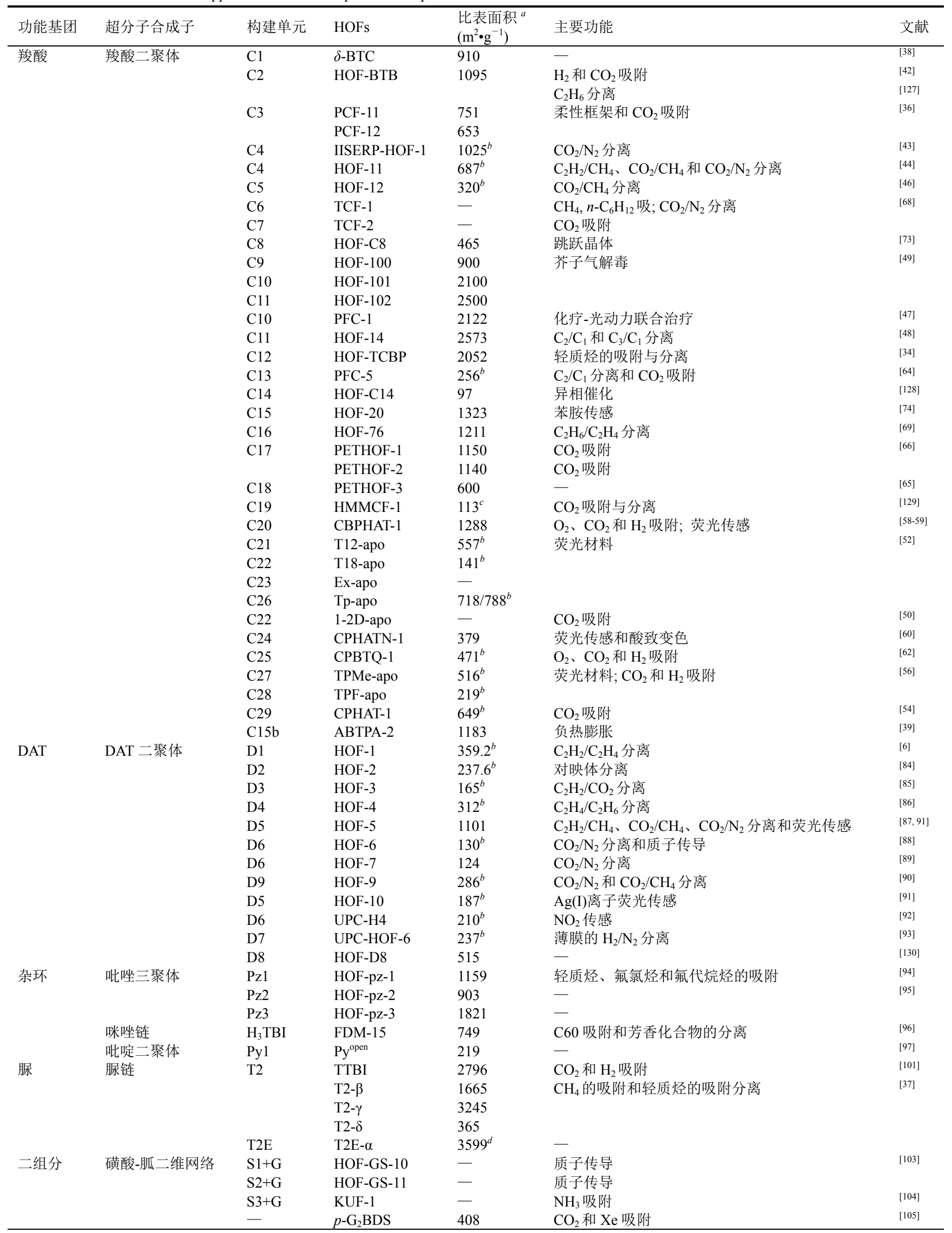




\begin{tabular}{|c|c|c|c|c|c|c|}
\hline 功能基团 & 超分子合成子 & 构建单元 & HOFs & $\begin{array}{l}\text { 比表面积 }{ }^{a} \\
\left(\mathrm{~m}^{2} \cdot \mathrm{g}^{-1}\right)\end{array}$ & 主要功能 & 文献 \\
\hline \multirow{19}{*}{ - } & \multirow[t]{5}{*}{ 羧酸-脒二聚体 } & 其它 & 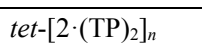 & $1470^{d}$ & - & {$[114]$} \\
\hline & & $\mathrm{M}+\mathrm{C} 30$ & $\mathrm{~A}^{\text {tere }}$ & $1590^{d}$ & - & \multirow[t]{3}{*}[110]{} \\
\hline & & $\mathrm{M}+\mathrm{C} 31$ & $\mathrm{~A}^{\text {biphen }}$ & $520^{d}$ & - & \\
\hline & & $\mathrm{M}+\mathrm{C} 6$ & $\mathrm{C}^{\text {biphenyl }}$ & $1130^{d}$ & - & \\
\hline & & $\mathrm{M}+\mathrm{C} 6$ & BioHOF-1 & - & 酶的封装 & [113] \\
\hline & \multirow[t]{4}{*}{ 羧酸-吡啶二聚体 } & $\mathrm{C} 32+\mathrm{Py} 2$ & SOF-7 & $900^{e}$ & $\mathrm{CO}_{2}$ 吸附 & [119] \\
\hline & & $\mathrm{C} 33+\mathrm{Py} 3$ & SOF-9 & $181^{e}$ & $\mathrm{CO}_{2}$ 吸附 & \multirow[t]{2}{*}[120]{} \\
\hline & & $\mathrm{C} 32+\mathrm{Py} 3$ & SOF-10 & $221^{e}$ & $\mathrm{CO}_{2}$ 吸附 & \\
\hline & & $\mathrm{C} 13+\mathrm{TPP}$ & TCPP-1,3-DPP & 258 & 化学-光动力联合治疗 & {$[117,121]$} \\
\hline & \multirow[t]{10}{*}{ 其它 } & - & ECUT-HOF-30 & $402^{b}$ & $\mathrm{C}_{2} \mathrm{H}_{2} / \mathrm{CO}_{2}$ 分离 & [71] \\
\hline & & - & $1-\mathrm{Co} / 1-\mathrm{Ni}$ & $1192 / 1239$ & 不对称催化 & [70] \\
\hline & & - & CPOS-1-4 & $12-216^{e}$ & 质子传导 & {$[108]$} \\
\hline & & - & HOF-19 & 685 & 异相催化 & [131] \\
\hline & & - & HOF-21 & $339^{b}$ & $\mathrm{CO}_{2}$ 吸附 & {$[132]$} \\
\hline & & - & MPM-1-TIFSIX & $637^{c}$ & $\mathrm{CO}_{2}$ 吸附 & {$[126]$} \\
\hline & & - & $\mathrm{ZrT} 1-\alpha$ & 527 & $\mathrm{CH}_{4}$ 吸附 & {$[133]$} \\
\hline & & - & $\mathrm{ZrT} 1-\beta$ & 1007 & & \\
\hline & & - & ZrT2- $\alpha$ & 454 & & \\
\hline & & - & $\mathrm{ZrT} 2-\beta$ & 870 & & \\
\hline
\end{tabular}

根据 $\mathrm{N}_{2}$ 吸附等温线计算的 BET 比表面积 $(77 \mathrm{~K}) ;{ }^{b}$ 基于 $\mathrm{CO}_{2}$ 吸附等温线计算的 BET 比表面积 $(195 \mathrm{~K}) ;{ }^{c}$ Langmuir 比表面积; ${ }^{d}$ 理论计算的比表面积; ${ }^{e}$ 基于 $\mathrm{CO}_{2}$ 吸附等温线计算的 BET 比表面积 $(273 \mathrm{~K})$.

(a)

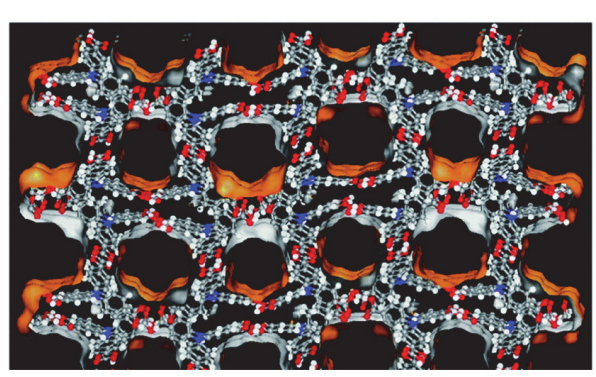

(b)

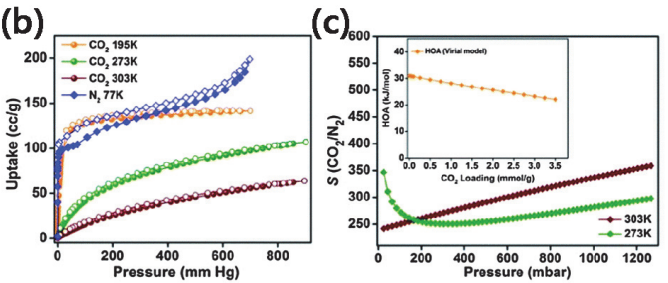

图 9 (a) IISERP-HOF1 的结构和其 $a$ 方向的孔道; (b) IISERP-HOF1 对 $\mathrm{CO}_{2}$ 和 $\mathrm{N}_{2}$ 吸附; (c) $\mathrm{CO}_{2} / \mathrm{N}_{2}$ 和 $\mathrm{CO}_{2} / \mathrm{CH}_{4}(50: 50)$ 的 IAST 分离系数. 经参考文献[43]许可转载, 版权 2016 英国皇家化学会

Figure 9 (a) The structure of IISERP-HOF1 and its 1D channels along crystallographic $a$ axis. (b) $\mathrm{CO}_{2}$ and $\mathrm{N}_{2}$ adsorption over IISERP-HOF1; (c) IAST selectivities of $\mathrm{CO}_{2} / \mathrm{N}_{2}(15: 85)$. Reprinted with permission from ref. [43], Copy right 2016 Royal Society of Chemistry

结构中, $\mathrm{S} 3$ 与 $\mathrm{G}$ 之间通过高密度的氢键相连接从而形成 三维的框架结构(图 10a). KUF-1 基本不吸附 $\mathrm{N}_{2} 、 \mathrm{H}_{2}$ 和 $\mathrm{O}_{2}$ (图 10b), 但却可以明显吸附 $\mathrm{NH}_{3}$ (图 10c). 在 $283 \mathrm{~K}$ 和 $1 \times 10^{5} \mathrm{~Pa}$ 的条件下, KUF- $1 \mathrm{a}$ 的氨气吸附等温线为典 型的 I 类型, 其氨气吸附量达到 $0.97 \mathrm{mmol} \cdot \mathrm{g}^{-1}$. 值得注 意的是, 在 $298 \mathrm{~K}$ 的条件下, KUF-1a 的氨气吸附等温线 变为 $\mathrm{S}$ 形, 其氨气吸附量从 $6.5 \times 10^{4} \mathrm{~Pa}$ 时的 3.41 $\mathrm{mmol} \cdot \mathrm{g}^{-1}$ 迅速升到 $1 \times 10^{5} \mathrm{~Pa}$ 时的 $6.67 \mathrm{mmol} \cdot \mathrm{g}^{-1}$. $\mathrm{S}$ 形 的吸附等温线可以归为 $\mathrm{V}$ 型吸附类型, 该吸附类型使得 KUF-1a 具有较高氨气工作容量和较温和的再生条件.
由于吸附类型的改变, 尽管工作温度从 $283 \mathrm{~K}$ 升到高 $298 \mathrm{~K}, \mathrm{KUF}-1 \mathrm{a}$ 的氨气吸附量却提升了 7 倍 $\left(1 \times 10^{5} \mathrm{~Pa}\right)$. 粉末 XRD 精修的结果表明, 随着 $\mathrm{NH}_{3}$ 吸附量的不断增 加, KUF-1a 的晶胞体积却从 $2.0057 \mathrm{~nm}^{3}$ 减小到 1.9891 $\mathrm{nm}^{3}$, 而脱附后 KUF-1a 的晶胞体积得以恢复. 作者推 测, 在 $283 \mathrm{~K}$ 的条件下, $\mathrm{NH}_{3}$ 主要吸附于 KUF-1a 晶体的 表面上; 而在 $298 \mathrm{~K}$ 时, $\mathrm{NH}_{3}$ 则进入 $\mathrm{KUF}-1 \mathrm{a}$ 晶体的内部, 并与 KUF-1a 框架形成多重氢键，最终表现出了 V 型的 吸附类型. 此外, KUF-1a 在连续 5 次吸附循环后, 其氨 气的吸附量基本没有降低. 因此, KUF-1a 非常有希望实 际用于 $\mathrm{NH}_{3}$ 的吸附.

(a)

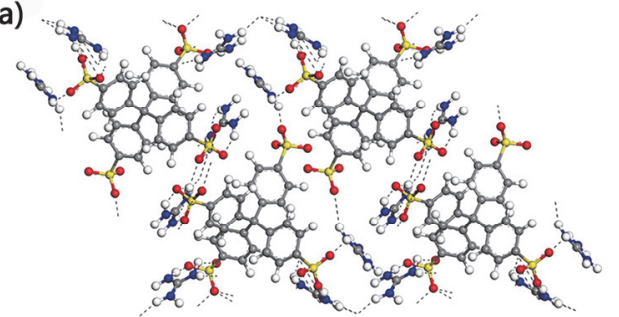

(b)

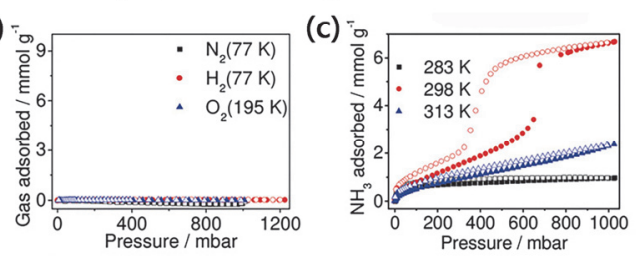

图 10 (a) KUF-1 的结构; (b) KUF-1 对 $\mathrm{N}_{2}, \mathrm{H}_{2}$ 和 $\mathrm{O}_{2}$ 的吸附; (c) KUF-1 对氨气的吸附. 经参考文献[104]许可转载, 版权 2019 Wiley-VCH Figure 10 (a) The structure of KUF-1. (b) $\mathrm{N}_{2}, \mathrm{H}_{2}$ and $\mathrm{O}_{2}$ sorption isotherms over KUF-1. (c) $\mathrm{NH}_{3}$ adsorption over KUF-1. Reprinted with permission from ref. [104], Copy right 2019 Wiley-VCH

\section{1 .2 气体分离}

轻质烃是石油化工行业中最重要的化工原料, 这类 化合物如乙烯、丙烯、乙炔和丙炔等主要用于生产各种 
各样的聚合物, 因此在使用之前必需进行提纯(达到聚 合级纯度). 传统纯化轻质烃的方法主要是低温蒸馏, 由于它们之间如乙炔-乙烯-乙烷或丙炔-丙烯-丙烷的沸 点十分相近, 因而这种纯化方法能耗非常高. 吸附分离 由于能耗低、操作简单, 因此被认为是一种最具有前途 的替代低温蒸馏的方法. 目前, HOFs 材料已广泛被用于 $\mathrm{C}_{1} \sim \mathrm{C}_{4}$ 的轻质烯的分离.

乙烯的生产主要依赖于乙烷或液化石油气的蒸汽 裂解, 而蒸汽裂解生产的乙烯不可避免地含有一些其它 的轻质烃杂质(主要是乙烷). 因此, 从乙烯中去除少量 的乙烷是乙烯提纯的不可缺少的一个步骤. 2014 年, 陈 邦林等 ${ }^{[86]}$ 利用 D4 构筑了一例具有选择性吸附 $\mathrm{C}_{2} \mathrm{H}_{4} / \mathrm{C}_{2} \mathrm{H}_{6}$ 的 HOF 材料(HOF-4, 图 11). HOF-4 是一个六 重穿插的结构, 它的孔道大小为 $0.38 \mathrm{~nm} \times 0.81 \mathrm{~nm}$, 比 表面积达到 $312 \mathrm{~m}^{2} \cdot \mathrm{g}^{-1}$ (图 11a). 在 $296 \mathrm{~K}$ 和 $1 \times 10^{5} \mathrm{~Pa}$ 的条件下, HOF-4 吸附 $\mathrm{C}_{2} \mathrm{H}_{4}$ 的能力 $\left(11.1 \mathrm{~cm}^{3} \cdot \mathrm{g}^{-1}\right)$ 优于吸 附 $\mathrm{C}_{2} \mathrm{H}_{6}\left(3.6 \mathrm{~cm}^{3} \cdot \mathrm{g}^{-1}\right.$ ) (图 $11 \mathrm{~b}$ ), 其 $\mathrm{C}_{2} \mathrm{H}_{4} / \mathrm{C}_{2} \mathrm{H}_{6}$ 分离系数 (IAST)达到 14 .

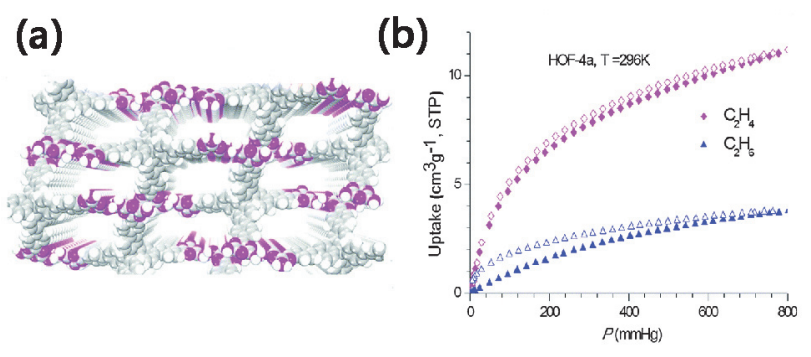

图 11 (a) HOF-4 的结构; (b) HOF-4 对 $\mathrm{C}_{2} \mathrm{H}_{4}$ 和 $\mathrm{C}_{2} \mathrm{H}_{6}$ 的吸附. 经参考 文献[86]许可转载, 版权 2019 英国皇家化学会

Figure 11 (a) The structure of HOF-4. (b) $\mathrm{C}_{2} \mathrm{H}_{4}$ and $\mathrm{C}_{2} \mathrm{H}_{6}$ adsorption over HOF-4. Reprinted with permission from ref. [86], Copy right 2014 Royal Society of Chemistry

通常来说, 选择性吸附乙烷比选择性吸附乙烯更有 利于吸附剂从乙烯中去除少量的乙烷. 因为前者可以通 过一步分离就可直接获得高纯度的乙烯, 而后者则还需 要经过乙烯脱附步骤, 不但增加了分离步骤, 更极大地 增加了能耗. 鉴于上述考虑, 陈邦林等 ${ }^{[69]}$ 又利用 $\mathrm{C} 16$ 制 备了一例具有 $\mathrm{C}_{2} \mathrm{H}_{6} / \mathrm{C}_{2} \mathrm{H}_{4}$ 选择性吸附性能的 $\mathrm{HOF}$ 材料 (HOF-76, 图 12). 在 HOF-76 的结构中, 每个 C16 通过 氢键与其它六个 $\mathrm{C} 16$ 相互连接, 这些氢键 $(\mathrm{O}-\mathrm{H} \cdots \mathrm{O})$ 的 键长和键角分别为 $0.2622 \mathrm{~nm}$ 和 $171.2^{\circ}$, 说明这些氢键 具有非常强的作用力以及方向性(图 12a). 值得注意的 是, C16 分子并不是共平面的, 其中有两个羧基与中心 苯环共平面, 而另外四个羧基则分别指向中心苯环平面 的上方和下方, 因而 HOF-76 可以简化成为 PCU 的拓扑 结构. 由于多重氢键与多重 $\pi-\pi$ 作用的协同作用, HOF-76 的稳定性非常好, 在 $\mathrm{pH}=1$ 或 10 的水溶液中浸 泡仍能保持非常好的晶形. HOF-76 具有一维的孔道, 孔 道大小约为 $0.7 \mathrm{~nm}$ (图 12b), 比表面积达到 $1121 \mathrm{~m}^{2} \cdot \mathrm{g}^{-1}$. 单组分气体吸附实验结果表明, HOF-76 具有十分优秀
的 $\mathrm{C}_{2} \mathrm{H}_{6} / \mathrm{C}_{2} \mathrm{H}_{4}$ 气体选择性. 在 $1 \times 10^{5} \mathrm{~Pa}$ 和 $296 \mathrm{~K}$ 的条件 下, HOF-76 可以吸附 $2.95 \mathrm{mmol} \cdot \mathrm{g}^{-1}$ 的乙烷，这个数值 是相同情况下乙烯吸附量 $\left(1.67 \mathrm{mmol} \cdot \mathrm{g}^{-1}\right.$ )的 $177 \%$ (图 $12 \mathrm{c}$ ). IAST 计算的表明, 在 $\mathrm{C}_{2} \mathrm{H}_{6} / \mathrm{C}_{2} \mathrm{H}_{4}$ 混气体积比为 $50 / 50$ 和 $10 / 90$ 时, HOF-76 的 $\mathrm{C}_{2} \mathrm{H}_{6} / \mathrm{C}_{2} \mathrm{H}_{4}$ 分离系数都大于 2.0. 该分离系数要优于目前报道的大部分 MOFs 材料的 $\mathrm{C}_{2} \mathrm{H}_{6} / \mathrm{C}_{2} \mathrm{H}_{4}$ 的 IAST 分离系数. 密度函数理论(DFT)计算 的结构表明, $\mathrm{C}_{2} \mathrm{H}_{6}$ 和 $\mathrm{C}_{2} \mathrm{H}_{4}$ 与框架结构之间的结合能分 别为 33.6 和 $29.3 \mathrm{~kJ} \bullet \mathrm{mol}^{-1} \cdot \mathrm{C}_{2} \mathrm{H}_{6}$ 具有较大的结合能源于 它与 HOF-76 的孔道较为匹配, 从而使其与框架存在着 较强的 $\mathrm{C}-\mathrm{H} \cdots \pi$ 作用力 (图 $12 \mathrm{~d} \sim 12 \mathrm{e}$ ). 理论计算和实际 突破实验的结果进一步证明, HOF-76 具有非常出色的 $\mathrm{C}_{2} \mathrm{H}_{6} / \mathrm{C}_{2} \mathrm{H}_{4}$ 选择性(图 12f). 在 $298 \mathrm{~K}$ 和 $1 \times 10^{5} \mathrm{~Pa}$ 以及混 气体积比为 $1: 1$ 的条件下, 通过一次的吸附过程, $\mathrm{HOF}-76$ 就可以分离出 $7.2 \mathrm{~L} \cdot \mathrm{kg}^{-1}$ 的聚合级 $\mathrm{C}_{2} \mathrm{H}_{4}$, 而在 $5 \times 10^{5} \mathrm{~Pa}$ 和 $298 \mathrm{~K}$ 以及混气体积比为 $1: 1$ 的条件下, HOF-76 一步分离聚合级乙烯的产能进一步提升到 18.8 $\mathrm{L} \cdot \mathrm{kg}^{-1}$.
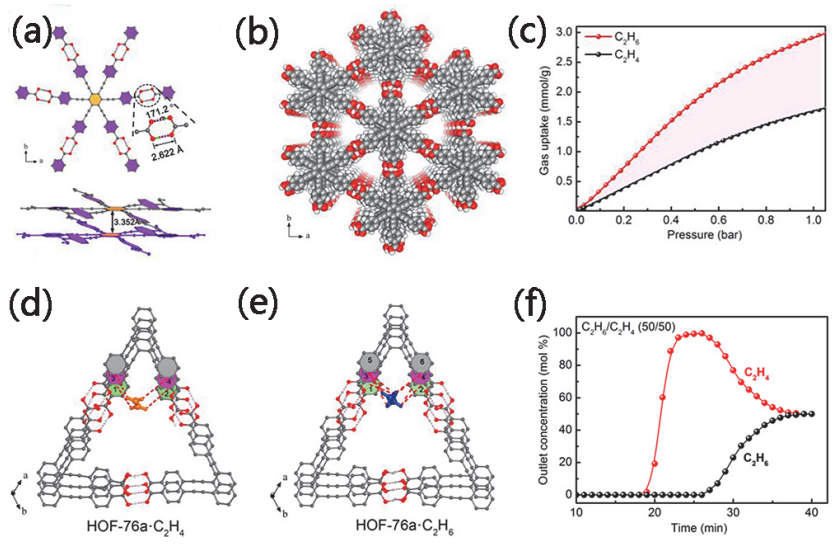

图 12 (a) HOF-76 构建单元的连接方式和 $\pi-\pi$ 堆积作用; (b) HOF-76 的结构; (c) 乙烷和乙烯的吸附; (d) 乙烯和(e) 乙烷与 HOF-76 框架之 间的作用; (f) 乙烯和乙烷 $(50: 50)$ 的突破实验 $\left(1 \times 10^{5} \mathrm{~Pa}\right.$ 和 $\left.298 \mathrm{~K}\right)$. 经参考文献[69]许可转载, 版权 2020 美国化学会

Figure 12 (a) The carboxy dimer and $\pi-\pi$ stacking in HOF-76. (b) The structure of HOF-76. (c) $\mathrm{C}_{2} \mathrm{H}_{4}$ and $\mathrm{C}_{2} \mathrm{H}_{6}$ adsorption over HOF-76. The interactions between (d) $\mathrm{C}_{2} \mathrm{H}_{4}$, (e) or $\mathrm{C}_{2} \mathrm{H}_{6}$ and HOF-76 framework. (f) Experimental breakthrough curves for the $\mathrm{C}_{2} \mathrm{H}_{6} / \mathrm{C}_{2} \mathrm{H}_{4}$ binary mixture at $298 \mathrm{~K}$ and $1 \times 10^{5} \mathrm{~Pa}$. Reprinted with permission from ref. [69], Copy right 2020 American Chemical Society

在乙烯生产过程中, 通常会伴随着约 $1 \%$ 的乙炔的 生成. 由于乙炔会使催化乙烯聚合反应的催化剂中毒, 因而从乙烯分离出少量的乙炔杂质也是非常重要的化 工过程. 2011 年, 陈邦林等 ${ }^{[6]}$ 利用 D1 合成了首例具有 $\mathrm{C}_{2} \mathrm{H}_{2} / \mathrm{C}_{2} \mathrm{H}_{4}$ 选择性吸附的 HOF-1(图 13a). 在 $273 \mathrm{~K}$ 和 $1.01 \times 10^{5} \mathrm{~Pa}$ 的条件下, HOF-1 能够吸附 $63.2 \mathrm{~cm}^{3} \cdot \mathrm{g}^{-1}$ 的 $\mathrm{C}_{2} \mathrm{H}_{2}$, 对应于 $\mathrm{C}_{2} \mathrm{H}_{2}$ 的储存密度达到 $0.17 \mathrm{~g} \cdot \mathrm{cm}^{-3}$, 或者相 当于 $16.4 \mathrm{MPa}$ 下乙炔气体的密度; 相同情况下, HOF-1 对乙烯的吸附只有 $8.3 \mathrm{~cm}^{3} \cdot \mathrm{g}^{-1}$, 其吸附 $\mathrm{C}_{2} \mathrm{H}_{2} / \mathrm{C}_{2} \mathrm{H}_{4}$ 物质 的量比为 7.6 (图 13b). 此外, 在 $273 \mathrm{~K}$ 和 $296 \mathrm{~K}$ 的条件 
下, HOF-1 的 $\mathrm{C}_{2} \mathrm{H}_{2} / \mathrm{C}_{2} \mathrm{H}_{4}$ 亨利分离系数分别达到 19.3 和 7.9. HOF-1 选择性吸附分离 $\mathrm{C}_{2} \mathrm{H}_{2} / \mathrm{C}_{2} \mathrm{H}_{4}$ 的主要原因是框 架与 $\mathrm{C}_{2} \mathrm{H}_{2}$ 具有非常强的作用力, 该作用力可能源于乙 炔酸性的氢原子与 HOF-1 碱性的氨基形成的较强的氢 键.
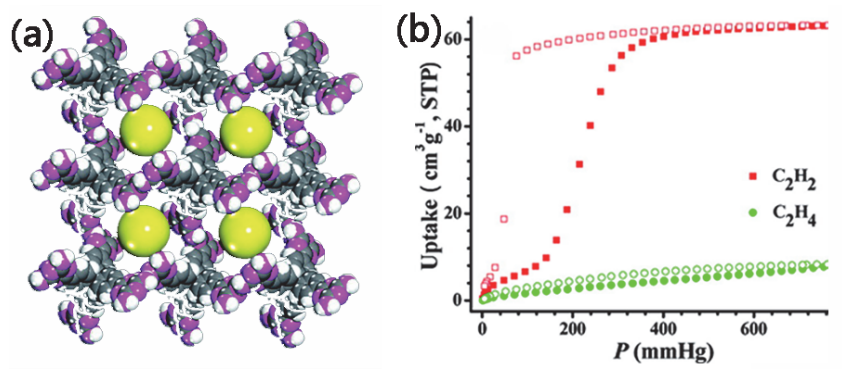

图 13 (a) HOF-1 的结构及其一维孔道; (b) 乙炔和乙烯的吸附等温线 (273 K). 经参考文献[6]许可转载, 版权 2011 美国化学会

Figure 13 (a) The 1D channels in HOF-1. (b) The sorption isotherms of $\mathrm{C}_{2} \mathrm{H}_{2}$ and $\mathrm{C}_{2} \mathrm{H}_{4}$ over HOF-1 at $273 \mathrm{~K}$. Reprinted with permission from ref. [6], Copy right 2011 American Chemical Society

2018 年, 陈邦林等 ${ }^{[132]}$ 又利用 $\left[\mathrm{Cu}_{2}(\text { ade })_{4}\right]^{4+}$ 与 $\mathrm{SiF}_{6}{ }^{2-}$ 构筑了另一例具有优异的 $\mathrm{C}_{2} \mathrm{H}_{2} / \mathrm{C}_{2} \mathrm{H}_{4}$ 分离性能的 $\mathrm{HOF}$ 材料(HOF-21, 图 14). HOF-21 与 Zaworotko 等 ${ }^{[126]}$ 构筑 的 MPM-1-TIFSIX 的合成步骤相同, 只是将平衡离子从 $\mathrm{TiF}_{6}{ }^{2-}$ 换成 $\mathrm{SiF}_{6}{ }^{2-}$, 但最终结构却是完全不同. 在 MPM-1-TIFSIX 的结构中, $\left[\mathrm{Cu}_{2}(\text { ade })_{4}\right]^{4+}$ 轴向的 $\mathrm{Cu}$ 配位 点直接与 $\mathrm{TiF}_{6}{ }^{2-}$ 配位从而形成中性的 $\left[\mathrm{Cu}_{2}(\mathrm{ade})_{4}\left(\mathrm{TiF}_{6}\right)_{2}\right]$ (图 7a), 而在 HOF-21 的结构中, $\left[\mathrm{Cu}_{2}\left(\mathrm{ade}_{4}\right]^{4+}\right.$ 轴向的 $\mathrm{Cu}$ 配位点则与水配位形成带正电的 $\left[\mathrm{Cu}_{2}(\mathrm{ade})_{4}\left(\mathrm{H}_{2} \mathrm{O}\right)_{2}\right]^{4+}$, $\mathrm{SiF}_{6}{ }^{2-}$ 则填充于 $\left[\mathrm{Cu}_{2}(\text { ade })_{4}\left(\mathrm{H}_{2} \mathrm{O}\right)_{2}\right]^{4+}$ 堆积的空隙中, $\mathrm{SiF}_{6}{ }^{2-}$ 与 $\left[\mathrm{Cu}_{2}(\mathrm{ade})_{4}\left(\mathrm{H}_{2} \mathrm{O}\right)_{2}\right]^{4+}$ 之间通过静电作用力以及多重的 $\mathrm{Si}-\mathrm{F} \cdots \mathrm{H}-\mathrm{O}$ 和 $\mathrm{Si}-\mathrm{F} \cdots \mathrm{H}-\mathrm{N}$ 氢键相连, 形成三维开放 的框架(图 14a). 此外, HOF-21 中还存在着嘧啶与嘧啶 之间的 $\pi-\pi$ 作用, 有效地增强了 HOF- 21 的稳定性. 由于 堆积方式不同, MPM-1-TIFSIX 和 HOF-21 孔道也不同, 前者的孔道大小为 $0.71 \mathrm{~nm}$, 而后者的孔道大小仅为 $0.36 \mathrm{~nm} . \mathrm{CO}_{2}$ 的吸附结果表明, HOF-21 的比表面积达到 $339.0 \mathrm{~m}^{2} \cdot \mathrm{g}^{-1}$, 但 HOF-21 却基本不吸附 $\mathrm{N}_{2}$. 这主要是因 为 HOF-21 的孔道大于 $\mathrm{CO}_{2}$ 的动力学直径但却与 $\mathrm{N}_{2}$ 的 动力学直径差不多. 由于 MPM-1-TIFSIX 具有更高的孔 隙率 $(49.4 \%)$ 和比表面积 $\left(840 \mathrm{~m}^{2} \cdot \mathrm{g}^{-1}\right)$, 因此在气体压力 大于 $25 \mathrm{kPa}$ 时, MPM-1-TIFSIX 比 HOF-21 能够吸附更 多的 $\mathrm{C}_{2} \mathrm{H}_{2}$ 和 $\mathrm{C}_{2} \mathrm{H}_{4}$ (图 14b). 值得注意的是, 当气体压力 小于 $25 \mathrm{kPa}$ 时, HOF-21 吸附 $\mathrm{C}_{2} \mathrm{H}_{2}$ 的量就比 MPM-1-TIFSIX 来得大. 更重要的是, HOF-21 比 MPM-1-TIFSIX 对 $\mathrm{C}_{2} \mathrm{H}_{2}$ 和 $\mathrm{C}_{2} \mathrm{H}_{4}$ 的吸附的差别更大. 这 些结果说明 HOF-21 比 MPM-1-TIFSIX 具有更优秀选择 性吸附 $\mathrm{C}_{2} \mathrm{H}_{2} / \mathrm{C}_{2} \mathrm{H}_{4}$ 的能力. IAST 计算的结果表明, 在 298 $\mathrm{K}$ 和 $100 \mathrm{kPa}$ 的条件下, HOF-21 的 $\mathrm{C}_{2} \mathrm{H}_{2} / \mathrm{C}_{2} \mathrm{H}_{4}(50: 50)$ 分离系数达到 7.1. 这是目前报道的 $\mathrm{HOFs}$ 材料最大的 $\mathrm{C}_{2} \mathrm{H}_{2} / \mathrm{C}_{2} \mathrm{H}_{4}$ 分离系数. HOF-21 的 $\mathrm{C}_{2} \mathrm{H}_{2} / \mathrm{C}_{2} \mathrm{H}_{4}(50: 50)$ 选择
性与 UTSA-100 (7.1)差不多, 但远远要优于 MMOF-74 $(\mathrm{M}=\mathrm{Mg}, \mathrm{Co}, \mathrm{Fe})(<2.2)$, UTSA-20 (1.5), NOTT-300 (2.3) 和 M'MOF-2 (3.3), 而仅比 M'MOF-3a (33.3), SIFSIX-2-Cu-I (41.0)和 SIFSIX-1-Cu (8.37)差. 突破实验 的结果表明, $\mathrm{C}_{2} \mathrm{H}_{4}$ 气流在 $4 \mathrm{~min}$ 后就快速通过了 HOF- 21 的填充床, 而经过吸附床的气流在 $32 \mathrm{~min}$ 内所含 $\mathrm{C}_{2} \mathrm{H}_{2}$ 的浓度都小于 $40 \mathrm{mg} / \mathrm{L}$ (图 14c). 孔道的篮分效应是 HOF-21 具有优异的 $\mathrm{C}_{2} \mathrm{H}_{2} / \mathrm{C}_{2} \mathrm{H}_{4}$ 选择性吸附的主要原因. 此外, $\mathrm{SiF}_{6}{ }^{2-}$ 中的 $\mathrm{F}$ 原子能与 $\mathrm{C}_{2} \mathrm{H}_{2}$ 的酸性氢原子形成较 强的 $\mathrm{Si}-\mathrm{F} \cdots \mathrm{H}-\mathrm{C}$ 作用力也有效提高了 $\mathrm{HOF}-21$ 的 $\mathrm{C}_{2} \mathrm{H}_{2} / \mathrm{C}_{2} \mathrm{H}_{4}$ 选择性(图 14d). (a)

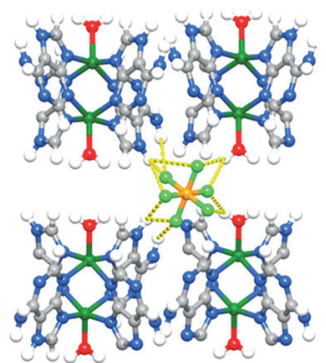

(c)

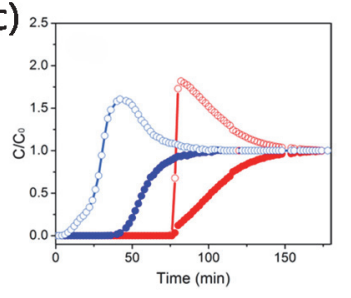

(b)

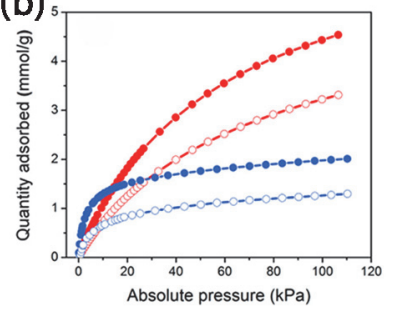

(d)

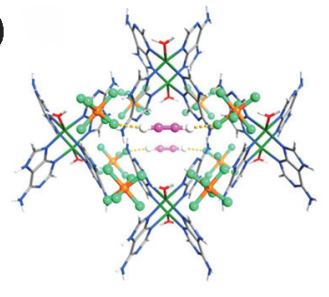

图 14 (a) HOF-21 的结构; (b) $\mathrm{C}_{2} \mathrm{H}_{2}$ (实心)和 $\mathrm{C}_{2} \mathrm{H}_{4}$ (空心)在 HOF-21 (蓝 色)和 MPM-1-TIFSIX(红色)的吸附 $\left(298 \mathrm{~K}\right.$ ); (c) $\mathrm{C}_{2} \mathrm{H}_{2} / \mathrm{C}_{2} \mathrm{H}_{4}(50: 50)$ 在 HOF-2 1 和 MPM-1-TIFSIX 的突破实验 $\left(1 \times 10^{5} \mathrm{~Pa}\right.$ 和 $\left.298 \mathrm{~K}\right)$; (d) DFT 计算的 $\mathrm{C}_{2} \mathrm{H}_{2}$ 和 HOF-21 之间的作用力. 经参考文献[132]许可转载, 版 权 2018 美国化学会

Figure 14 (a) The structure of HOF-21. (b) Adsorption isotherms of $\mathrm{C}_{2} \mathrm{H}_{2}$ (solid) and $\mathrm{C}_{2} \mathrm{H}_{4}$ (hollow) on HOF-21 (blue) and MPM-1-TIFSIX at $298 \mathrm{~K}$. (c) Experimental column breakthrough curves for $\mathrm{C}_{2} \mathrm{H}_{2} / \mathrm{C}_{2} \mathrm{H}_{4}$ $(50: 50)$ binary mixture at $298 \mathrm{~K}$ and $1 \times 10^{5} \mathrm{~Pa}$ in an adsorber bed packed with HOF-21a (blue) or MPM-1-TIFSIX (red). (d) The interactions between $\mathrm{C}_{2} \mathrm{H}_{2}$ and HOF-21 calculated by DFT. Reprinted with permission from ref. [132], Copy right 2018 American Chemical Society

乙炔通常是利用碳氢化合物如甲烷的部分氧化或 蒸汽裂解来制备的. 该过程通常会伴随着一些 $\mathrm{CO}_{2}$ 的产 生, 所以 $\mathrm{CO}_{2}$ 去除是乙炔提纯的一个很重要的步骤. 由 于两者之间的沸点 $\left(-84{ }^{\circ} \mathrm{C}\right.$ vs. $\left.-78.5{ }^{\circ} \mathrm{C}\right)$ 和分子的形 状(都是直线形)与尺寸大小 $(0.33 \mathrm{~nm} \times 0.33 \mathrm{~nm} \times 0.57$ $\mathrm{nm}$ vs. $0.32 \mathrm{~nm} \times 0.33 \mathrm{~nm} \times 0.54 \mathrm{~nm})$ 都非常相似, 因而 采用吸附的方法分离乙炔和二氧化碳是一个巨大的挑 战. 2015 年, 陈邦林等利用 D3 构筑了一例具有优秀的 $\mathrm{C}_{2} \mathrm{H}_{2} / \mathrm{CO}_{2}$ 吸附分离的 HOF 材料(HOF-3, 图 15) ${ }^{[85]}$. HOF-3 是第一例具有 srs 拓扑类型的三维开放框架, 其 一维孔道的大小为 $0.70 \mathrm{~nm}$, 比表面积为 $165.0 \mathrm{~m}^{2} \cdot \mathrm{g}^{-1}$ (图 15a). 在 $1 \times 10^{5} \mathrm{~Pa}$ 和 $273 / 296 \mathrm{~K}$ 时, HOF-3 的 $\mathrm{C}_{2} \mathrm{H}_{2}$ 吸附量为 $58 \mathrm{~cm}^{3} \cdot \mathrm{g}^{-1} / 47 \mathrm{~cm}^{3} \cdot \mathrm{g}^{-1}$, 是相同情况下 $\mathrm{CO}_{2}$ 吸 
附量的两倍 $\left(1 \times 10^{5} \mathrm{~Pa}\right.$ 和 $273 \mathrm{~K}, 31 \mathrm{~cm}^{3} \cdot \mathrm{g}^{-1} ; 1 \times 10^{5} \mathrm{~Pa}$ 和 $296 \mathrm{~K}, 21 \mathrm{~cm}^{3} \cdot \mathrm{g}^{-1}$ ) (图 15b). 在总压力接近为 0 时, HOF-3 的 $\mathrm{C}_{2} \mathrm{H}_{2} / \mathrm{CO}_{2}(50: 50)$ 的 IAST 分离系数依然大于 14 (图 15d). 随着混合气体的压力增大, $\mathrm{C}_{2} \mathrm{H}_{2} / \mathrm{CO}_{2}$ 的 IAST 分离系数也随着增大, 在 $1.01 \times 10^{5} \mathrm{~Pa}$ 时, $\mathrm{C}_{2} \mathrm{H}_{2} / \mathrm{CO}_{2}$ 的 IAST 分离系数大于 21 . HOF-3 的 $\mathrm{C}_{2} \mathrm{H}_{2} / \mathrm{CO}_{2}$ 分离系数要远远大于 CuBTC、UTSA-30 和 UTSA-50 (图 $15 \mathrm{~d})$. 突破实验进一步表明了, HOF-3 可以高效地分离 $\mathrm{C}_{2} \mathrm{H}_{2} / \mathrm{CO}_{2}$ (图 $15 \mathrm{e}$ ). 值得注意的是, HOF-3 的 $\mathrm{C}_{2} \mathrm{H}_{2}$ 吸附 焓非常的小 (小于 $21 \mathrm{~kJ} \cdot \mathrm{mol}^{-1}$ ), 远远要小于 $\mathrm{CuBTC、}$ UTSA-30 和 UTSA-50 的 $\mathrm{C}_{2} \mathrm{H}_{2}$ 吸附焓(图 15c), 因此 $\mathrm{HOF}-3$ 有望在极低的能耗下实现 $\mathrm{C}_{2} \mathrm{H}_{2} / \mathrm{CO}_{2}$ 的高效分离.
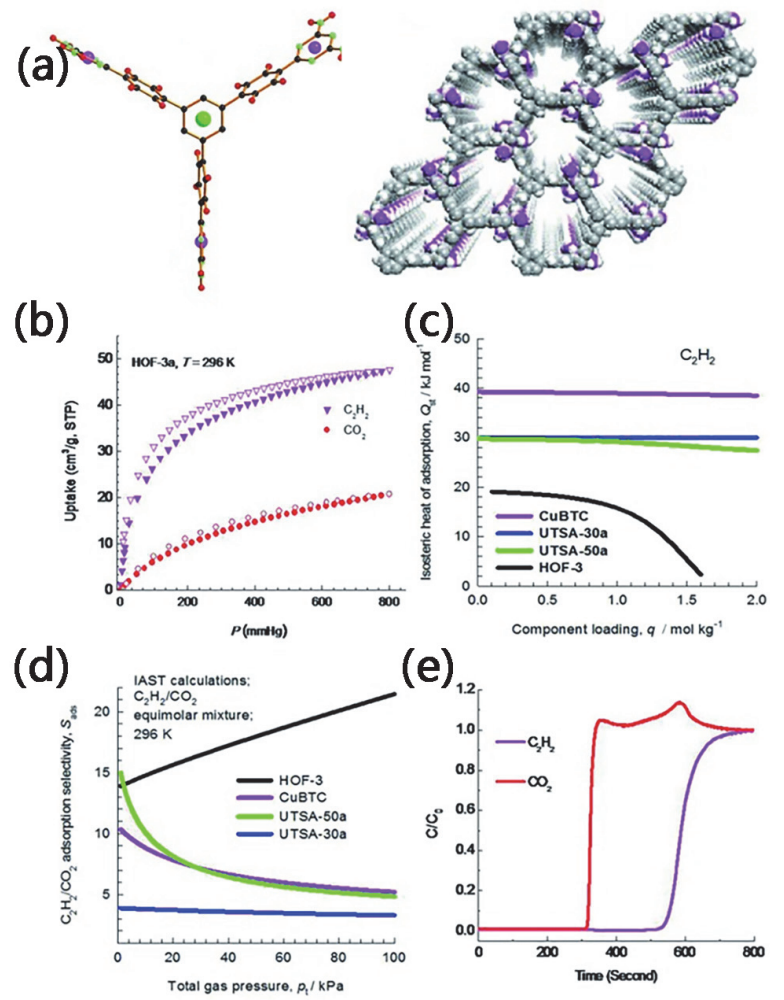

图 15 (a) HOF-3 的构建单元和结构; (b) HOF-3 对 $\mathrm{C}_{2} \mathrm{H}_{2}$ 和 $\mathrm{CO}_{2}$ 的吸附; (c) 不同吸附剂的乙炔的吸附焓对比; (d) HOF-3 和其它三个 MOF 吸 附剂 $\mathrm{C}_{2} \mathrm{H}_{2} / \mathrm{CO}_{2}$ 的 IAST 分离系数对比; (e) $\mathrm{C}_{2} \mathrm{H}_{2} / \mathrm{CO}_{2}(50: 50)$ 的突破实 验 $\left(1 \times 10^{5} \mathrm{~Pa}\right.$ 和 $\left.296 \mathrm{~K}\right)$. 经参考文献[85]许可转载, 版权 2015 Wiley- $\mathrm{VCH}$

Figure 15 (a) The building units and structure of HOF-3. (b) $\mathrm{C}_{2} \mathrm{H}_{2}$ and $\mathrm{CO}_{2}$ sorption isotherms over HOF-3. (c) Comparison of the adsorption enthalpies in HOFs and various MOFs. (d) IAST adsorption selectivities of $\mathrm{C}_{2} \mathrm{H}_{2} / \mathrm{CO}_{2}$ in equimolar mixture in HOF-3a and various MOFs at 296 K. (e) Breakthrough curve for an equimolar $\mathrm{C}_{2} \mathrm{H}_{2} / \mathrm{CO}_{2}$ mixture at $1 \times 10^{5}$ $\mathrm{Pa}$ and 296 K. Reprinted with permission from ref. [85], Copy right 2015 Wiley-VCH

近日, 罗峰等 ${ }^{[71]}$ 构筑了一例具有高效分离 $\mathrm{C}_{2} \mathrm{H}_{2} / \mathrm{CO}_{2}$ 的 HOF 材料(ECUT-HOF-30). ECUT-HOF-30 具有一维长方形的孔道, 孔道大小约为 $0.40 \mathrm{~nm} \times 0.41$ nm. ECUT-HOF-30 基本不吸附 $\mathrm{N}_{2}$, 但却能很好地吸附 $\mathrm{CO}_{2} . \mathrm{CO}_{2}$ 吸附的结果表明, ECUT-HOF-30 的比表面积 为 $402 \mathrm{~m}^{2} \cdot \mathrm{g}^{-1}$. 在 $1 \times 10^{5} \mathrm{~Pa}$ 时, ECUT-HOF-30 吸附 $\mathrm{C}_{2} \mathrm{H}_{2}$
的量达到 $53.8 \mathrm{~cm}^{3} \cdot \mathrm{g}^{-1}(273 \mathrm{~K})$ 和 $43.7 \mathrm{~cm}^{3} \cdot \mathrm{g}^{-1}(298 \mathrm{~K})$, 但 $\mathrm{C}_{2} \mathrm{H}_{2}$ 的吸附量却只有 $17 \mathrm{~cm}^{3} \cdot \mathrm{g}^{-1}(273 \mathrm{~K})$ 和 $9 \mathrm{~cm}^{3} \cdot \mathrm{g}^{-1}$ $(298 \mathrm{~K})$. 克劳修斯-克拉伯龙方程计算的结果表明, ECUT-HOF-30 的 $\mathrm{C}_{2} \mathrm{H}_{2}$ 和 $\mathrm{CO}_{2}$ 吸附焓分别为 $23.8 \mathrm{~kJ} \bullet$ $\mathrm{mol}^{-1}$ 和 $21 \mathrm{~kJ} \cdot \mathrm{mol}^{-1}$. 在 $298 \mathrm{~K}$ 和 $100 \mathrm{kPa}$ 的条件下, ECUT-HOF-30 的 $\mathrm{C}_{2} \mathrm{H}_{2} / \mathrm{CO}_{2}(50: 50)$ 的 IAST 分离系数 达到 9. 突破实验进一步证明, ECUT-HOF-30 在 $298 \mathrm{~K}$ 、 $100 \mathrm{kPa}$ 和 1: 1 的混气的条件下可以有效地分离出 $\mathrm{C}_{2} \mathrm{H}_{2}$ 和 $\mathrm{CO}_{2}$.

天然气的纯化是一个非常重要的化工过程, 将 $\mathrm{C}_{3}$ 和 $\mathrm{C}_{4}$ 烃与 $\mathrm{C}_{1}$ (即甲烷, 天然气的主要成分)分离, 有助于 降低天然气的露点, 从而避免天然气在管道输送的过程 中冷凝而堵塞管道. 甲烷的裂化是工业上制备乙炔常用 的方法, 为获得高纯度的乙炔就必需高效地分离乙炔与 甲烷混合气体. 利用甲烷部分氧化耦联制备乙烯或乙烷 时，未反应的甲烷也必须从产物乙烯或乙烷中分离开， 因而 $\mathrm{C}_{2} / \mathrm{C}_{1}$ 的分离也是一个非常重要的化工过程. 此外, 天然气品质的提升和运输时为避免管送的腐蚀要求尽 量地去除残余的 $\mathrm{CO}_{2}$ 气体. 目前 $\mathrm{HOFs}$ 材料已被应用于 $\mathrm{C}_{2} \sim \mathrm{C}_{4} / \mathrm{C}_{1}$ 和 $\mathrm{CO}_{2} / \mathrm{C}_{1}$ 的分 离 ${ }^{[64]}$.

2016 年，袁大强和吴明燕等 ${ }^{[34,134]}$ 制备的 HOF-TCBP 就具有出色的 $\mathrm{C}_{3} \sim \mathrm{C}_{4} / \mathrm{C}_{1}$ 的分离能力(图 16). HOF-TCBP 具有良好的稳定性, 其孔道大小为 $1.781 \mathrm{~nm}$ $\times 2.634 \mathrm{~nm}$ ，比表面积达到 $2066 \mathrm{~m}^{2} \cdot \mathrm{g}^{-1}$ (图 16a, 16b). 在 $295 \mathrm{~K}$ 和 $1 \times 10^{5} \mathrm{~Pa}$ 以及 $1: 1$ 的混气中, 其 $i-\mathrm{C}_{4} \mathrm{H}_{10} / \mathrm{CH}_{4}, n-\mathrm{C}_{4} \mathrm{H}_{10} / \mathrm{CH}_{4}, 1-\mathrm{C}_{4} \mathrm{H}_{8} / \mathrm{CH}_{4},(E)-2-\mathrm{C}_{4} \mathrm{H}_{8} / \mathrm{CH}_{4}$ 和 $(Z)-2-\mathrm{C}_{4} \mathrm{H}_{8} / \mathrm{CH}_{4}$ 的 IAST 分离系数分别为 147,171 , 188,231 和 241 (图 16c 16f).

2015 年，陈邦林等 ${ }^{[87}$ 报道了一例具有优异的 $\mathrm{C}_{2} \mathrm{H}_{2} / \mathrm{CH}_{4}$ 和 $\mathrm{CO}_{2} / \mathrm{CH}_{4}$ 分离性能的 HOFs 材料(HOF-5, 图 $17)^{[87]}$. HOF-5 具有二维贯穿的孔道, 其中 $[-1,0,1]$ 方向 的孔道大小约为 $0.40 \mathrm{~nm} \times 0.68 \mathrm{~nm}$ (图 17a), 而 $\mathrm{c}$ 方向的 孔道有两种, 其大小分别为 $0.39 \mathrm{~nm} \times 0.54 \mathrm{~nm}$ 和 0.41 $\mathrm{nm} \times 0.68 \mathrm{~nm}$. HOF-5 的孔隙率为 $41.1 \%$, 比表面积高达 $1101 \mathrm{~m}^{2} \cdot \mathrm{g}^{-1}$. HOF-5 能够吸附大量的 $\mathrm{CO}_{2}$, 在 $1.01 \times 10^{5}$ $\mathrm{Pa}$ 时, HOF-5 吸附 $\mathrm{CO}_{2}$ 的量分别为 $117.1 \mathrm{~cm}^{3} \cdot \mathrm{g}^{-1}(273 \mathrm{~K})$ 和 $90 \mathrm{~cm}^{3} \cdot \mathrm{g}^{-1}(296 \mathrm{~K}$ ) (图 17b). HOF-5 同样具有十分优 秀的 $\mathrm{C}_{2} \mathrm{H}_{2}$ 吸附能力, 在 $1.01 \times 10^{5} \mathrm{~Pa}$ 时, HOF-5 的 $\mathrm{C}_{2} \mathrm{H}_{2}$ 吸附量分别达到 $182.0 \mathrm{~cm}^{3} \cdot \mathrm{g}^{-1}(273 \mathrm{~K})$ 和 $101.7 \mathrm{~cm}^{3} \cdot \mathrm{g}^{-1}$ $(296 \mathrm{~K})$ (图 17c). HOF-5 具有优异的 $\mathrm{C}_{2} \mathrm{H}_{2} / \mathrm{CH}_{4}$ 和 $\mathrm{CO}_{2} / \mathrm{CH}_{4}$ 分离性能, 在 $296 \mathrm{~K}$ 和 $1: 1$ 的混气中, 其 $\mathrm{C}_{2} \mathrm{H}_{2} / \mathrm{CH}_{4}$ 和 $\mathrm{CO}_{2} / \mathrm{CH}_{4}$ 的 IAST 分离系数分别达到 13.6 和 5.0 (图 17d). 2019 年, 我们课题组 ${ }^{[135]}$ 报道了一例具有 $\mathrm{C}_{2} / \mathrm{C}_{1}$ 分离性能的 $\mathrm{HOF}$ 材料(PFC-2). PFC-2 具有非常高 的孔隙率 $(68.1 \%)$, 它的两种孔道的大小分别为 1.07 和 $2.97 \mathrm{~nm}$, 比表面积达到 $1014 \mathrm{~m}^{2} \cdot \mathrm{g}^{-1}$. PFC-2 对 $\mathrm{C}_{2} \mathrm{H}_{4}$ 和 $\mathrm{C}_{2} \mathrm{H}_{2}$ 的吸附要远远优于对 $\mathrm{CH}_{4}$ 的吸附, 在 $298 \mathrm{~K}$ 和 1 $\mathrm{kPa}$ 的条件下, 其 $\mathrm{C}_{2} \mathrm{H}_{2} / \mathrm{CH}_{4}(50: 50)$ 和 $\mathrm{CO}_{2} / \mathrm{CH}_{4}(50$ : 
(a)

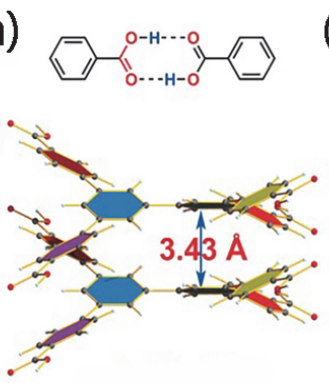

(b)

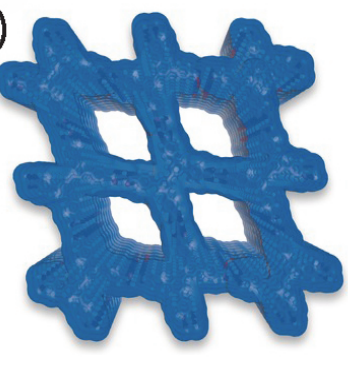

$\left(c_{100}\right.$
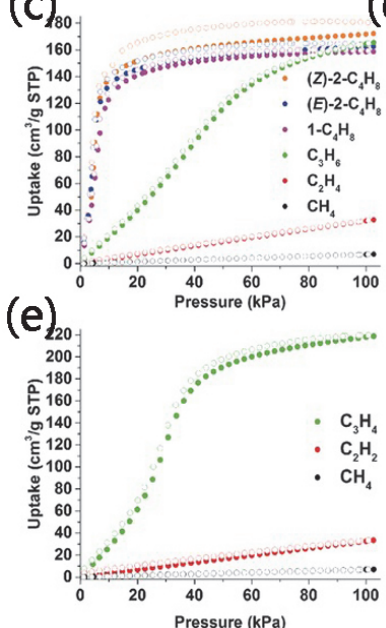

$(\mathrm{d})_{100}$

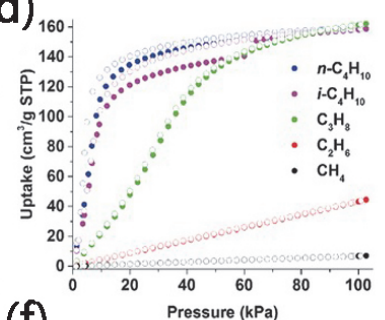

$(f)$

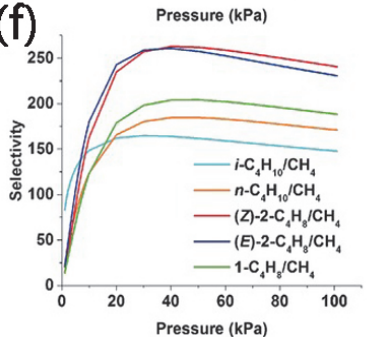

图 16 (a) HOF-TCBP 中的羧酸二聚体和 $\pi-\pi$ 堆积作用; (b) HOF-TCBP 的一维孔道; (c c e) HOF-TCBP 在 $295 \mathrm{~K}$ 时对各种轻质烃 的吸附; (f) HOF-TCBP 的 $\mathrm{C}_{4} / \mathrm{C}_{1}$ 的 IAST 选择性 $(295 \mathrm{~K}$ 和 $101 \mathrm{kPa})$. 经 参考文献[116]许可转载, 版权 2016 自然出版集团

Figure 16 (a) The carboxy dimer and $\pi-\pi$ stacking in HOF-TCBP; (b) 1D channel in HOF-TCBP; $(\mathrm{c} \sim \mathrm{e})$ The adsorption isotherms of various $\mathrm{C}_{4}$ over HOF-TCBP at $295 \mathrm{~K}$; (f) IAST predicted the adsorption selectivities of $\mathrm{C}_{4} / \mathrm{C}_{1}$ for HOF-TCBP at $295 \mathrm{~K}$ and $101 \mathrm{kPa}$. Reprinted with permission from ref. [116], Copy right 2016 Nature Publishing Group

(a)
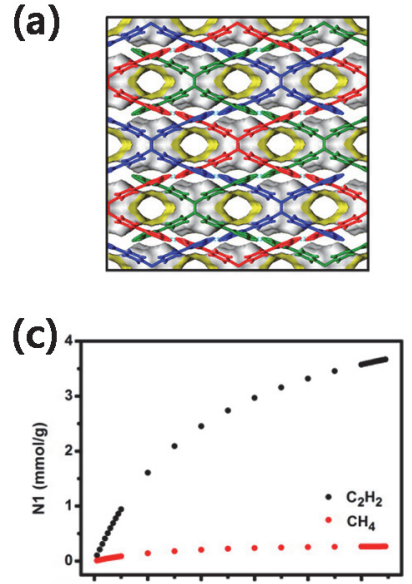

(b)

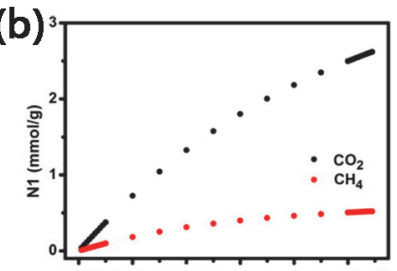

(d)

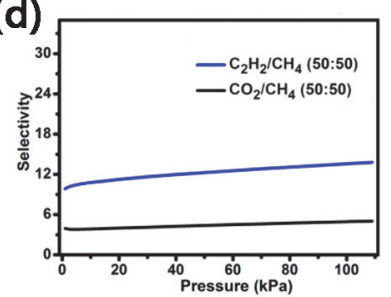

图 17 (a) HOF-5 的结构与 1D 孔道; (b) $\mathrm{CO}_{2}$ 和 $\mathrm{CH}_{4}$ 的吸附等温线; (c) $\mathrm{C}_{2} \mathrm{H}_{2}$ 和 $\mathrm{CH}_{4}$ 的吸附等温线; (d) $\mathrm{CO}_{2} / \mathrm{CH}_{4}$ 和 $\mathrm{C}_{2} \mathrm{H}_{2} / \mathrm{CH}_{4}$ 的 IAST 分离系数. 经参考文献[87]许可转载, 版权 2015 美国化学会

Figure 17 (a) The structure of HOF-5. (b) The sorption isotherms of $\mathrm{CO}_{2}$ and $\mathrm{CH}_{4}$ over HOF-5. (c) The sorption isotherms of $\mathrm{C}_{2} \mathrm{H}_{2}$ and $\mathrm{CH}_{4}$ over HOF-5. (d) IAST selectivities of $\mathrm{CO}_{2} / \mathrm{CH}_{4}$ and $\mathrm{C}_{2} \mathrm{H}_{2} / \mathrm{CH}_{4}$. Reprinted with permission from ref. [87], Copy right 2015 American Chemical Society

50)的 IAST 分离系数分别达到 27 和 17.

合成氨驰放气中氢气的回收是合成氨工业的一个 重要的分离过程. 孙道峰等 ${ }^{[93]}$ 首次报道了利用溶液加 工技术来制备 UPC-HOF-6 薄膜并将该薄膜应用于压力 响应的 $\mathrm{H}_{2} / \mathrm{N}_{2}$ 分离(图 18). 块状的 UPC-HOF-6 单晶可由 DAT 功能化的 D7 在溶剂热的条件下自组装而成. 在 UPC-HOF-6 的结构中, D7 上的每个 DAT 基团通过 4 个 $\mathrm{N}-\mathrm{H} \cdots \mathrm{N}$ 键分别与邻近的来自其它构建单元的 DAT 基 团相连, 形成氢键构筑的二维层状结构(图 18c); 层与层 之间再通过 DAT 基团形成的氢键和芳香环之间形成的 $\pi-\pi$ 作用堆积成三维开放的框架(图 18). 由于层与层之 间采用 $[\mathrm{ABCD}]$ 的堆叠方式堆叠, 因而 UPC-HOF-6 仅具 有一维狭窄的孔道, 孔道尺寸大小约为 $0.28 \mathrm{~nm}$ (图 18d). 二氧化碳的吸附结果表明, UPC-HOF-6 具有永久 性的孔道, 比表面积达到 $237 \mathrm{~m}^{2} \cdot \mathrm{g}^{-1}$. 由于多重的氢键 和 $\pi-\pi$ 作用的存在, UPC-HOF- 6 具在非常优异的稳定性, 在 $250{ }^{\circ} \mathrm{C}$ 或在 $\mathrm{pH}$ 为 $2 \sim 12$ 水溶液中浸泡后 UPC-HOF-6 仍能保持良好的晶态结构. 利用简单的溶液加工技术, UPC-HOF-6 微晶可以致密地生长在多孔 $\mathrm{Al}_{2} \mathrm{O}_{3}$ 基底上, 形成厚度约为 $1 \mu \mathrm{m}$ 的薄膜(图 18e). 单组分气体渗透实 验结果表明, 随着跨膜压力从 $1.2 \times 10^{5} \mathrm{~Pa}$ 增大到 $2.0 \times$ $10^{5} \mathrm{~Pa}$, 氢气渗透率从 $461 \mathrm{GPU}$ 增加到 $1051 \mathrm{GPU}$, 而 $\mathrm{N}_{2}$

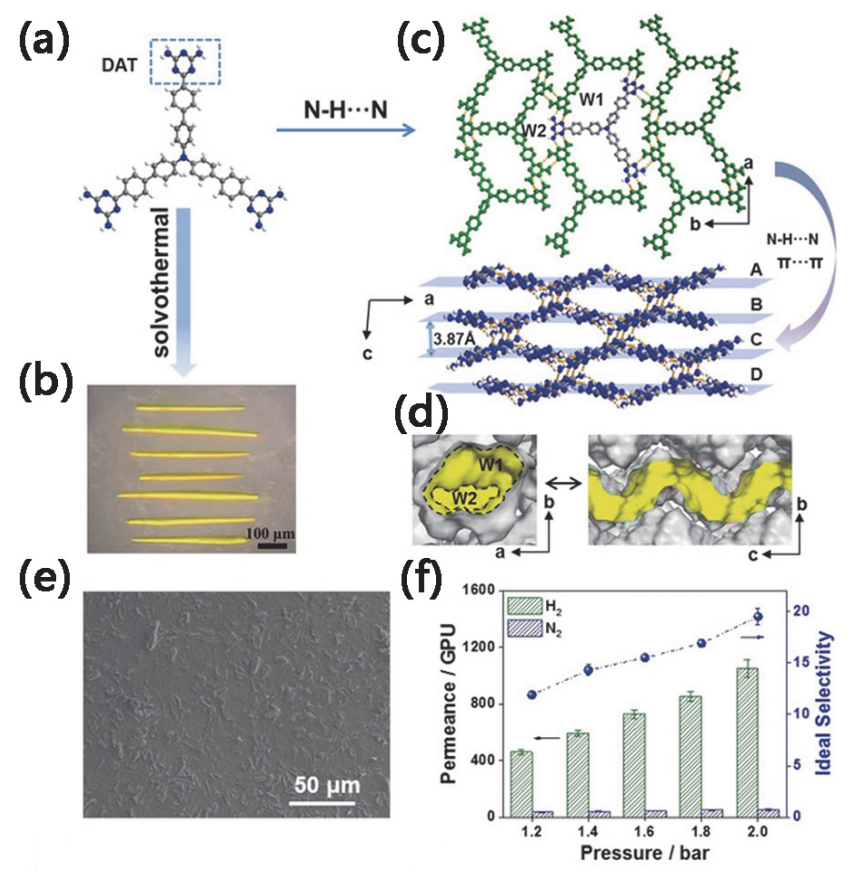

图 18 (a) UPC-HOF-6 的构建单元; (b) UPC-HOF-6 电子照片; (c) UPC-HOF-6 的结构; (d) 一维孔道; (e) UPC-HOF-6-120 薄膜的电子扫 描电镜图; (f) 不同跨膜压力下单组分气体渗透率 $\left(25{ }^{\circ} \mathrm{C}\right)$. 经参考文 献[93]许可转载, 版权 2020 Wiley-VCH

Figure 18 (a) The building unit of UPC-HOF-6. (b) Digital photo of UPC-HOF-6. (c) The structure of UPC-HOF-6. (d) 1D channel in UPC-HOF-6. (e) Top-view SEM of UPC-HOF-6-120 film. (f) Single gas permeation of UPC-HOF-6-120 membrane at $25{ }^{\circ} \mathrm{C}$. Reprinted with permission from ref. [93], Copy right 2020 Wiley-VCH 
的渗透率仅从 $39 \mathrm{GPU}$ 增加到 $54 \mathrm{GPU}$, 因而 $\mathrm{H}_{2} / \mathrm{N}_{2}$ 的选 择性从 11.9 增加到 19.5(图 18f). X 射线粉末衍射精修以 及理论计算的结果表明, UPC-HOF-6 的结构具有一定的 柔性, 其孔道在气体压力增加的情况下能够微微增大. 孔道尺寸的微小增大能够极大地促进分子较小的 $\mathrm{H}_{2}$ 在 孔道中的扩散, 而对分子较大的氮气则增加较少, 最终 $\mathrm{H}_{2} / \mathrm{N}_{2}$ 的选择性随着压力的增加而提高. 与单组分气体 渗透的结果相似, 随着跨膜压力的增大, $\mathrm{H}_{2} / \mathrm{N}_{2}$ 的选择性 也逐渐增加, 在 $25{ }^{\circ} \mathrm{C}$ 和 $2.0 \times 10^{5} \mathrm{~Pa}$ 以及混气比例为 $3: 1\left(\mathrm{H}_{2} / \mathrm{N}_{2}\right)$ 的条件下, $\mathrm{H}_{2} / \mathrm{N}_{2}$ 的分离因子达到 20.5. 除此 之外, 刮伤的 UPC-HOF-6 薄膜经过二甲基亚砜蒸汽处 理能够实现自我修复, 完美恢复薄膜的气体分离性能. 因此, UPC-HOF-6 薄膜非常有希望应于工业回收合成氨 弛放气中的氢气.

\section{2 质子传导}

为了解决全球面临的能源危机和环境污染等问题, 燃料电池逐渐成为科学家研究的一个热点. 质子交换膜 燃料电池(proton exchange membrane fuel cell, PEMFC) 具有工作温度低、启动速度快、模块式安装和操作方便 等特点, 因而被认为是一种适用于电动车和各种移动电 源等最有前途的燃料电池. 质子传导膜是质子交换膜燃 料电池的核心之一. 目前常用的质子交换膜是全氟磺酸 型质子交换膜如杜邦公司开发的 Nafion 膜, 这种膜具有 优良的导电性能. 为了能够优化质子传输通道, 阐明质 子传输机理以及提高质子交换膜的性能, 晶态多孔材料 如 MOFs 或 COFs 也被用作质子传导体. HOFs 具有良好 的溶剂加工性和结构可调节性, 原则上 HOFs 在质子传 导也具有十分广阔的应用前景 ${ }^{[136-137]}$. 特别是, HOFs 是 基于氢键连接而形成的, 而由布朗斯特酸碱对构筑的氢 键网络本身就可以作为质子传导的通道; 同时, HOFs 是 一类晶态的多孔材料, 质子载体可以有序地引入到 HOFs 材料的孔道从而作为质子传输的通道; 此外, 作 为一类晶态的多孔材料, HOFs 材料还可以作为研究质 子传输通道和质子传导机理以及揭示构-效关系的理想 平台.

2016 年, Ghosh 等 ${ }^{[103]}$ 首次将多孔 HOFs 材料作为固 态的质子传导材料. 他们利用 1,5-菜磺酸(S1)和 4,4'-联 苯二磺酸 $(\mathrm{S} 2)$ 分别与盐酸胍自组装合成了两例多孔的 HOFs 材料(HOF-GS-10 和 HOF-GS-11, 图 19). 在这两 例磺酸-胍的 HOFs 中, 磺酸根与胍盐阳离子通过氢键连 接分别形成准六边形以及带状的二维层, 这些二维层再 与芳香环脚手架相互连接最终形成经典的层-柱结构(图 19a). 变温 X 射线粉末衍射表明, HOF-GS-10 和 HOF-GS-11 在 $320{ }^{\circ} \mathrm{C}$ 之内都可以保持良好的晶形. 由 于具有高密度的质子接收和给予位点以及无限延伸的 氢键网络, HOF-GS-10 和 HOF-GS-11 具有非常好的质子 传导性能, 在湿度为 $60 \%$ 和温度为 $30{ }^{\circ} \mathrm{C}$ 的情况下, 它 们的质子传导率分别达到 $0.75 \times 10^{-2} \mathrm{~S} \cdot \mathrm{cm}^{-1}$ 和 $1.8 \times$
$10^{-2} \mathrm{~S} \cdot \mathrm{cm}^{-1}$. 该质子传导率可謧美于常用的质子传导膜 如 Nifion 隔膜, 并且是当时 HOFs 最大的质子传导率. 活化能的计算结果表明, HOF-GS-10 和 HOF-GS-11 质子 传输主要是基于 Grotthuss 传导机理(图 19b). HOFs 孔道 内结晶水含量对质子传输性能起了关键的作用, 在 HOF-GS-11 的结构中, 联苯单元疏水性比萘来得小, 因 而 HOF-GS-11 比 HOF-GS-10 具有更好的质子传输性能. 同时，随着温度的不断增加，它们的质子传导率也不断 地增加(图 19c). 同年，陈邦林等 ${ }^{[88}$ 利用 D6 合成了另一 例具有质子传导性能的多孔 HOFs 材料(HOF-6). HOF-6 的良好的质子传导能力源于卟啉和 DAT 质子载体，在 $27{ }^{\circ} \mathrm{C}$ 和湿度为 $97 \%$ 的条件下, HOF-6 的质子传导率达 到 $3.6 \times 10^{-6} \mathrm{~S} \cdot \mathrm{cm}^{-1}$.

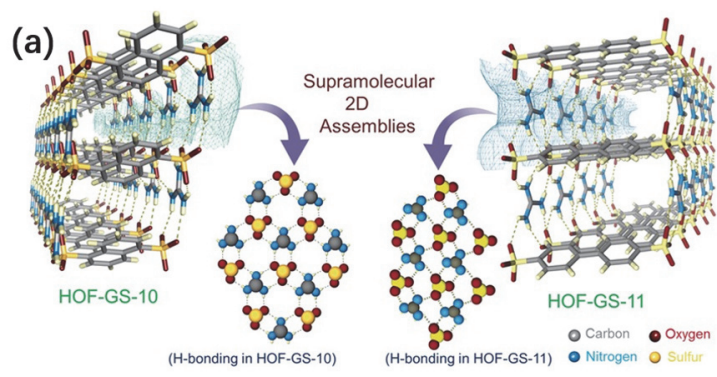

(b)

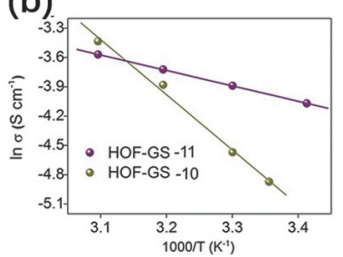

(c)

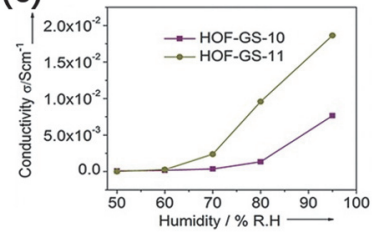

图 19 (a) HOF-GS-10 和 HOF-GS-11 的结构; (b) 阿仑尼乌斯曲线图; (c) HOF-GS-10 和 HOF-GS-11 在不同湿度下的质子传导率 $\left(30{ }^{\circ} \mathrm{C}\right)$. 经参考文献[103]许可转载, 版权 2016 Wiley-VCH

Figure 19 (a) The structure of HOF-GS-10 and HOF-GS-11. (b) Arrhenius plot of HOF-GS-10 and HOF-GS-11. (c) Proton conduction values of HOF-GS-10 and HOF-GS-11 at various humidity and $30{ }^{\circ} \mathrm{C}$. Reprinted with permission from ref. [103], Copy right 2016 Wiley-VCH

2018 年, 贲腾等 ${ }^{[108]}$ 使用四磺酸 S3 或四着酸 C6 分 别与反式-1,4-环已二胺、对苯二胺和 4,4'-二胺基联苯制 备了四例 HOFs 材料(分别为 CPOS-1, CPOS-2, CPOS-3 和 CPOS-4). 以 CPOS-1 的结构为例, S3 与反式-1,4-环己 二胺反应后, 磺酸根的质子转移到氨基上, 形成氢键与 静电作用协同作用的 CPOS-1 框架. 在 CPOS-1 的结构 中, 磺酸根与氨基通过 $\mathrm{N}-\mathrm{H}^{+} \cdots \mathrm{O}-\mathrm{S}$ 相互作用从而形 成螺旋链. CPOS-1 在晶体学 $c$ 方向上具有一维孔道, 孔 道内被水分子所填充, 这些水分子通过氢键与邻近的磺 酸根以及铵基相互连接同样形成的螺旋链. CPOS-2 到 CPOS-4 的结构与 CPOS-1 的结构相似, 它们都具有一维 孔道, 孔道内都填充了由氢键相互连接而形成的一维水 链. $\mathrm{CO}_{2}$ 的吸附表明, CPOS-1-CPOS-4 都具有永久性的 孔道, 它们的比表面积分别为 216、129、12、和 $29 \mathrm{~m}^{2}$. $\mathrm{g}^{-1}$. 在 $303 \mathrm{~K}$, 相对湿度为 $98 \%$ 的情况下, CPOS-1- 
CPOS-4 的质子传导率分别为 $6.0 \times 10^{-4} \mathrm{~S}^{-} \mathrm{cm}^{-1} 、 3.7 \times$ $10^{-3} \mathrm{~S} \cdot \mathrm{cm}^{-1} 、 3.7 \times 10^{-4} \mathrm{~S} \cdot \mathrm{cm}^{-1}$ 和 $5.6 \times 10^{-5} \mathrm{~S} \cdot \mathrm{cm}^{-1}$; 而 当温度升高到 $333 \mathrm{~K}$ 时, CPOS- 1 和 CPOS- 2 的质子传导 率升高到 $1.0 \times 10^{-2} \mathrm{~S} \bullet \mathrm{cm}^{-1}$ 和 $2.2 \times 10^{-2} \mathrm{~S} \cdot \mathrm{cm}^{-1}$. 在 CPOS 质子传输体系, 水的含量越高, 质子传导能力也 越强. CPOS-4 的质子传输能力小于 CPOS-1-CPOS-3, 这是由于后者含有大量的磺酸根, 这些磺酸根通过给出 质子可以有效地增加质子载体的数量从而提高它们的 质子传输效率. CPOS-1-CPOS-4 的活化能在 0.63 到 0.93 $\mathrm{eV}$ 之间, 这些活化能都大于 $0.4 \mathrm{eV}$, 因此, CPOS-1CPOS-4 的质子传导机理主要是 vehicular 机理, 也就是 质子的传导主要源于水分子(作为质子载体)在 HOFs 孔 道传输.

咪唑是一种两亲化合物, 它具有十分优异的质子传 导性能. Das 等 ${ }^{[138]}$ 利用金属咪唑配阳离子 $\left[\mathrm{Ni}(\mathrm{Imdz})_{6}\right]^{2+}$ 分别与 1,5 -萗二磺酸、 2,6 -萗二磺酸以及 $4,4^{\prime}$-联苯二甲 酸合成了 MHOF-1-3. 在 MHOF-1-3 的结构当中, $\left[\mathrm{Ni}(\mathrm{Imdz})_{6}\right]^{2+}$ 通过 $\mathrm{N}-\mathrm{H} \cdots \mathrm{O}-\mathrm{S}$ 或 $\mathrm{N}-\mathrm{H} \cdots \mathrm{O}-\mathrm{C}$ 氢键以 及静电作用与芳香二磺酸或芳香二羧酸相连接, 形成三 维的氢键网络. 在 $50{ }^{\circ} \mathrm{C}$ 和相对湿度为 $98 \%$ 的情况下, MHOF-1-3 的质子传导率分别达到 $1.6 \times 10^{-4} 、 2.1 \times$ $10^{-5}$ 和 $5.8 \times 10^{-5} \mathrm{~S} \cdot \mathrm{cm}^{-1}$; 随着温度的提升, 质子传导率 也增大, 当温度提高到 $80{ }^{\circ} \mathrm{C}$ 时, MHOF-1-3 的质子传导 率分别达到 $0.75 \times 10^{-3} 、 3.5 \times 10^{-3}$ 和 $0.97 \times 10^{-3} \mathrm{~S} \cdot$ $\mathrm{cm}^{-1}$. 在 $80{ }^{\circ} \mathrm{C}$ 和相对湿度为 $98 \%$ 的条件下, MHOF- 1 和 MHOF-3 的质子传导性能要优于大部分的优秀的 COFs 和 HOFs 质子传输材料. MHOF-1-3 的活化能分别为 0.90、0.80 和 $1.3 \mathrm{eV}$, 说明 MHOF-1-3 传导的机理主要 为 vehicular 机理. 晶格水对质子传导起了非常重要的作 用, MHOF-1 和 MHOF-3 具有晶格水, 因此它们的质子 传输性能要优于没有结晶水的 MHOF-2.

HOFs 在质子传输领域已崭露头角. 由于 HOFs 易 合成、低密度、高稳定性以及晶态的结构, 因而 HOFs 有望作为轻质质子传输材料应用于燃料电池领域.

\section{3 异相催化}

催化剂广泛应用于化学化工和医药行业领域, 开发 具有良好催化性能且易回收再利用的异相催化剂具有 十分重要的意义. MOFs 和 COFs 作为一类含有机组分的 晶态多孔材料, 它们具有结构可设计性和功能可调节 性, 因而已被用作异相催化剂广泛应用于催化各种化学 反应 ${ }^{[139-141]}$. 与 MOFs 和 COFs 相比较, HOFs 由于分子 构建单元之间的作用力相对较弱从而大部分 HOFs 稳定 性也相对较弱, 因而 HOFs 在催化领域中的应用还相对 较少. 随着一些具有永久性孔道和超高稳定性的 HOFs 材料的开发, HOFs 也开始慢慢地被用于异相催化领 域 ${ }^{[142]}$. 目前, HOFs 作为异相催化剂主要可以通过以下 方式实现: (1) HOFs 作为载体, 将催化剂如贵金属纳米 颗粒负载于 HOFs 框架; (2) 利用具有催化性能的构建
单元来构筑 HOFs 材料.

2015 年, 李珺等 ${ }^{[128]}$ 利用卟啉四羧酸 $\mathrm{C} 14$ 制备一例 多孔的 HOF-C14. 在 HOF-C4 的结构中, 四连接的卟啉 脚手架与羒酸二聚体连接形成 $\mathbf{s q l}$ 二维层, 层与层之间 通过 $\pi-\pi$ 和 $\mathrm{C}-\mathrm{H} \cdots \pi$ 作用相连接从而形成三维开放的结 构. HOF-C14 可以用于烷基苯的选择性氧化, 在催化剂 用量为 $5 \mathrm{mmol} \%$, TBHP 用量为 5 倍当量时, HOF-C14 可以高效催化苯乙烷选择性氧化成苯乙酮, 产率为 $83.1 \%$, 选择性高达 $99 \%$. 考虑到 HOF-C14 孔道大小仅 有 $0.398 \mathrm{~nm} \times 0.647 \mathrm{~nm}, \mathrm{HOF}-\mathrm{C} 14$ 的催化性能可能主要 源于表面催化.

手性的有机磷酸作为一种经典的布朗斯特酸 (Brønsted acid)已经广泛应用于不对称催化各种的有机 反应。硫酰杯 [4]芳烃与金属离子配位则容易制备羽毛 球状的四核金属簇(图 20a), 这种金属簇可以作为理想 的四连接的结点与其它有机配体配位合成金属-有机纳 米笼. 2019 年, 刘艳和崔勇等 ${ }^{[70]}$ 选择了四羧酸功能化的 手性有机磷酸 $\mathrm{H}_{4} \mathrm{~L}$ 、硫酰杯 [4]芳烃和 $\mathrm{Ni}(\mathrm{II}) / \mathrm{Co}(\mathrm{II})$ 自组 装设计合成了两例手性八面体的金属-有机纳米笼(图 20). 在这个纳米笼中, $\mathrm{H}_{4} \mathrm{~L}$ 的三个羧酸作为一个平面位 于八面体的面上, 而剩余的一个未配位的羧酸以及磷酸 则朝着八面体向外伸展. 有趣的是, 向外伸展羧酸以及 磷酸通过氢键连接从而将八面体金属-有机笼连接形成 稳定的三维 HOF 材料(简称为 $1-\mathrm{Ni} / 1-\mathrm{Co}$ ). $1-\mathrm{Ni}$ 和 1-Co 的都具有永久性的孔道，比表面积分别达到 1239 和 $1192 \mathrm{~m}^{2} \cdot \mathrm{g}^{-1}$. 1-Ni/1-Co 被用于高效催化吲哚与苯醌单缩 酮不对称的 $[3+2]$ 环化反应和催化吲哚与亚胺的 Friedel-Crafts 烷基化反应(图 20b). 当催化剂加入量仅为

(a)

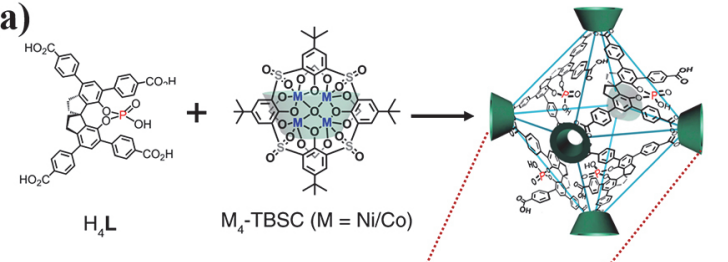

(b)

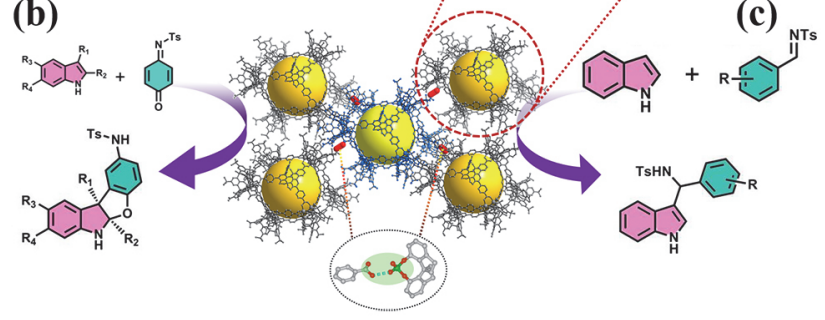

图 20 (a) 手性金属-有机八面体纳米笼的构筑; (b) 1-Co/1-Ni 催化吲 哚与苯醌单缩酮不对称 $[3+2]$ 环化反应; (c) $1-\mathrm{Co} / 1-\mathrm{Ni}$ 催化吲哚与亚 胺的 Friedel-Crafts 烷基化反应. 经参考文献[70]许可转载, 版权 2020 自然出版集团

Figure 20 (a) The construction of homochiral nanoscale metal-organic cages. (b) Asymmetric [3+2] coupling of 3 -substituted indoles with quinone monoimine. (c) Asymmetric Friedel-Crafts reaction of $N$-sulfonyl aldimines with indole. Reprinted with permission from ref. [70], Copy right 2020 Nature Publishing Group 
$0.04 \mathrm{~mol} \%$ 时, 1 -Ni 催化 3-甲基吲哚与苯醌单缩酮环化反 应和吲哚与亚胺的 Friedel-Crafts 烷基化的产率都可以 达到 92\%, ee 值分别达到 99.9\%和 91\%. 此外, 1-Ni/1-Co 催化剂可以回收再利用, 经过十次循环后, 催化剂的催 化活性和对映体选择性仍没有明显的降低.

2019 年, 王海龙等 ${ }^{[131]}$ 利用三嗪类的有机分子笼作 为构建单元成功制备了 HOF-19(图 21). 在 HOF-19 的结 构中, 分子笼与笼之间通过苯环之间的 $\pi-\pi$ 键、C-H $-\mathrm{H} \pi$ 作用以及 $\mathrm{N}-\mathrm{H} \cdots \mathrm{N}$ 氢键作用相互连接, 形成三维开放 的框架结构(图 21a). HOF-19 具有一维开放的孔道, 其 尺寸为 $0.80 \mathrm{~nm} \times 1.36 \mathrm{~nm}$. 由于多重 $\pi-\pi$ 键和氢键存在, HOF-19 具有永久性的孔道, 其比表面积达到 $685 \mathrm{~m}^{2} \bullet$ $\mathrm{g}^{-1}$. HOF-19 具有丰富的氮原子(位于三嗪环和氨基上), 因而利用后合成的方法, $\operatorname{Pd}(\mathrm{II})$ 可以有效地被负载于 HOF-19 的框架上. 与醋酸钯或市售的钯碳相比, Pd(II)@HOF-19 在催化 Suzuki-Miyaura 偶联反应中表现 出更好的催化活性(图 21b). 当催化剂加入量为 0.260 mmol\%时, Pd(II)@HOF-19 催化 Suzuki-Miyaura 偶联反 应的回收产率达到 $96 \% \sim 98 \%$. 值得指出的是, Pd(II)@HOF-19 可以实现催化剂的再生与重复利用, 通 过重结晶再生的方法, Pd(II)@HOF-19 催化活性基本不 降低.
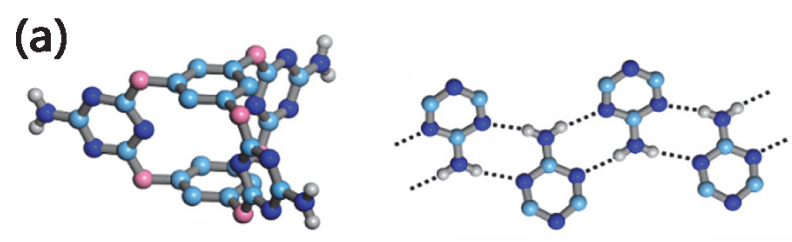

(b)

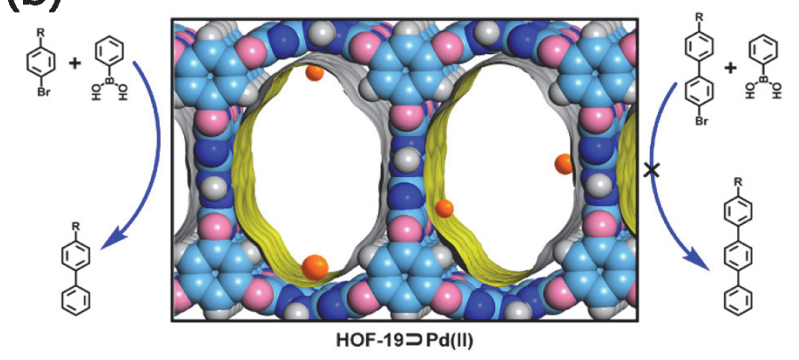

图 21 (a) HOF-19 的构建单元以及构建单元之间氢键的连接方式; (b) HOF-19כPd(II)催化铃木偶联反应. 经参考文献[131]许可转载, 版权 2019 美国化学会

Figure 21 (a) The cage-based organic building units and the intramolecular hydrogen bonding between building units. (b) Suzuki-Miyaura coupling reactions catalyzed by HOF-19כPd(II). Reprinted with permission from ref. [131], Copy right 2019 American Chemical Society

最近, Cooper 等 ${ }^{[143]}$ 采用 C10 配体预测并合成了多 孔的 TBAP- $\alpha$. TBAP- $\alpha$ 的结构与 PCF-1 或 HOF-101 结构 完全相同, 它们具有非常好的稳定性并且孔道大小达到 $1.8 \mathrm{~nm} \times 2.3 \mathrm{~nm}$. 由于萠环的存在, TBAP- $\alpha$ 具有良好的 可见光响应, 在 $1 \mathrm{mg} \cdot \mathrm{mL}^{-1}$ 催化剂 BBAP- $\alpha, 1 \% \mathrm{Pt}$ 助催 化剂, $0.1 \mathrm{~mol} \cdot \mathrm{L}^{-1}$ 的牺牲试剂(抗坏血酸), $\mathrm{pH}=7$ 和可见 光辐射 $5 \mathrm{~h}$ 的反应条件下, TBAP- $\alpha$ 产氢的速率达到了
$3108 \mu \mathrm{mol} \cdot \mathrm{h}^{-1} \cdot \mathrm{g}^{-1}$. 值得注意的是, 该反应速率比相同 反应条件下非晶态 TBAP 要高 20 倍. TBAP- $\alpha$ 的结晶性 随着产氢反应进行会慢慢降低，从而导致其产氢速率会 随着反应时间的增长而慢慢的下降. 这些实验结果表 明, HOFs 材料的结晶性以及构建单元的堆积方式对光 催化性能起了非常重要的作用. 孙柏旺等 ${ }^{[144]}$ 利用 C13 合成了三个基于卟啉的 HOFs 材料, 其中, TCPP-4(DMF) 能在 $660 \mathrm{~nm}$ 的 LED 灯的照射下产生单线 态氧并催化分解 9,10-二苯基葱.

\section{4 荧光和传感}

由于构筑 HOFs 材料的脚手架通常都含有共轭的芳 环，因此许多 HOFs 材料都会有荧光，尤其是当脚手架 含聚集诱导苂光发射(aggregation induced emission, AIE) 分子片断时, 构单元之间的相互堆积能够有效增强 HOFs 的苂光, 因此 HOFs 可以作为一种新型的苂光材 料. 此外, HOFs 具有多孔性, 孔道内的微环境有可能能 够识别和富集某些客体分子，而这些客体分子与 HOFs 框架相互作用时就有可能引起 HOFs 苂光性能发生变 化，因而 HOFs 有望应用于苂光传感 ${ }^{[72]}$.

Hisaki 等 ${ }^{[50,52]}$ 利用各种各样刚性的共轭芳香性的构 建单元 $(\mathrm{C} 21 \sim \mathrm{C} 23 、 \mathrm{C} 26)$ 构筑了一系列具有苂光发射的 HOFs 材料(图 22). C21 C $23 、 C 26$ 均含有六个羧酸官能 团, 中心脚手架共平面且具有 $C_{3}$ 对称性. 在这类 HOFs
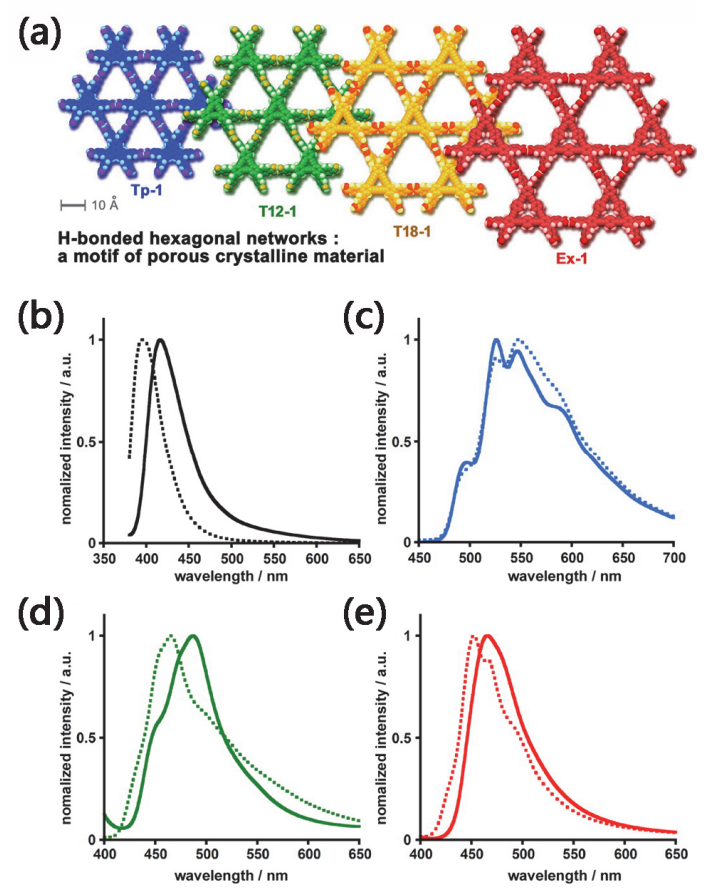

图 22 (a) Tp-1、T12-1、T18-1 和 Ex-1 的结构; (b e) Tp-1、T12-1、 T18-1 和 Ex-1 的荧光发射(实线). 经参考文献 $[50,52]$ 许可转载, 版权 2016 美国化学会

Figure 22 (a) The structure of Tp-1, T12-1, T18-1, and Ex-1. The luminescence (solid line) of (b) Tp-1, (c) T12-1, (d) T18-1, and (e) Ex-1. Reprinted with permission from ref. [50, 52], Copy right 2016 American Chemical Society 
如 Tp-1、T12-1、T18-1 和 Ex-1 的结构中, 每个构建单 元利用羧酸二聚体与邻近的六个其它的构建单元相互 连接形成 $2 \mathrm{D}$ 的六边形网络, 层与层之间再通过 $\pi-\pi$ 堆 积和 $\mathrm{C}-\mathrm{H} \cdots \pi$ 作用从而形成三维开放的框架(图 22a). 其中, Tp- 1 、 T12-1、T18-1 和 Ex-1 的孔隙率分别为 54\%、 $41 \% 、 58 \%$ 和 59\%. 这些 HOFs 具有很高的稳定性, 比表 面积在 $557 \sim 788 \mathrm{~m}^{2} \cdot \mathrm{g}^{-1}$ 之间. 由于具有较大的共轭芳 香体系, Tp-1、T12-1、T18-1 和 Ex-1 具有在 416 546 nm 具有较强的苂光发射, 荧光量子产率达到 $5.5 \%$ $25 \%$ (图 22b 22e). 此外, 这些多孔的 HOFs 还具有吸附 $\mathrm{CO}_{2} 、 \mathrm{H}_{2}$ 和轻质烃的性能.

2015 年, 陈莉和谢志刚等 ${ }^{[145]}$ 利用四苯乙烯脚手架 (TPE)和 DAT 二聚体构筑了 HOF-1111. 在 HOF-1111 的 结构中, 每个 D5 与另外其它四个 D5 相互连接形成二维 层, 层与层之间再通过 $\pi-\pi$ 作用形成三维开放的框架. HOF-1111 孔道大小为 $0.68 \mathrm{~nm} \times 1.09 \mathrm{~nm}$. 由于 HOF-1111 的四苯乙烯脚手架(TPE)处于聚集状态, 苯环 的转动被限制, 因此 HOF-1111 具有很强的荧光. 在吸 电子芳香化合物和给电子芳香化合物的蒸汽中, HOF-1111 的荧光分别会发生淬灭和增强. 其中, 硝基 苯对 HOF-1111 的苂光具有最大的淬灭效率, 它可以使 HOF-1111 的荧光降低 73\%. 因而 HOF-1111 有望用于硝 基苯的苂光传感. 2017 年, 陈邦林等同样使用 D5 合成 了两例多孔的 HOFs 材料(HOF-5 和 HOF-10, 图 23) ${ }^{[91]}$. 在 HOF-5 与 HOF-10 的结构当中, 每个 D5 分别与 8 个 和 6 个的邻近的 D5 分子相连接, 分别形成(4,6)-连接和 $(4,4)$-连接的拓扑结构(图 23a 23c). 由于 TPE 脚手架之 间的相互堆积, HOF-5 与 HOF-10 都具有较强的荧光. 有 趣的是, 经过不同浓度的 $\mathrm{Ag}(\mathrm{I})$ 离子溶液处理后, HOF-5 与 HOF-10 的苂光会随着 $\mathrm{Ag}(\mathrm{I})$ 离子浓度的增强而不断 的红移(图 23d, 23e). HOF-5 和 HOF-10 对 Ag(I) 离子的选 择性响应源于 $\mathrm{Ag}(\mathrm{I})$ 离子与 $\mathrm{DAT}$ 基团上 $\mathrm{N}$ 原子发生的配 位作用, 这种配位作用改变了 HOFs 的 LUMO-HOMO 能级从而引起苂光的红移.

2019 年, 池振国等 ${ }^{[35]}$ 利用 TPE-4pn 配体制备了一 系列 HOFs 材料(8PN, 图 24). 在 $8 \mathrm{PN}$ 的结构中, 每个 TPE-4pn 配体分别与其它四个 TPE-4pn 配体通过弱的 $\mathrm{N}-\mathrm{O} \cdots \mathrm{H}-\mathrm{C}$ 相连接, 形成二维的超分子层, 层与层之 间同样通过 $\mathrm{N}-\mathrm{O} \cdots \mathrm{H}-\mathrm{C}$ 连接形成三维的框架结构(图 $24 \mathrm{a})$. 由于 $\mathrm{N}-\mathrm{O} \cdots \mathrm{H}-\mathrm{C}$ 氢键弱, 同时脚手架四苯乙烯 (TPE)的苯环可以旋转, $8 \mathrm{PN}$ 的框架具有很强的柔性, 在 不同溶剂合成的条件下可以合成制备得到 9 种含溶剂 $8 \mathrm{PN}$ 结构. 有意思的是, 包裹不同溶剂的 $8 \mathrm{PN}$ 框架不但 结构发生了很大的改变(如孔道大小不同), 而且苂光性 能也发生了显著的变化(如苂光的最大发射波长可以从 $518 \mathrm{~nm}$ 变化到 $580 \mathrm{~nm}$ ) (图 24c). 其中, THF 溶剂化的结 构 $8 \mathrm{PN}-\mathrm{THF}$ 具有最强的苂光发射, 它的苂光量子产率 达到了 $0.55 .8 \mathrm{PN}$ 的苂光性能如波长, 荧光寿命和亮度 在不同的溶剂下会发生明显的改变, 其苂光颜色和亮度
的改变甚至是肉眼可见(图 24b 24c), 这些结果使得 $8 \mathrm{PN}$ 有望用于不同溶剂的传感.
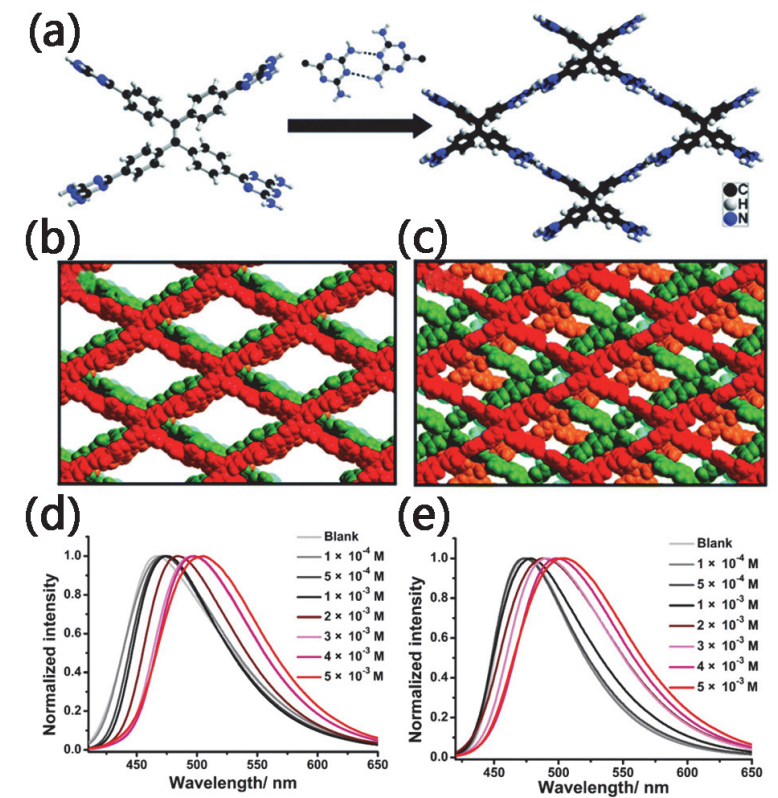

(e)

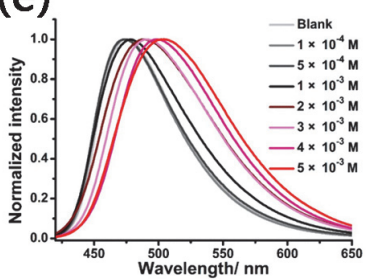

图 23 (a) HOF-10 和 HOF-5 的构筑; (b) HOF-10 的结构; (c) HOF-5 的 结构; (d) HOF-10 对 $\mathrm{Ag}(\mathrm{I})$ 的响应; (e) HOF-5 对 $\mathrm{Ag}(\mathrm{I})$ 的响应. 经参考文 献[91]许可转载, 版权 2017 英国皇家化学会

Figure 23 (a) The construction of HOF-10 and HOF-5. The structure of (b) HOF-10 and (c) HOF-5. Luminescent response of (d) HOF-10 and (e) HOF-5 to various concentration of $\mathrm{Ag}(\mathrm{I})$. Reprinted with permission from ref. [91], Copy right 2017 Royal Society of Chemistry
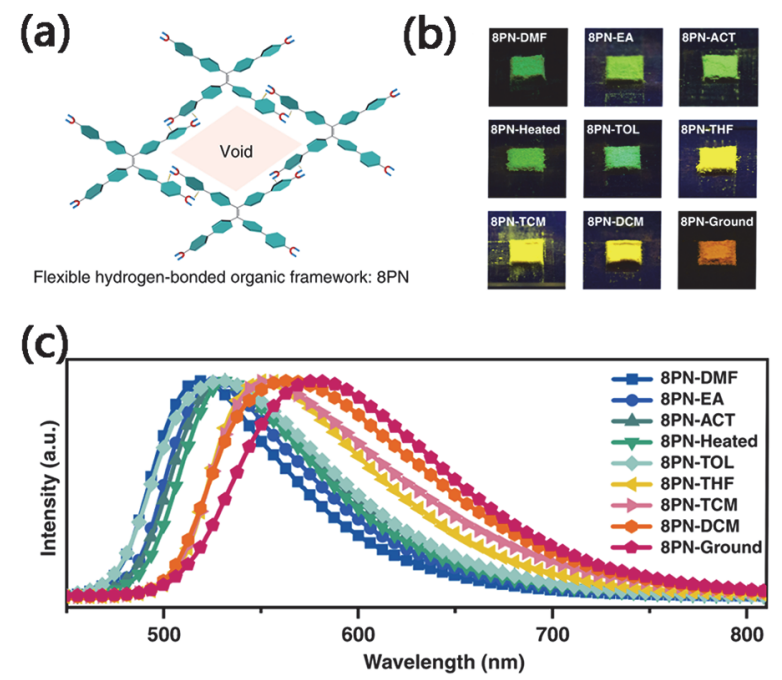

图 24 (a) $8 \mathrm{PN}$ 的结构; (b) $8 \mathrm{PN}$ 在波长为 $365 \mathrm{~nm}$ 紫外光照射下的照 片; (c) 不同溶剂化的 $8 \mathrm{PN}$ 的苂光光谱(激发波长, $365 \mathrm{~nm}$ ). 经参考文 献[35]许可转载, 版权 2019 自然出版集团

Figure 24 (a) The structure of 8PN. (b) Photographs of 8PN taken under UV-light irradiation $(365 \mathrm{~nm}$ ). (c) Emission spectra of 8PN excited at $365 \mathrm{~nm}$. Reprinted with permission from ref. [35], Copy right 2019 Nature Publishing Group

Hisaki 等利用 $C_{3}$ 对称性的构建单元合成了一系列 苂光 HOFs 材 料 (CPHATN-1 ${ }^{[60]}$, CBPHAT- ${ }^{[59]}$, CPBTQ-1 ${ }^{[62]}$ ). 这些 HOFs 材料的脚手架都含有吡嗪分 
子片断, 遇到 $\mathrm{HCl}$ 后, 吡嗪分子片断上的氮原子会质子 化, 伴随着 HOFs 的颜色会从黄色变化成棕色以及 HOFs 的荧光强度变弱或红移, 而氮原子脱质子后, HOFs 的颜色以及苂光会可逆恢复, 因此这些 HOFs 可 以用做 $\mathrm{HCl}$ 的比色传感或苂光传感.

2020 年, 陈邦林等 ${ }^{[74]}$ 利用四羧酸构筑单元 $\mathrm{C} 15$ 设 计合成了一例微孔 HOF 材料(HOF-20, 图 25). 在 HOF-20 的结构中, 羧酸二聚体与四面体的脚手架相互 连接, 形成 $\mathrm{ThSi} 2$ 拓扑结构的三维开放框架(图 25a, 25b). HOF-20 的孔道达到 $1.30 \mathrm{~nm}$, 比表面积为 1323 $\mathrm{m}^{2} \cdot \mathrm{g}^{-1}$. 由于具有高密度的羧酸二聚体以及穿插结构之 间非常强的 $\pi-\pi$ 作用, HOF-20 具有十分优异的化学稳定 性. HOF-20 在浓盐酸或沸水中浸泡 $24 \mathrm{~h}$ 后仍能保持很 好的结晶性; 此外, 在丙酮、二氧六环、乙酸乙酯、乙 腈、乙醇等常用溶剂中 HOF-20 均能稳定存在. HOF-20 的荧光对苯胺具有非常好的响应, 随着苯胺浓度的逐渐 增加, HOF-20 的荧光强度逐渐增强(图 25c). 因此, HOF-20 被用于苯胺的传感, 苯胺检测的线性范围为 $0.03 \sim 0.31 \mathrm{mmol} \cdot \mathrm{L}^{-1}$, 检测下限为 $2.24 \mu \mathrm{mol} \cdot \mathrm{L}^{-1}$. HOF-20 对苯胺的检测具有非常好的选择性, 在苯胺加 入量仅为 $10 \mu \mathrm{L}\left(100 \mathrm{mmol} \cdot \mathrm{L}^{-1}\right)$ 时, HOF-20 的荧光增强 了 $142 \%$, 而其它苯系物对 HOF-20 的荧光基本没有影 响. 进一步研究显示, 在其它苯系物存在的情况下, 苯 胺依然能使 HOF-20 的荧光增强效率维持在原来的 $82 \%$. 对吸附苯胺的 HOF-20 的结构解析发现, 苯胺分子主要 分布于 HOF-20 菱形孔的角落(图 3a), 位于该角落的苯
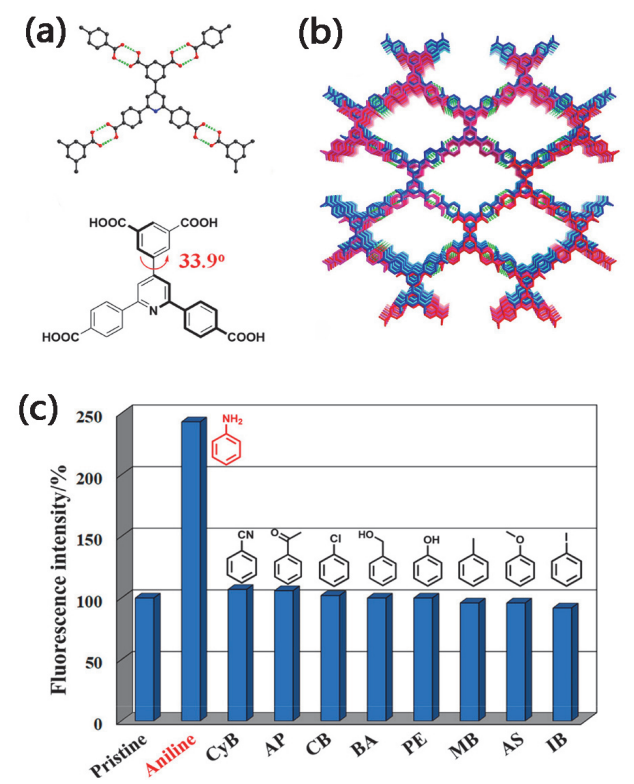

图 25 （a）构建单元的连接方式和构型; (b) HOF-20 的结构; (c) HOF-20 对各种苯系物的苂光响应. 经参考文献[74]许可转载, 版权 2016 美国化学会

Figure 25 (a) Carboxy dimer and building unit in HOF-20. (b) The structure of HOF-20. (c) Luminescent response of HOF-20 to various aromatic compounds. Reprinted with permission from ref. [74], Copy right 2020 American Chemical Society
胺分子可以和 HOF-20 的框架形成多重相互作用: 苯胺 氨基的 $\mathrm{H}$ 原子和 $\mathrm{N}$ 原子分别可以和 $\mathrm{C} 15$ 羧基的 $\mathrm{O}$ 原子 以及 $\mathrm{H}$ 原子形成氢键作用; 此外, 苯胺的苯环可以和 C15 的苯环形成边对面的 $\pi-\pi$ 作用. 这些分子间的相互 作用使得进入孔道中的苯胺分子起到了限制 C15 构筑 单元转动的作用. 这种限制作用可以减少非辐射衰变途 径, 从而增强 HOF-20 的荧光. DFT 计算进一步说明了 HOF-20 的苂光增强是源于配体转动受限引起的.

开发具有敏感性高以及可靠性强的非接触荧光比 例传感器用于温度监测仍然是一个巨大的挑战. 近日, 我们课题组 ${ }^{[146]}$ 利用电泳沉积的方法制备了一例镧系金 属离子负载的 HOFs 薄膜 (Eu@HOF-TCBP). Eu@HOF-TCBP 薄膜的苂光对温度变化能够敏感做出 响应, 其位于 $400 \mathrm{~nm}$ 的荧光强度逐渐的降低, 而位于 $613 \mathrm{~nm}$ 的红光强度却不断增强. 因此, Eu@HOF-TCBP 薄膜被用于温度的荧光比例传感. 在 $297 \sim 377 \mathrm{~K}$ 之间, $\mathrm{Eu} @$ HOF-TCBP 薄膜位于 613 与 $400 \mathrm{~nm}$ 的荧光强度比 $(Y)$ 与温度 $(T)$ 之间的线性关系为: $Y=0.0908 T-25.692$, 最大的相对灵敏度达到了 $5.787 \% \cdot \mathrm{K}^{-1}$. 此外, $\mathrm{Eu} @ \mathrm{HOF}-\mathrm{TCBP}$ 薄膜容易再生, 且再生后的薄膜传感性 能基本没有改变.

除了荧光传感之外, HOFs 还能作为有机半导体材 料用于气体传感. 姜建壮等 ${ }^{[92]}$ 基于卟啉的构建单元 D6 构筑了一例具有 $\mathrm{n}$ 型有机半导体性能的 HOFs 材料 (UPC-H4a) 并将其应用于 $\mathrm{NO}_{2}$ 的传感. UPC-H4a 具有永 久性的孔道, 其比表面积达到 $210.5 \mathrm{~m}^{2} \cdot \mathrm{g}^{-1}$. UPC-H4 涂 敷于叉指型电极表面后就可以制备成半导体薄膜，该敏 感膜可作为化学阻抗传感器用于 $\mathrm{NO}_{2}$ 气体的传感. 由于 UPC-H4 具有良好的导电性以及孔道内具有高密度的氨 基，半导体薄膜对 $\mathrm{NO}_{2}$ 传感具有优异的高效性和选择 性，其检测下限低至 $0.040 \mathrm{~mL} / \mathrm{L}$ ，响应时间小至 $17.6 \mathrm{~s}$, 恢复时间低于 $15.4 \mathrm{~s}$. 此外, UPC-H4 在连续使用 10 次以 后，其结构与传感性能均没有明显的下降.

\section{5 生物应用}

大部分的 HOFs 都不含金属离子, 因此 HOFs 一般 比 MOFs 拥有更低的细胞毒性和更好的生物相容性, 再 结合结构多样性和多孔性, HOFs 在生物应用领域具有 广泛的应用前景. 事实上, HOFs 在生物领域的应用已经 有了初步的进展. 2018 年, 我们课题组 ${ }^{[47]}$ 设计合成了一 例多孔的 PFC-1. 如前文所述, PFC-1 具有高比表面积、 优异的化学和热稳定性, 其孔道大小达到 $1.8 \mathrm{~nm} \times 2.3$ $\mathrm{nm}$. 通过调节溶剂的极性和合成条件, PFC-1 的尺寸可 以均一地控制在 $100 \mathrm{~nm} \times 300 \mathrm{~nm}$ (标记为 Nano-PFC-1). 一方面, Nano-PFC-1 的构建单元的脚手架为含有萠, 它 在可见光光照下可以产生单线态氧, 因此 PFC-1 有望用 于癌症的光动力学治疗 (图 26); 另一方面, 抗癌药物阿 霉素(Doxo)非常容易被负载于 Nano-PFC-1, 其负载量 最大可达到 26.5\% (标记为 Doxo@Nano-PFC-1), 并且被 
负载的阿霉素在弱酸性条件下可以慢慢释放出来, 因而 Doxo@Nano-PFC-1 有望用于癌症的化学治疗. 体外细 胞实验表明, Doxo@Nano-PFC-1 具有非常低的细胞毒 性, 它在癌症治疗(Hela 细胞)中表现出了优异的化学-光 动力学联合治疗的效果(图 26).

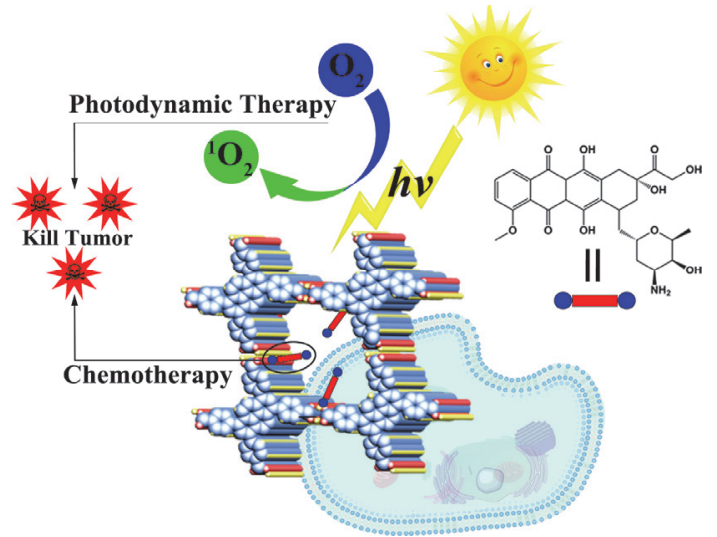

图 26 Doxo@Nano-PFC-1 的化学-光动力学联合治疗示意图. 经参考 文献[47]许可转载, 版权 2018 Wiley-VCH

Figure 26 The synergistic chemo-photodynamic therapy by Doxo@Nano-PFC-1. Reprinted with permission from ref. [47], Copy right 2018 Wiley-VCH

同年, 孙柏旺、罗洋辉研究小组 ${ }^{[117]}$ 利用血红素类化 合物中-四(4-羧基苯基)卟啉(C13)和 1,3-二(4-吡啶基)丙 烷(1,3-DPP)制备了 TCPP-1,3-DPP. 在 TCPP-1,3-DPP 的 结构中, TCPP 与 DPP 通过氢键(羧酸-吡啶超分子合成 子)连接形成一维条带结构, 而条带结构通过相对较弱 $\pi-\pi$ 相互作用进一步堆积成三维 HOF 材料(图 27). 值得 注意的是, TCPP-1,3-DPP 在加压情况下, 一维条带结构 可以向外滑移, 伴随着 $\mathrm{HOF}$ 的形貌由棱柱状演变成二 维纳米片状. 随后, 该研究小组 ${ }^{[121]}$ 利用超声辅助液体 剥离技术, 成功将 TCPP-1,3-DPP 结构中的一维条带结 构剥离开来, 获得具有原子级厚度的纳米带 (nr-HOF). $n r-H O F$ 在水溶液中具有非常好的分散性和较大的比表

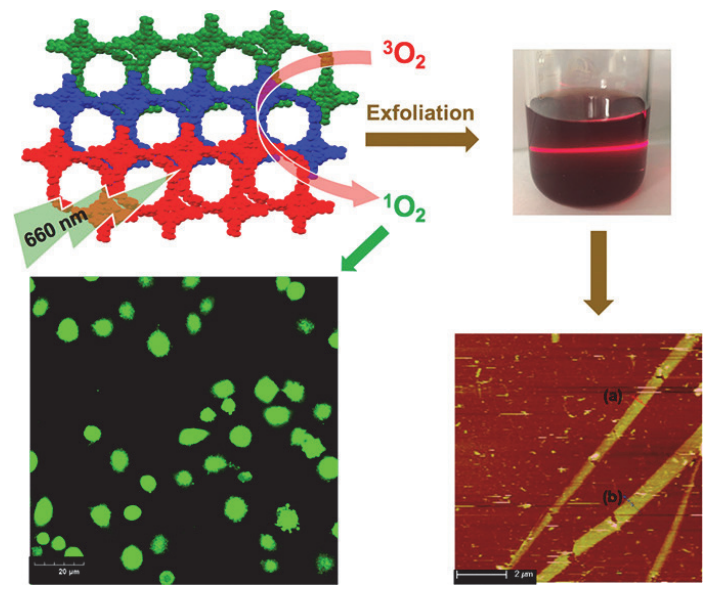

图 27 nr-HOF@Doxo 的结构和化学-光动力学联合治疗性能. 经参考 文献[121]许可转载, 版权 2019 美国化学会

Figure 27 The structure and synergistic chemo-photodynamic therapy of nr-HOF@Doxo. Reprinted with permission from ref. [121], Copy right 2019 American Chemical Society
面，它可以高效负载抗癌药物阿霉素得到 nr-HOF@Doxo 载药体系. 由于卟啉在含氧的环境下光 照能产生单线态氧, 因而赋予了nr-HOF@Doxo 光动力 学治疗的性能. 体外细胞实验表明, HOF@Doxo 集化 疗-光动力学治疗于一身, 表现出比单一化疗或光动力 学治疗更好的抗癌效果.

生物大分子或生物组装体系如酶、多肽、蛋白质、 DNA 和 RNA 等一般都具有高级的空间结构，这些空间 结构对环境非常敏感，因而它们的功能容易受到外界环 境的影响，例如：酶催化活性非常容易受到温度、 $\mathrm{pH}$ 、 金属离子、离子强度和其它酶降解等因素的影响. 因而, 对生物组装体系或生物大分子的保护，从而提高它们抵 抗外界环境干扰的能力, 增加可操作性, 有利于它们的 大规模的实际应用. 将生物组装体系或生物大分子封装 于多孔材料如 HOFs 框架是一种降低它们受外界条件影 响的办法. 基于上述考虑，White、Falcaro 和 Doonan 等 ${ }^{[113]}$ 于 2019 年报道了一例具备封装和保护生物大分子 的生物相容性 HOF 材料(BioHOF-1, 图 28). BioHOF-1 由多榺阳离子 $(\mathrm{M})$ 和多羧酸阴离子 $(\mathrm{C} 6)$ 在水溶液中自组 装而成, 它具有一维的正方形的开放孔道, 其孔道的大 小为 $0.64 \mathrm{~nm} \times 0.64 \mathrm{~nm}$. 当生物大分子如苂光黄标记的 过氧化氢酶(FTCA)与 M、C6 共同自组装时, FTCA 能够 原位并且均匀地负载于 BioHOF-1 框架中从而得到 FTAC@BioHOF-1 复合材料. BioHOF-1 不但能够封装 FTAC, 而且能够有效减轻被封装的 FTAC 的催化活化 受外界条件的影响，例如：FTAC 催化过氧化氢分解的 最佳 $\mathrm{pH}$ 为 $7 \sim 8$, 在其它的 $\mathrm{pH}$ 值下, 其催化活性会大大 降低. 然而,FTAC@BioHOF-1 不但保持了FTAC 非常好 的催化活性, 而且在 $\mathrm{pH}$ 为 5 10 之间, 其催化活性依然 能达到最佳催化活性的 $90 \%$; FTAC 在 $60{ }^{\circ} \mathrm{C}$ 热或胰蛋白 酶(蛋白质水解酶)或尿素(离液剂)后，其催化活性基本 消失, FTAC 吸附于 BioMOF-1 表面所形成的复合材料的 催化活性降低了 70\% 80\%，而FTAC@BioHOF-1 在相 同的实验条件下仍能保持良好的最催化活性(达到最佳 催化活性的 $75 \% \sim 79 \%$ ); FTAC 难以回收再利用，而 FTAC@BioHOF-1 在循环使用 10 次后, 其催化活性基本 没有降低. 采用相同的封装策略, 苂光黄标记的醇氧化 酶(FTO $x$ )也非常容易负载于 BioHOF-1 材料中. 同样地,

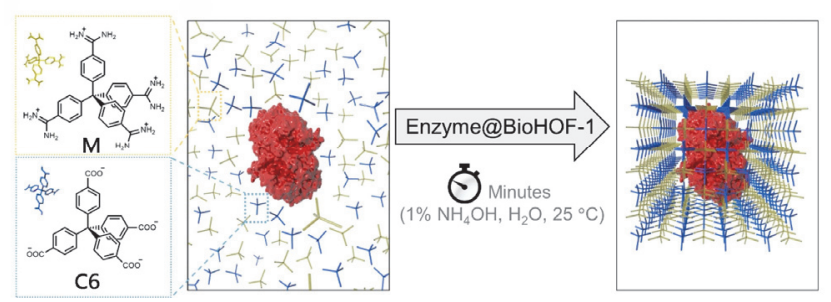

图 28 酶在 BioHOF-1 框架的原位封装. 经参考文献[113]许可转载, 版权 2019 美国化学会

Figure 28 The in situ encapsulation of enzyme in BioHOF-1. Reprinted with permission from ref. [113], Copy right 2019 American Chemical Society 
BioHOF-1 不但能够有效提高 FTO $x$ 抵抗外界苛刻条件 的能力, 而且比类比材料 MOFs 能更好地保持 FTO $x$ 的 结构与活性, 例如: FTOx@BioHOF-1 催化醇氧化的活 性达到了 FTO $x$ 活性的 $60 \%$, 而 FTO $x$ 被封装于金属-有 机框架材料如 ZIF-8、ZIF-60 或者 MAF-7 时, 其催化活 性完全消失. 这些结果充分说明 HOFs 非常有希望应用 于生物大分子或生物自组装体系的保护从而提高它们 的稳定性和可操作性.

\section{6 对映体拆分和芳香化合物的分离}

2014 年, 陈邦林等 ${ }^{[84]}$ 利用单一手性的联菱二酚 D2 构筑了手性的 HOF-2(图 29). 在 HOF-2 的结构当中, 每 个 D2 配体通过 DAT 二聚体分别与其它 6 个相邻 D2 相 连接从而形成三维的开放框架. HOF-2 具有一维的孔道, 其尺寸为 $0.48 \mathrm{~nm}$ (图 29a 29b). 由于多重氢键与 $\pi-\pi$ 相互作用, HOF-2 框架很稳定, 其比表面积达到 237.6 $\mathrm{m}^{2} \cdot \mathrm{g}^{-1}$. 由于具有手性的孔道, 因此 HOF-2 被用于吸附 拆分各种二级醇. HOF-2 对芳香二级醇如苯乙醇具有很 强的对映体拆分能力, 吸附在 HOF-2 的苯乙醇 $e e$ 值高 达 $92 \%$. 相比而言, HOF-2 对脂肪二级醇的拆分能力较 差. 将 HOF-2 置于外消旋的苯乙醇后, 单晶衍射的结果 表明, HOF-2 只能选择性吸附 $R$ 构型的苯乙醇(图 29c, $29 \mathrm{~d})$, 这种选择性不但是因为手性孔道的限域效应, 而 且还由于 $R$ 构型的苯乙醇和 HOF-2 框架的乙氧基能形 成氢键(图 29f). 进一步对置于 $S$-苯乙醇后的 HOF-2 进 (a)

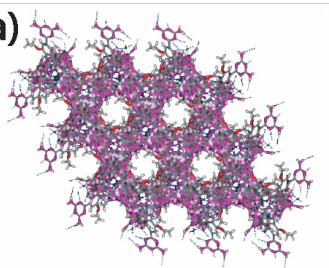

(c)

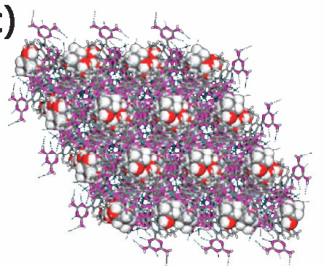

(e)

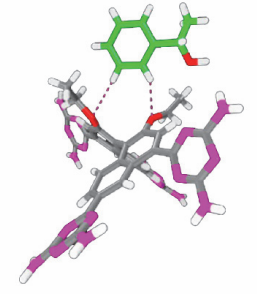

(b)

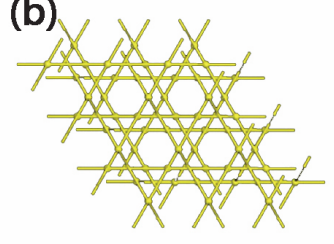

(d)

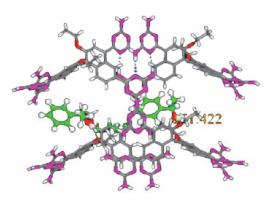

(f)

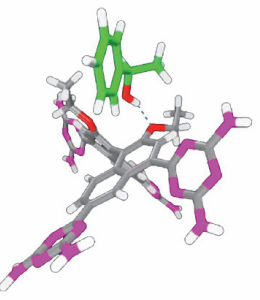

图 29 (a) HOF-2 的结构和 (b) 拓扑结构; (c) 吸附 $R$-1-苯乙醇的 HOF-2; (d) HOF-2 的手性空腔; (e) $S$-1-苯乙醇/(f) $R$-1-苯乙醇与 HOF-2 的相互作用. 经参考文献[84]许可转载, 版权 2014 美国化学会

Figure 29 (a) The structure of HOF-2. (b) The topology of HOF-2. (c) The structure of HOF-2 after the adsorption of $R-1$-phenylethanol. (d) The chiral cavity in HOF-2. The interactions between HOF-2 and (e) $R$-1-phenylethanol/(f) $S$-1-phenylethanol. Reprinted with permission from ref. [84], Copy right 2014 American Chemical Society
行单晶结构分析, 结果表明, HOF-2 与 $S$-苯乙醇之间的 作用力要比 HOF-2 与 $R$-苯乙醇之间的作用力要小得多 (图 29e). 该工作充分说明, HOFs 在对映体拆分领域具 有很重要的发展前景.

李巧伟等 ${ }^{[96]}$ 构筑的 FDM-15 具有选择性吸附对二 甲苯的性能. 将 FDM-15 置于对二甲苯与苯的混合溶液 中，仅有对二甲苯被吸附到 FDM-15 的孔道中. 鉴于 FDM-15 的孔道达到 $1.15 \mathrm{~nm}$, 并且对二甲苯的尺寸比苯 来得大, 因此体积排阻显然不是 FDM-15 选择性吸附对 二甲苯的原因. FDM-15 还具有选择性吸附对二甲苯/邻 二甲苯(分离系数为 $1.87: 1$ )和对二甲苯/乙苯(分离系数 为 $1.41: 1)$ 的性能. FDM-15 对对二甲苯的选择性吸附 可能源于对二甲苯与框架的弱作用较强的原因.

\section{7 环境污染物去除}

作为一类晶态的多孔材料, MOFs 与 COFs 已经广泛 用于环境污染物的处理 ${ }^{[147-148]}$. COF 作为一类新型的晶 态多孔材料，原则上应该与 $\mathrm{MOFs} / \mathrm{COFs}$ 一样也具有吸 附环境污染物的能力. 2014 年, Miljanic 等 $^{[94]}$ 基于吡唑三 聚体制备了 HOF-Pz-1. HOF-Pz-1 非常稳定，孔道大小 约为 $1.65 \mathrm{~nm}$, 比表面积达到 $1159 \mathrm{~m}^{2} \cdot \mathrm{g}^{-1}$. 值得注意的 是, HOF-Pz-1 具有良好的吸附氟氯烃和氟代烷烃等有毒 有害的温室气体性能，例如: HOF-Pz-1 对全氟己烷、 CFC-113 和 HCFC-225ca 的质量吸附分别达到 74.0\%、 $65.6 \%$ 和 $58 \%$.

2017 年，姚建年等 ${ }^{[149]}$ 基于 $\mathrm{TPPZ}$ 与 $\mathrm{Tb}\left(\mathrm{NO}_{3}\right)_{3}$ • $\left(\mathrm{H}_{2} \mathrm{O}\right)_{3}$ 制备了一例含金属的氢键有机框架材料 HOIF-1. 在 HOIF-1 的结构中, TPPZ 上的氮原子与硝酸铽上的配 位水分子形成 $\mathrm{N} \cdots \mathrm{H}-\mathrm{O}$ 氢键, 硝酸根离子上的氧原子 与 TPPZ 的芳环上的氢原子形成弱的 $\mathrm{O} \cdots \mathrm{H}-\mathrm{C}$ 氢键. 通 过多重氢键的相互连接, $\mathrm{TPPZ}$ 与 $\mathrm{Tb}\left(\mathrm{NO}_{3}\right)_{3} \cdot\left(\mathrm{H}_{2} \mathrm{O}\right)_{3}$ 之间 形成具有一维孔道的 HOIF-1 框架, HOIF-1 孔道的大小 为 $0.75 \mathrm{~nm}$. 将 HOIF-1 溶解并转移到阳极氧化铝(AAO) 模板上就可以制备氧化铝支撑的 HOIF-1 薄膜，该薄膜 能够有效且选择性过滤尺寸大于 $0.75 \mathrm{~nm} \times 0.75 \mathrm{~nm}$ 的染 料如罗丹明 B、锥虫蓝和活性蓝 19 等.

同年, $\mathrm{Ke}$ 等 ${ }^{[150]}$ 制备了一例共价键交联的氢键有机 框架材料 $\mathrm{H}_{\mathrm{c}} \mathrm{OF}-1$ (图 30). $\mathrm{H}_{\mathrm{c}} \mathrm{OF}-1$ 能够从水中高效地吸附 碘单质. 他们首先利用四苯乙烯功能化的构建单元构筑 晶态的 HOFs 材料 $\left(1_{\text {crystal }}\right)$, 再利用炔基与硫醇的光化学 反应实现 HOF 在单晶状态下的交联反应(图 30a). 集共 价键与氢键于一身, $\mathrm{H}_{\mathrm{c}} \mathrm{OF}-1$ 综合了 $\mathrm{HOFs}$ 与 COFs 的优 点, 比如: $\mathrm{H}_{\mathrm{c}} \mathrm{OF}-1$ 保持了晶态的结构且具有非常优秀的 稳定性, 它在 $\mathrm{pH}$ 为 $0 \sim 14$ 的水溶液中仍能结构仍然不 被破坏. $\mathrm{H}_{\mathrm{c}} \mathrm{OF}-1$ 能够快速地吸附水中的 $\mathrm{I}_{2}$, 其最大的 $\mathrm{I}_{2}$ 吸附量达到 $2.1 \mathrm{~g} / \mathrm{g}$ (图 30b,30c). 该吸附量相当于每个 四苯乙烯的脚手架就能够吸附了 16.5 个 $\mathrm{I}_{2}$ 分子, 远远大 于 $\mathrm{H}_{\mathrm{c}} \mathrm{OF}-1$ 理论吸附碘单质的量. 粉末衍射实验的结果 表明, $\mathrm{H}_{\mathrm{c}} \mathrm{OF}-1$ 在吸附碘单质后由晶态变成非晶态物质, 
这可能是由于较强的 $\mathrm{N}-\mathrm{H} \cdots \mathrm{I}$ 氢键以及 $\mathrm{N} \cdots \mathrm{I}$ 和 $\mathrm{S} \cdots \mathrm{I}$ 卤键的形成破坏了 $\mathrm{H}_{\mathrm{c}} \mathrm{OF}-1$ 原有的氢键网络. 由于 $-\mathrm{S}-\mathrm{CH}_{2} \mathrm{CH}_{2} \mathrm{~S}-$ 交联链具有很强的柔性, 因而 $\mathrm{H}_{\mathrm{c}} \mathrm{OF}-1$ 的孔 道随着碘单质的吸附而不断的增大. 在 $75{ }^{\circ} \mathrm{C}$ 的碘蒸汽 气氛下, $\mathrm{H}_{\mathrm{c}} \mathrm{OF}-1$ 吸附 $\mathrm{I}_{2}$ 单质的量达到 $2.9 \mathrm{~g} / \mathrm{g}$, 这个碘单 质的吸附量要远远大于相同情况条件下 $\mathrm{MOFs}^{[151]}$ 和多 孔有机聚合物 ${ }^{[152-153]}$ 的吸附量. 值得注意的是, 随着吸 附的碘单质的释放, $\mathrm{H}_{\mathrm{c}} \mathrm{OF}-1$ 能慢慢地恢复其晶态的结 构. 这些结果表明, $\mathrm{H}_{\mathrm{c}} \mathrm{OF}-1$ 有望实际用于碘单质的捕捉 与分离.

(a)

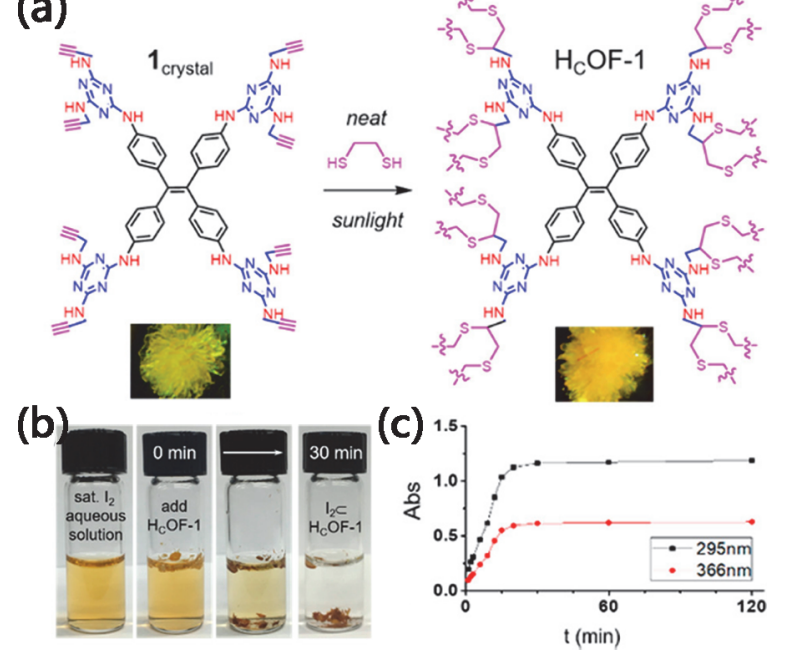

图 30 (a) 从 $1_{\text {crystal }}$ 合成 $\mathrm{H}_{\mathrm{C}} \mathrm{OF}-1$; (b) $\mathrm{H}_{\mathrm{C}} \mathrm{OF}-1$ 对饱和碘的水溶液中碘 的吸附; (c) $\mathrm{I}_{2} @ \mathrm{H}_{\mathrm{C}} \mathrm{OF}-1$ 在 DMSO 的脱附过程. 经参考文献[150]许可 转载, 版权 2017 美国化学会

Figure 30 (a) Synthesis of $\mathrm{H}_{\mathrm{c}} \mathrm{OF}-1$ from $1_{\text {crystal }}$. (b) A saturated iodine aqueous solution $\left(c a .1 .2 \mathrm{mmol} \cdot \mathrm{L}^{-1}\right)$ upon addition of $\mathrm{H}_{\mathrm{C}} \mathrm{OF}-1(3.0 \mathrm{mg})$. (c) The iodine desorption of $\mathrm{I}_{2} @ \mathrm{HCOF}-1$ in DMSO. Reprinted with permission from ref. [150], Copy right 2017 American Chemical Society

\section{8 结构测定}

对于有机分子, 特别是手性的和具有高级空间结构 的有机分子来说, 单晶 X-射线衍射仍然是测定分子结 构特别是空间绝对结构的最好方法. 然而, 许多化合物 却常以油状液体或粉末的形式存在, 难以获得适合 X射线单晶衍射测试的所需要的单晶. 解决分子难以结晶 的方法包括将分子吸附到晶态多孔材料如 MOFs 的孔道 内, 或者将分子与其它易于结晶的分子共结晶, 然后再 利用单晶衍射测试分子的绝对空间构型 ${ }^{[154-156]}$. 作为一 类晶态的多孔材料, HOFs 材料尤其是基于磺酸-胍的 HOFs 材料(GS-HOFs) 在分子结构测定领域具有如下优 点: 首先, GS-HOFs 结构多样(目前超过 500 种), 这些材 料不需要特殊作用位点就能均一封装各种尺寸和形状 的客体分子; 其次, GS-HOFs 是由 $\mathrm{N}-\mathrm{H} \cdots \mathrm{O}-\mathrm{S}$ 氢键连 接而成, 这类 HOFs 框架通常具有很强的柔性, 这种柔 性能够使 GS-HOFs 框架紧紧包裹着客体分子从而有效 减小客体分子的无序以及结晶的溶剂; 此外, $\mathrm{S}$ 的原子 量较大, 也有利于单晶结构的确定. 2019 年 Ward 等 ${ }^{[157]}$
根据待测的客体分子形状与尺寸合理选择不同的 GS-HOFs 主体，随后采用一步结晶的方法将一系列的 客体小分子(含天然的小分子)封装于不同的 GS-HOFs 材料中(图 31). 例如, $(3 \mathrm{a} R)-(+)$-香紫苏内酯和屈螺酮被 成功封装于 $G_{2} N D S$, 而黄体酮则被封装于 $G_{2} B D P Y D S$. 虽然这些 HOFs 与被封装的小分子并没有特殊的作用位 点, 但是这些客体分子却能够均匀且定量地被封装于 GS-HOFs 孔道内并用于单晶结构的测试. 单晶结构解 析的结果表明, 有机分子包含 $(3 \mathrm{a} R)-(+)$-香紫苏内酯、屈 螺酮和黄体酮等不易结晶和手性的有机分子的结构都 能非常好地解析出来. 因此, HOFs 有望用于不易结晶或 结构复杂的有机分子结构测定.

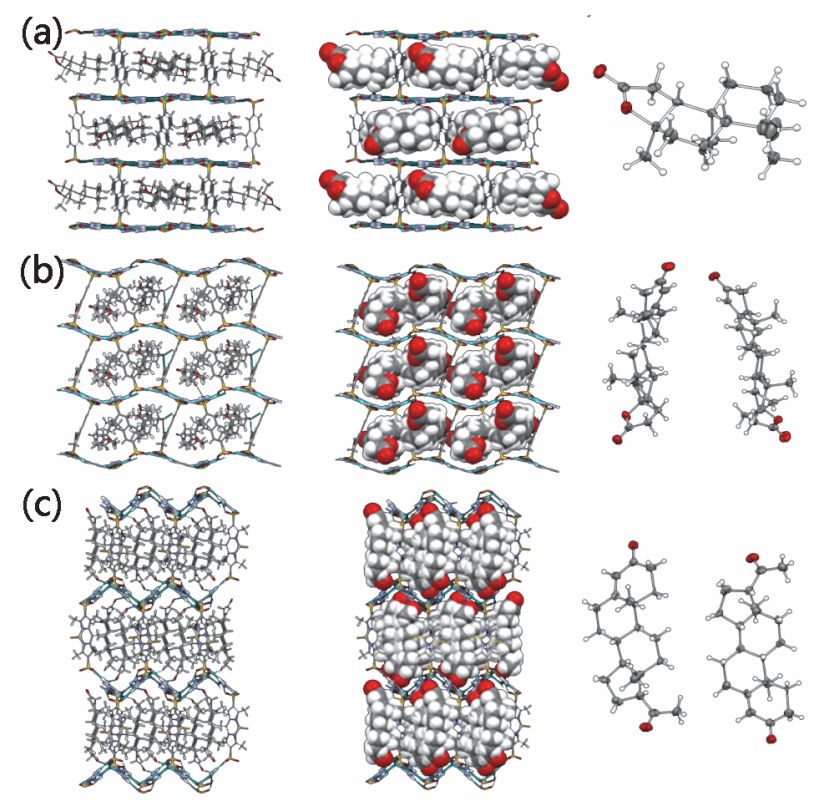

图 31 (a) $\left(\mathrm{G}_{2} \mathrm{NDS}\right) \supset(3 \mathrm{a} R)-(+)$-Sclareolide 和被包封的香紫苏内酯的 结构; (b) $\left(\mathrm{G}_{2} \mathrm{NDS}\right) \supset($ drospirenone $)(\text { methanol })_{0.84}\left(\mathrm{H}_{2} \mathrm{O}\right)_{0.1}$ 和被包封的屈 螺酮的结构; (c) ( $\mathrm{G}_{2}$ BDPYDS) (progesterone)和被包封的黄体酮的结 构. 经参考文献[157]许可转载, 版权 2019 自然出版集团

Figure 31 (a) The structure of $\left(\mathrm{G}_{2} \mathrm{NDS}\right) \supset(3 \mathrm{a} R)-(+)$-Sclareolide and encapsulated Sclareolide, (b) $\left(\mathrm{G}_{2} \mathrm{NDS}\right) \supset($ drospirenone $)(\text { methanol })_{0.84-}$ $\left(\mathrm{H}_{2} \mathrm{O}\right)_{0.1}$ and encapsulated drospirenone, and (c) (G $\left.\mathrm{G}_{2} \mathrm{BDPYDS}\right) \supset$ (progesterone) and encapsulated progesterone. Reprinted with permission from ref. [157], Copy right 2019 Nature Publishing Group

\section{4 总结与展望}

本综述总结了近 10 年来 $\mathrm{HOF}$ 的进展, 主要包含 $\mathrm{HOFs}$ 与 $\mathrm{MOF} / \mathrm{COFs}$ 等类比材料的对比, HOFs 结构设 计的一些基本原则, 构筑 HOFs 常用的超分子合成子, HOFs 材料在气体吸附与分离、质子传导、异相催化、 苂光和传感、生物应用、对映体拆分和芳香化合物的分 离、环境污染物去除和结构测定等领域的应用. HOFs 是由氢键构筑而成的, 氢键具有较强的可逆性和柔性, 因而 HOFs 材料一般具有合成条件温和、结晶度高、溶 剂加工性好、容易回收重复利用，甚至可自我修复等特 点. 尽管氢键的作用力弱和方向性差, 但利用具有较强 作用力和方向性的超分子合成子以及合适的脚手架, 
HOFs 的多孔性能够被建立起来. 通过结构穿插或引入 其它分子间的作用力如 $\pi-\pi$ 作用、范德华力、静电作用 等, HOFs 框架的稳定性能进一步得到加强. 一些具有超 高稳定性如在强酸、强碱、沸水和高温下仍能保持晶态 结构的 HOFs 也逐渐被开发出来. 此外, 目前合成的大 部分 HOFs 材料都不含金属离子, 因此 HOFs 一般具有 更低的密度、更好的生物相容性和细胞毒性, 有利于其 应用于药物传输与控制释放、细胞成像、生物大分子保 护等生物领域的应用. 继 MOFs 和 COFs 后, HOFs 有望 成为另一类具有独特功能的多孔材料.

尽管过去 10 年, HOFs 取得了巨大的成就, 然而 HOFs 的发展仍然远远落后于 MOFs 和 COFs. HOFs 的 发展仍然存在受到诸多因素的挑战: (1) 由于氢键的方 向性差和作用力弱, HOFs 结构的精准合成仍然非常困 难. 一方面, 理论上 HOFs 的孔道形状和尺寸大小可调、 孔表面可修饰, 但构建单元的延长或基团的引入非常容 易引起最终结构的变化, 因此实际上孔道形状、大小和 孔表面的修饰仍然处于待发展的阶段; 另一方面, HOFs 在不同的合成条件如不同溶剂可能会得到不同的结构, 严重影响了目标结构的精准合成, 甚至不同结构之间可 随外界条件的转变而相互转化, 不利于探讨 HOFs 结构性能的关系. (2) HOFs 框架的稳定性与多孔性通常类似 鱼和熊掌的关系, 因而如何制备孔隙率高、比表面积大 和稳定性好的 HOFs 材料也仍然是一个巨大的挑战. (3) 目前合成的大多数的 HOFs 材料仍缺少功能性的基团如 不饱和配位点、路易斯酸和布朗斯特酸位点, 不但限制 了 HOFs 材料的应用, 而且使得 HOFs 材料难以后修饰. 虽然 HOFs 理论上可修饰, 但由于大部分框架稳定性, HOFs 后修饰的工作仍少有报道. 尽管 HOFs 的应用已 经取得了一定的进展, 但仍然难以像 MOFs 一样广泛应 用于化学与材料的各个领域. (4) 氢键的本质赋予 HOFs 独特的优势, 虽然溶剂加工性、溶剂修复、材料重结晶 再生和循环利用等已有报道, 但 HOFs 有别于 MOFs 和 COFs 的独特性能仍有待于进一步的开发. (5) 二元或多 元 HOFs 材料的开发有利于增加 HOFs 的结构, 从而有 助于拓展 HOFs 材料在不同领域的应用. 虽然基于羧酸脒、磺酸-胍和羧酸-吡啶等二元/二组分的 HOFs 已有报 道, 但是二元或多元 HOFs 材料的开发也仍然是一个巨 大的挑战.

目前, HOFs 的发展已驶入快车道. 越来越多的研究 人员开始从事 HOFs 结构的开发与功能应用等相关工 作. HOFs 结构的设计和构-效关系也已经初步建立起来, 理论计算和高通量结晶实验也已分别用于 HOFs 的结构 设计和功能预测, 相信不久的将来科学家定能陆续攻克 上述的挑战.

今后, 我们应该更专注于 HOFs 材料独特性的开发. 例如, HOFs 一般不含金属离子, 大部分 HOFs 都缺少不 饱和金属配位点, 因此客体分子通常只能和有机组分相
互作用，所以 HOFs 更容易具有吸附 “反转” 的性能 (如 轻质烃中的 $\mathrm{C}_{2} \mathrm{H}_{6} / \mathrm{C}_{2} \mathrm{H}_{4} 、 \mathrm{C}_{3} \mathrm{H}_{8} / \mathrm{C}_{3} \mathrm{H}_{6}$ 分离性能), 这种吸附 “反转” 有利于一步生产高纯度的原料如乙炔和乙炔, 大 大缩短工业分离过程，降低分离成本; 大部分 HOFs 不 含有毒的金属离子, 因此具有更好的生物相容性和细胞 毒性, HOFs 作为独特的纳米载药体系或者显影剂等生 物材料具有广阔的应用前景; HOFs 具有更好的溶剂加 工性, 因此 HOFs 的器件化也是未来发展的一个重要方 向; 氢键具有很强的柔性和可逆性, MOFs 很有可能发 展成为一种自愈材料. 此外, HOFs 易于再生且一些 HOFs 在溶剂中可以保持很好的稳定性, 因此 HOFs 在 含溶剂的应用体系里也具有广阔的应用前景. 展望未 来, HOFs 将作为一类独特的功能多孔材料登上历史的 舞台.

\section{作者简介}

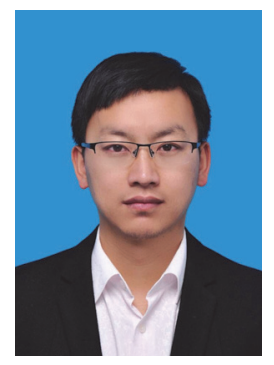

林祖金, 福建农林大学生命科学学院副教授、硕士生导师. 2012 年 7 月于中国科学院福建物质结构研究所无机化学专业 取得理学博士学位. 随后, 留所参加工作并于 2015 年晋升为 副研究员. 2015 年 11 月加入福建农林大学生命科学学院应用 化学系. 2019 年 10 月赴德州大学圣安东尼奥分校陈邦林课题 组访学. 主要的研究方向为功能多孔 MOFs 和 HOFs 的设计合 成及其应用.

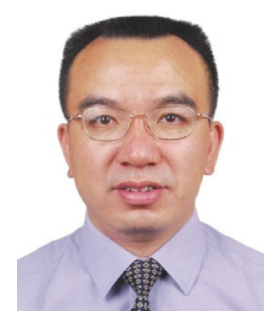

曹荣, 中国科学院福建物质结构研究所研究员、博士生导 师, 国家自然科学基金杰出青年科学基金获得者. 长期从事 金属-有机框架(MOFs)和多孔氢键有机框架(HOFs)材料的设 计合成及其在气体吸附与分离、催化和荧光传感等领域的研 究.

\section{References}

[1] Yaghi, O. M.; Li, G.; Li, H. Nature 1995, 378, 703.

[2] Zhang, X.; Wang, X.; Fan, W.; Sun, D. Chin. J. Chem. 2020, 38, 509.

[3] Kitagawa, S.; Kitaura, R.; Noro, S.-i. Angew. Chem. Int. Ed. 2004, 43, 2334.

[4] Côté, A. P.; Benin, A. I.; Ockwig, N. W.; O'Keeffe, M.; Matzger, A. J.; Yaghi, O. M. Science 2005, 310, 1166. 
[5] Lv, H.; Sa, R.; Li, P.; Yuan, D.; Wang, X.; Wang, R. Sci. China Chem. 2020, 63, 1289.

[6] He, Y.; Xiang, S.; Chen, B. J. Am. Chem. Soc. 2011, 133, 14570.

[7] Lin, Z.-J.; Lü, J.; Hong, M.; Cao, R. Chem. Soc. Rev. 2014, 43, 5867.

[8] Hoskins, B. F.; Robson, R. J. Am. Chem. Soc. 1989, 111, 5962.

[9] Hoskins, B. F.; Robson, R. J. Am. Chem. Soc. 1990, 112, 1546.

[10] Li, H.; Eddaoudi, M.; Groy, T. L.; Yaghi, O. M. J. Am. Chem. Soc. 1998, $120,8571$.

[11] Kondo, M.; Yoshitomi, T.; Matsuzaka, H.; Kitagawa, S.; Seki, K. Angew. Chem. Int. Ed. 1997, 36, 1725.

[12] Kim, J.; Chen, B.; Reineke, T. M.; Li, H.; Eddaoudi, M.; Moler, D. B.; O'Keeffe, M.; Yaghi, O. M. J. Am. Chem. Soc. 2001, 123, 8239.

[13] Eddaoudi, M.; Moler, D. B.; Li, H.; Chen, B.; Reineke, T. M.; O'Keeffe, M.; Yaghi, O. M. Acc. Chem. Res. 2001, 34, 319.

[14] Ockwig, N. W.; Delgado-Friedrichs, O.; O'Keeffe, M.; Yaghi, O. M. Acc. Chem. Res. 2005, 38, 176.

[15] O'Keeffe, M.; Peskov, M. A.; Ramsden, S. J.; Yaghi, O. M. Acc. Chem. Res. 2008, 41, 1782.

[16] O'Keeffe, M. Chem. Soc. Rev. 2009, 38, 1215.

[17] Zeng, Y.-N.; Zheng, H.-Q.; Gu, J.-F.; Cao, G.-J.; Zhuang, W.-E.; Lin, J.-D.; Cao, R.; Lin, Z.-J. Inorg. Chem. 2019, 58, 13360.

[18] Zeng, Y.-N.; Zheng, H.-Q.; He, X.-H.; Cao, G.-J.; Wang, B.; Wu, K.; Lin, Z.-J. Dalton Trans. 2020, 49, 9680.

[19] Zheng, H.-Q.; Liu, C.-Y.; Zeng, X.-Y.; Chen, J.; Lü, J.; Lin, R.-G.; Cao, R.; Lin, Z.-J.; Su, J.-W. Inorg. Chem. 2018, 57, 9096.

[20] Wang, Z.; Zhang, S.; Chen, Y.; Zhang, Z.; Ma, S. Chem. Soc. Rev. 2020, 49, 708 .

[21] Liu, J. G.; Zhang, M. Y.; Wang, N.; Wang, C. G.; Ma, L. L. Acta Chim. Sinica 2020, 78, 311 (in Chinese). (刘建国, 张明月, 王楠, 王晨光，马隆龙，化学学报, 2020, 78, 311.)

[22] Peng, Z. K.; Ding, H. M.; Chen, R. F.; Gao, C.; Wang, C. Acta Chim. Sinica 2019, 77, 681 (in Chinese). (彭正康, 丁慧敏, 陈如凡, 高 超, 汪成, 化学学报, 2019, 77, 681.)

[23] Luo, J.; Wang, J.-W.; Zhang, J.-H.; Lai, S.; Zhong, D.-C. CrystEngComm 2018, 20, 5884.

[24] Hisaki, I.; Xin, C.; Takahashi, K.; Nakamura, T. Angew. Chem. Int. Ed. 2019, 58, 11160.

[25] Lin, R.-B.; He, Y.; Li, P.; Wang, H.; Zhou, W.; Chen, B. Chem. Soc. Rev. 2019, 48, 1362.

[26] Yang, J.; Wang, J.; Hou, B.; Huang, X.; Wang, T.; Bao, Y.; Hao, H. Chem. Eng. J. 2020, 399, 125873.

[27] Wang, B.; Lin, R.-B.; Zhang, Z.; Xiang, S.; Chen, B. J. Am. Chem. Soc. 2020, 14399.

[28] Lü, J.; Cao, R. Angew. Chem. Int. Ed. 2016, 55, 9474.

[29] Duchamp, D. J.; Marsh, R. E. Acta Crystallogr. B 1969, 25, 5.

[30] Simard, M.; Su, D.; Wuest, J. D. J. Am. Chem. Soc. 1991, 113, 4696.

[31] Wang, X.; Simard, M.; Wuest, J. D. J. Am. Chem. Soc. 1994, 116, 12119.

[32] Yang, W.; Greenaway, A.; Lin, X.; Matsuda, R.; Blake, A. J.; Wilson, C.; Lewis, W.; Hubberstey, P.; Kitagawa, S.; Champness, N. R.; Schröder, M. J. Am. Chem. Soc. 2010, 132, 14457.

[33] Hu, Y.-X.; Li, W.-J.; Jia, P.-P.; Wang, X.-Q.; Xu, L.; Yang, H.-B. Adv. Opt. Mater. 2020, 8, 2000265.

[34] Hu, F.; Liu, C.; Wu, M.; Pang, J.; Jiang, F.; Yuan, D.; Hong, M. Angew. Chem. Int. Ed. 2017, 56, 2101.

[35] Huang, Q.; Li, W.; Mao, Z.; Qu, L.; Li, Y.; Zhang, H.; Yu, T.; Yang, Z.; Zhao, J.; Zhang, Y.; Aldred, M. P.; Chi, Z. Nat. Commun. 2019, $10,3074$.

[36] Li, Y.-L.; Alexandrov, E. V.; Yin, Q.; Li, L.; Fang, Z.-B.; Yuan, W.; Proserpio, D. M.; Liu, T.-F. J. Am. Chem. Soc. 2020, 142, 7218.

[37] Pulido, A.; Chen, L.; Kaczorowski, T.; Holden, D.; Little, M. A.; Chong, S. Y.; Slater, B. J.; McMahon, D. P.; Bonillo, B.; Stackhouse, C. J.; Stephenson, A.; Kane, C. M.; Clowes, R.; Hasell, T.; Cooper, A. I.; Day, G. M. Nature 2017, 543, 657.

[38] Cui, P.; McMahon, D. P.; Spackman, P. R.; Alston, B. M.; Little, M. A.; Day, G. M.; Cooper, A. I. Chem. Sci. 2019, 10, 9988.

[39] Cui, P.; Svensson Grape, E.; Spackman, P. R.; Wu, Y.; Clowes, R.; Day, G. M.; Inge, A. K.; Little, M. A.; Cooper, A. I. J. Am. Chem. Soc. 2020, 12743.

[40] Desiraju, G. R. Angew. Chem. Int. Ed. 1995, 34, 2311.

[41] Herbstein, F. H.; Kapon, M.; Reisner, G. M. J. Incl. Phenom. 1987, $5,211$.

[42] Zentner, C. A.; Lai, H. W. H.; Greenfield, J. T.; Wiscons, R. A.; Zeller, M.; Campana, C. F.; Talu, O.; FitzGerald, S. A.; Rowsell, J. L. C. Chem. Commun. 2015, 51, 11642.
[43] Nandi, S.; Chakraborty, D.; Vaidhyanathan, R. Chem. Commun. 2016, 52, 7249.

[44] Yang, W.; Wang, J.; Wang, H.; Bao, Z.; Zhao, J. C.-G.; Chen, B. Cryst. Growth Des. 2017, 17, 6132.

[45] Lai, H. W. H.; Wiscons, R. A.; Zentner, C. A.; Zeller, M.; Rowsell, J. L. C. Cryst. Growth Des. 2016, 16, 821.

[46] Yang, W.; Zhou, W.; Chen, B. Cryst. Growth Des. 2019, 19, 5184.

[47] Yin, Q.; Zhao, P.; Sa, R. J.; Chen, G. C.; Lu, J.; Liu, T. F.; Cao, R. Angew. Chem. Int. Ed. 2018, 57, 7691.

[48] Wang, B.; Lv, X.-L.; Lv, J.; Ma, L.; Lin, R.-B.; Cui, H.; Zhang, J.; Zhang, Z.; Xiang, S.; Chen, B. Chem. Commun. 2020, 56, 66.

[49] Ma, K.; Li, P.; Xin, J. H.; Chen, Y.; Chen, Z.; Goswami, S.; Liu, X.; Kato, S.; Chen, H.; Zhang, X.; Bai, J.; Wasson, M. C.; Maldonado, R. R.; Snurr, R. Q.; Farha, O. K. Cell Reports Physical Science 2020, 1,100024 .

[50] Hisaki, I.; Nakagawa, S.; Tohnai, N.; Miyata, M. Angew. Chem. Int. Ed. 2015, 54, 3008.

[51] Hisaki, I.; Ikenaka, N.; Tohnai, N.; Miyata, M. Chem. Commun. 2016, 52, 300.

[52] Hisaki, I.; Nakagawa, S.; Ikenaka, N.; Imamura, Y.; Katouda, M.; Tashiro, M.; Tsuchida, H.; Ogoshi, T.; Sato, H.; Tohnai, N.; Miyata, M. J. Am. Chem. Soc. 2016, 138, 6617.

[53] Hisaki, I.; Nakagawa, S.; Sato, H.; Tohnai, N. Chem. Commun. 2016, 52, 9781 .

[54] Hisaki, I.; Ikenaka, N.; Gomez, E.; Cohen, B.; Tohnai, N.; Douhal, A. Chem. Eur. J. 2017, 23, 11611.

[55] Hisaki, I.; Toda, H.; Sato, H.; Tohnai, N.; Sakurai, H. Angew. Chem. Int. Ed. 2017, 56, 15294.

[56] Hisaki, I.; Ikenaka, N.; Tsuzuki, S.; Tohnai, N. Mater. Chem. Front. 2018, 2, 338.

[57] Hisaki, I.; Nakagawa, S.; Suzuki, Y.; Tohnai, N. Chem. Lett. 2018, $47,1143$.

[58] Hisaki, I.; Suzuki, Y.; Gomez, E.; Cohen, B.; Tohnai, N.; Douhal, A. Angew. Chem. Int. Ed. 2018, 57, 12650.

[59] Gomez, E.; Suzuki, Y.; Hisaki, I.; Moreno, M.; Douhal, A. J. Mater. Chem. C 2019, 7, 10818.

[60] Hisaki, I.; Suzuki, Y.; Gomez, E.; Ji, Q.; Tohnai, N.; Nakamura, T.; Douhal, A. J. Am. Chem. Soc. 2019, 141, 2111.

[61] Gomez, E.; di Nunzio, M. R.; Moreno, M.; Hisaki, I.; Douhal, A. J. Phys. Chem. C 2020, 124, 6938.

[62] Hisaki, I.; Ji, Q.; Takahashi, K.; Tohnai, N.; Nakamura, T. Cryst. Growth Des. 2020, 20, 3190.

[63] Hisaki, I. J. Incl. Phenom. Macro. 2020, 96, 215.

[64] Yin, Q.; Lü, J.; Li, H.-F.; Liu, T.-F.; Cao, R. Cryst. Growth Des. 2019, 19, 4157.

[65] Li, P.; Chen, Z.; Ryder, M. R.; Stern, C. L.; Guo, Q.-H.; Wang, X.; Farha, O. K.; Stoddart, J. F. J. Am. Chem. Soc. 2019, 141, 12998.

[66] Li, P.; Li, P.; Ryder, M. R.; Liu, Z.; Stern, C. L.; Farha, O. K.; Stoddart, J. F. Angew. Chem. Int. Ed. 2019, 58, 1664.

[67] Zhou, Y.; Liu, B.; Sun, X.; Li, J.; Li, G.; Huo, Q.; Liu, Y. Cryst. Growth Des. 2017, 17, 6653.

[68] Bassanetti, I.; Bracco, S.; Comotti, A.; Negroni, M.; Bezuidenhout, C.; Canossa, S.; Mazzeo, P. P.; Marchió, L.; Sozzani, P. J. Mater. Chem. A 2018, 6, 14231.

[69] Zhang, X.; Li, L.; Wang, J.-X.; Wen, H.-M.; Krishna, R.; Wu, H.; Zhou, W.; Chen, Z.-N.; Li, B.; Qian, G.; Chen, B. J. Am. Chem. Soc. 2020, 142, 633 .

[70] Gong, W.; Chu, D.; Jiang, H.; Chen, X.; Cui, Y.; Liu, Y. Nat. Commun. 2019, 10, 600.

[71] Wang, L.; Yang, L.; Gong, L.; Krishna, R.; Gao, Z.; Tao, Y.; Yin, W.; Xu, Z.; Luo, F. Chem. Eng. J. 2020, 383, 123117.

[72] Liu, T.; Wang, B.; He, R.; Arman, H.; Schanze, K. S.; Xiang, S.; Li, D.; Chen, B. Can. J. Chem. 2020, 98, 352.

[73] Takeda, T.; Ozawa, M.; Akutagawa, T. Angew. Chem. Int. Ed. 2019, $58,10345$.

[74] Wang, B.; He, R.; Xie, L.-H.; Lin, Z.-J.; Zhang, X.; Wang, J.; Huang, H.; Zhang, Z.; Schanze, K. S.; Zhang, J.; Xiang, S.; Chen, B. J. Am. Chem. Soc. 2020, 142, 12478.

[75] Brunet, P.; Simard, M.; Wuest, J. D. J. Am. Chem. Soc. 1997, 119, 2737.

[76] Fournier, J.-H.; Maris, T.; Wuest, J. D. J. Org. Chem. 2004, 69, 1762.

[77] Demers, E.; Maris, T.; Wuest, J. D. Cryst. Growth Des. 2005, 5, 1227.

[78] Malek, N.; Maris, T.; Simard, M.; Wuest, J. D. J. Am. Chem. Soc. 2005, 127, 5910 . 
[79] Maly, K. E.; Gagnon, E.; Maris, T.; Wuest, J. D. J. Am. Chem. Soc. 2007, 129, 4306.

[80] Helzy, F.; Maris, T.; Wuest, J. D. Cryst. Growth Des. 2008, 8, 1547.

[81] Helzy, F.; Maris, T.; Wuest, J. D. J. Org. Chem. 2016, 81, 3076.

[82] Beaudoin, D.; Blair-Pereira, J.-N.; Langis-Barsetti, S.; Maris, T.; Wuest, J. D. J. Org. Chem. 2017, 82, 8536.

[83] Duong, A.; Rajak, S.; Tremblay, A. A.; Maris, T.; Wuest, J. D. Cryst. Growth Des. 2019, 19, 1299.

[84] Li, P.; He, Y.; Guang, J.; Weng, L.; Zhao, J. C.-G.; Xiang, S.; Chen, B. J. Am. Chem. Soc. 2014, 136, 547.

[85] Li, P.; He, Y.; Zhao, Y.; Weng, L.; Wang, H.; Krishna, R.; Wu, H.; Zhou, W.; O'Keeffe, M.; Han, Y.; Chen, B. Angew. Chem. Int. Ed. 2015, 54, 574

[86] Li, P.; He, Y.; Arman, H. D.; Krishna, R.; Wang, H.; Weng, L.; Chen, B. Chem. Commun. 2014, 50, 13081.

[87] Wang, H.; Li, B.; Wu, H.; Hu, T.-L.; Yao, Z.; Zhou, W.; Xiang, S.; Chen, B. J. Am. Chem. Soc. 2015, 137, 9963.

[88] Yang, W.; Yang, F.; Hu, T.-L.; King, S. C.; Wang, H.; Wu, H.; Zhou, W.; Li, J.-R.; Arman, H. D.; Chen, B. Cryst. Growth Des. 2016, 16, 5831.

[89] Yang, W.; Li, B.; Wang, H.; Alduhaish, O.; Alfooty, K.; Zayed, M. A.; Li, P.; Arman, H. D.; Chen, B. Cryst. Growth Des. 2015, 15, 2000.

[90] Wang, H.; Wu, H.; Kan, J.; Chang, G.; Yao, Z.; Li, B.; Zhou, W.; Xiang, S.; Cong-Gui Zhao, J.; Chen, B. J. Mater. Chem. A 2017, 5, 8292.

[91] Wang, H.; Bao, Z.; Wu, H.; Lin, R.-B.; Zhou, W.; Hu, T.-L.; Li, B.; Zhao, J. C.-G.; Chen, B. Chem. Commun. 2017, 53, 11150.

[92] Wang, Y.; Liu, D.; Yin, J.; Shang, Y.; Du, J.; Kang, Z.; Wang, R.; Chen, Y.; Sun, D.; Jiang, J. Chem. Commun. 2020, 56, 703.

[93] Feng, S.; Shang, Y.; Wang, Z.; Kang, Z.; Wang, R.; Jiang, J.; Fan, L.; Fan, W.; Liu, Z.; Kong, G.; Feng, Y.; Hu, S.; Guo, H.; Sun, D. Angew. Chem. Int. Ed. 2020, 59, 3840.

[94] Chen, T.-H.; Popov, I.; Kaveevivitchai, W.; Chuang, Y.-C.; Chen, Y.-S.; Daugulis, O.; Jacobson, A. J.; Miljanić, O. Š. Nat. Commun. 2014, 5, 5131 .

[95] Hashim, M. I.; Le, H. T. M.; Chen, T.-H.; Chen, Y.-S.; Daugulis, O.; Hsu, C.-W.; Jacobson, A. J.; Kaveevivitchai, W.; Liang, X.; Makarenko, T.; Miljanić, O. Š.; Popovs, I.; Tran, H. V.; Wang, X.; Wu, C.-H.; Wu, J. I. J. Am. Chem. Soc. 2018, 140, 6014.

[96] Yan, W.; Yu, X.; Yan, T.; Wu, D.; Ning, E.; Qi, Y.; Han, Y.-F.; Li, Q. Chem. Commun 2017, 53, 3677.

[97] Yamagishi, H.; Sato, H.; Hori, A.; Sato, Y.; Matsuda, R.; Kato, K.; Aida, T. Science 2018, 361, 1242

[98] Luo, X.-Z.; Jia, X.-J.; Deng, J.-H.; Zhong, J.-L.; Liu, H.-J.; Wang, K.-J.; Zhong, D.-C. J. Am. Chem. Soc. 2013, 135, 11684.

[99] Smith, A. Acta Crystallographica 1952, 5, 224

[100] Harris, K. D. M. Chem. Soc. Rev. 1997, 26, 279.

[101] Mastalerz, M.; Oppel, I. M. Angew. Chem. Int. Ed. 2012, 51, 5252.

[102] Adachi, T.; Ward, M. D. Acc. Chem. Res. 2016, 49, 2669.

[103] Karmakar, A.; Illathvalappil, R.; Anothumakkool, B.; Sen, A.; Samanta, P.; Desai, A. V.; Kurungot, S.; Ghosh, S. K. Angew. Chem. Int. Ed. 2016, 55, 10667.

[104] Kang, D. W.; Kang, M.; Kim, H.; Choe, J. H.; Kim, D. W.; Park, J. R.; Lee, W. R.; Moon, D.; Hong, C. S. Angew. Chem. Int. Ed. 2019, $58,16152$.

[105] Brekalo, I.; Deliz, D. E.; Barbour, L. J.; Ward, M. D.; Friščić, T.; Holman, K. T. Angew. Chem. Int. Ed. 2020, 59, 1997.

[106] Yamamoto, A.; Hirukawa, T.; Hisaki, I.; Miyata, M.; Tohnai, N. Tetrahedron Lett. 2013, 54, 1268.

[107] Comotti, A.; Bracco, S.; Yamamoto, A.; Beretta, M.; Hirukawa, T.; Tohnai, N.; Miyata, M.; Sozzani, P. J. Am. Chem. Soc. 2014, 136, 618.

[108] Xing, G.; Yan, T.; Das, S.; Ben, T.; Qiu, S. Angew. Chem. Int. Ed. 2018, 57, 5345 .

[109] Morshedi, M.; Ward, J. S.; Kruger, P. E.; White, N. G. Dalton Trans. 2018, 47, 783 .

[110] Boer, S. A.; Morshedi, M.; Tarzia, A.; Doonan, C. J.; White, N. G. Chem. Eur. J. 2019, 25, 10006.

[111] Boer, S. A.; Wang, P.-X.; MacLachlan, M. J.; White, N. G. Cryst. Growth Des. 2019, 19, 4829.

[112] Cullen, D. A.; Gardiner, M. G.; White, N. G. Chem. Commun. 2019, 55, 12020.

[113] Liang, W.; Carraro, F.; Solomon, M. B.; Bell, S. G.; Amenitsch, H.; Sumby, C. J.; White, N. G.; Falcaro, P.; Doonan, C. J. J. Am. Chem.
Soc. 2019, 141, 14298.

[114] Morshedi, M.; Thomas, M.; Tarzia, A.; Doonan, C. J.; White, N. G. Chem. Sci. 2017, 8, 3019.

[115] Morshedi, M.; White, N. G. CrystEngComm 2017, 19, 2367.

[116] Huang, Y.-G.; Shiota, Y.; Wu, M.-Y.; Su, S.-Q.; Yao, Z.-S.; Kang, S.; Kanegawa, S.; Li, G.-L.; Wu, S.-Q.; Kamachi, T.; Yoshizawa, K.; Ariga, K.; Hong, M.-C.; Sato, O. Nat.Commun. 2016, 7, 11564.

[117] Luo, Y.-H.; He, X.-T.; Hong, D.-L.; Chen, C.; Chen, F.-H.; Jiao, J.; Zhai, L.-H.; Guo, L.-H.; Sun, B.-W. Adv. Funct. Mater. 2018, 28, 1804822 .

[118] Zheng, X.; Xiao, N.; Long, Z.; Wang, L.; Ye, F.; Fang, J.; Shen, L.; Xiao, X. Synth. Met. 2020, 263, 116365.

[119] Lü, J.; Perez-Krap, C.; Suyetin, M.; Alsmail, N. H.; Yan, Y.; Yang, S.; Lewis, W.; Bichoutskaia, E.; Tang, C. C.; Blake, A. J.; Cao, R.; Schröder, M. J. Am. Chem. Soc. 2014, 136, 12828.

[120] Lü, J.; Perez-Krap, C.; Trousselet, F.; Yan, Y.; Alsmail, N. H.; Karadeniz, B.; Jacques, N. M.; Lewis, W.; Blake, A. J.; Coudert, F.-X.; Cao, R.; Schröder, M. Cryst. Growth Des. 2018, 18, 2555.

[121] He, X.-T.; Luo, Y.-H.; Hong, D.-L.; Chen, F.-H.; Zheng, Z.-Y.; Wang, C.; Wang, J.-Y.; Chen, C.; Sun, B.-W. ACS Appl. Nano Mater. 2019, 2, 2437.

[122] Suh, M. P.; Park, H. J.; Prasad, T. K.; Lim, D.-W. Chem. Rev. 2012 112,782

[123] Wang, B.; Zhang, X.; Huang, H.; Zhang, Z.; Yildirim, T.; Zhou, W.; Xiang, S.; Chen, B. Nano Res. 2020, doi: 10.1007/s12274-0202713-0.

[124] Sumida, K.; Brown, C. M.; Herm, Z. R.; Chavan, S.; Bordiga, S.; Long, J. R. Chem. Commun. 2011, 47, 1157.

[125] Farha, O. K.; Spokoyny, A. M.; Mulfort, K. L.; Galli, S.; Hupp, J. T.; Mirkin, C. A. Small 2009, 5, 1727.

[126] Nugent, P. S.; Rhodus, V. L.; Pham, T.; Forrest, K.; Wojtas, L.; Space, B.; Zaworotko, M. J. J. Am. Chem. Soc. 2013, 135, 10950.

[127] Yoon, T.-U.; Baek, S. B.; Kim, D.; Kim, E.-J.; Lee, W.-G.; Singh, B. K.; Lah, M. S.; Bae, Y.-S.; Kim, K. S. Chem. Commun. 2018, 54 9360

[128] Zhang, Z.; Li, J.; Yao, Y.; Sun, S. Cryst. Growth Des. 2015, 15, 5028 .

[129] Stackhouse, C.; Ren, J.; Shan, C.; Nafady, A.; Al-Enizi, A. M.; Ubaidullah, M.; Niu, Z.; Ma, S. Cryst. Growth Des. 2019, 19, 6377.

[130] Khadivjam, T.; Che-Quang, H.; Maris, T.; Ajoyan, Z.; Howarth, A. J.; Wuest, J. D. Chem. Eur. J. 2020, 26, 7026.

[131] Han, B.; Wang, H.; Wang, C.; Wu, H.; Zhou, W.; Chen, B.; Jiang, J. J. Am. Chem. Soc. 2019, 141, 8737 .

[132] Bao, Z.; Xie, D.; Chang, G.; Wu, H.; Li, L.; Zhou, W.; Wang, H.; Zhang, Z.; Xing, H.; Yang, Q.; Zaworotko, M. J.; Ren, Q.; Chen, B. J. Am. Chem. Soc. 2018, 140, 4596.

[133] Zhou, M.; Liu, G.; Ju, Z.; Su, K.; Du, S.; Tan, Y.; Yuan, D. Cryst. Growth Des. 2020, 20, 4127.

[134] Chen, B. Sci.China Chem. 2017, 60, 683.

[135] Yin, Q.; Li, Y.-L.; Li, L.; Lü, J.; Liu, T.-F.; Cao, R. ACS Appl. Mater. Inter. 2019, 11, 17823 .

[136] Shi, Z.-Q.; Ji, N.-N.; Guo, K.-M.; Li, G. Appl. Surf. Sci. 2020, 504, 144484 .

[137] Yang, Q.; Wang, Y.; Shang, Y.; Du, J.; Yin, J.; Liu, D.; Kang, Z.; Wang, R.; Sun, D.; Jiang, J. Cryst. Growth Des. 2020, 20, 3456.

[138] Chand, S.; Pal, S. C.; Pal, A.; Ye, Y.; Lin, Q.; Zhang, Z.; Xiang, S.; Das, M. C. Chem. Eur. J. 2019, 25, 1691.

[139] Zheng, H.-Q.; He, X.-H.; Zeng, Y.-N.; Qiu, W.-H.; Chen, J.; Cao, G.-J.; Lin, R.-G.; Lin, Z.-J.; Chen, B. J. Mater. Chem. A 2020, 8 , 17219.

[140] Gong, W.; Liu, Y.; Li, H.; Cui, Y. Coord. Chem. Rev. 2020, 420, 213400.

[141] Chen, Z. Y.; Liu, J. W.; Cui, H.; Zhang, L.; Su, C. Y. Acta Chim. Sinica 2019, 77, 242 (in Chinese). (陈之尧, 刘捷威, 崔浩, 张利, 苏成勇, 化学学报, 2019, 77, 242.)

[142] Liu, F. Q.; Liu, J. W.; Gao, Z.; Wang, L.; Fu, X.-Z.; Yang, L. X.; Tao, Y.; Yin, W. H.; Luo, F. Appl. Catal. B: Environ. 2019, $258,117973$.

[143] Aitchison, C. M.; Kane, C. M.; McMahon, D. P.; Spackman, P. R.; Pulido, A.; Wang, X.; Wilbraham, L.; Chen, L.; Clowes, R.; Zwijnenburg, M. A.; Sprick, R. S.; Little, M. A.; Day, G. M.; Cooper, A. I. J. Mater. Chem. A 2020, 8, 7158 .

[144] He, X.-T.; Luo, Y.-H.; Zheng, Z.-Y.; Wang, C.; Wang, J.-Y.; Hong, D.-L.; Zhai, L.-H.; Guo, L.-H.; Sun, B.-W. ACS Appl. Nano Mater. 2019, $2,7719$.

[145] Sun, Z.; Li, Y.; Chen, L.; Jing, X.; Xie, Z. Cryst. Growth Des. 2015, 
$15,542$.

[146] Feng, J.-F.; Yan, X.-Y.; Ji, Z.-Y.; Liu, T.-F.; Cao, R. ACS Appl. Mater. Inter. 2020, 12, 29854.

[147] Lin, Z.-J.; Zheng, H.-Q.; Zeng, Y.-N.; Wang, Y.-L.; Chen, J.; Cao, G.-J.; Gu, J.-F.; Chen, B. Chem. Eng. J. 2019, 378, 122196.

[148] Lin, Z.-J.; Zheng, H.-Q.; Zheng, H.-Y.; Lin, L.-P.; Xin, Q.; Cao, R. Inorg. Chem. 2017, 56, 14178.

[149] Zeng, C.-H.; Luo, Z.; Yao, J. CrystEngComm 2017, 19, 613.

[150] Lin, Y.; Jiang, X.; Kim, S. T.; Alahakoon, S. B.; Hou, X.; Zhang, Z.; Thompson, C. M.; Smaldone, R. A.; Ke, C. J. Am. Chem. Soc. 2017, $139,7172$.

[151] Yao, R.-X.; Cui, X.; Jia, X.-X.; Zhang, F.-Q.; Zhang, X.-M. Inorg. Chem. 2016, 55, 9270.
[152] Liao, Y.; Weber, J.; Mills, B. M.; Ren, Z.; Faul, C. F. J. Macromolecules 2016, 49, 6322.

[153] Ren, F.; Zhu, Z.; Qian, X.; Liang, W.; Mu, P.; Sun, H.; Liu, J.; Li, A. Chem. Commun. 2016, 52, 9797.

[154] Hoshino, M.; Khutia, A.; Xing, H.; Inokuma, Y.; Fujita, M. IUCrJ 2016, 3, 139 .

[155] Lee, S.; Kapustin, E. A.; Yaghi, O. M. Science 2016, 353, 808.

[156] Pei, X.; Bürgi, H.-B.; Kapustin, E. A.; Liu, Y.; Yaghi, O. M. J. Am. Chem. Soc. 2019, 141, 18862 .

[157] Li, Y.; Tang, S.; Yusov, A.; Rose, J.; Borrfors, A. N.; Hu, C. T.; Ward, M. D. Nat. Commun. 2019, 10, 4477.

(Cheng, B.) 